\title{
Estratégias de controle do mosquito transmissor da dengue e seus impactos financeiros
}

\author{
Simone Aparecida de Brito Oliveira
}

\author{
DISSERTAÇÃO APRESENTADA \\ $\mathrm{AO}$ \\ Instituto DE MATEMÁticA E EstatísticA \\ DA \\ Universidade DE SÃo PaUlo \\ PARA \\ OBTENÇÃO DO TÍTULO \\ DE \\ Mestre EM CiÊnCIAS \\ Programa: Matemática Aplicada \\ Orientadora: Profa. Dra. Joyce da Silva Bevilacqua
}

Durante o desenvolvimento deste trabalho o autor recebeu auxílio financeiro da CNPq

São Paulo, 16 de outubro de 2019 


\section{Estratégias de controle do mosquito transmissor da dengue e seus impactos financeiros}

Esta versão da dissertação contém as correções e alterações sugeridas pela Comissão Julgadora durante a defesa da versão original do trabalho, realizada em 16/10/2019. Uma cópia da versão original está disponível no

Instituto de Matemática e Estatística da Universidade de São Paulo.

Comissão Julgadora:

- Prof ${ }^{a}$. Dra ${ }^{\mathrm{a}}$. Joyce da Silva Bevilacqua - IME-USP

- Prof ${ }^{a}$. Dra ${ }^{a}$. Claudia Pio Ferreira - UNESP

- Prof. Dr. Renato Mendes Coutinho - UFABC 


\section{Agradecimentos}

Agradeço à minha família: meus irmãos Gilberto e Gilmar, minhas cunhadas Sandra e Lene, aos meus sobrinhos Thais, Ellen, Layene, Lorranne, Júlia, Dylan, Isabela e Isadora, tia Delice e minha prima Adenilde, todo afago e amparo.

Aos meus amigos de Jundiaí Zeza, Keli Paes, Débora Porto, Mônica André, Fábio Bardi, Célio Arantes, Gleyde Anacleto e Roberto Lima que torcem e se alegram com minhas conquistas.

Ao "Pássaro" que cantava na minha porta e deixava bilhetinhos carinhosos me incentivando a seguir em frente.

À minha orientadora Dra Joyce da Silva Bevilacqua que acreditou no meu trabalho e me deu todo o apoio.

Agradeço aos funcionários e aos professores do IME, em especial, os Professores Saulo Rabello Maciel de Barros e Pedro da Silva Peixoto as conversas e recomendações.

Aos meus amigos do LabMap Bruna Santos, Larissa Sartori, Jefferson Brambatti, Ana Rojas, Ana Isabel, Vanessa Steindorf e Leonardo Poveda Cuevas, com quem tive a satisfação de conviver durante esses anos de mestrado e que me auxiliaram muito, compartilhando deliciosos almoços, bate-papos, ideias e muitas risadas, tornando-se pessoas mais que especiais para mim e que vou levar para a vida toda.

Aos amigos Bruno Espadoto e Fernando Valdez Ravelo que se colocaram à disposição, discutindo e me assistindo na otimização dos programas em R. Também a algumas pessoas que já não estão mais no IME, mas que fizeram parte dessa minha trajetória, Lorena, Laura, Jeovanny, Benigno, Anderson e Belmiro. Aos colegas Arcelinho, Pollyana, Jerusa e Luana, Felipe, e aos demais colegas que tive o imenso prazer de conhecer no IME.

A todos os amigos do tênis, especilamente, a Alice Mieko Hanashiro, a Telma Tomé Lopes e o Professor Thales Bon, que me proporcionaram grandes momentos de muita alegria, muita diversão e adrenalina.

A todos os colegas do CRUSP, em especial, ao meu amigo Jota, pessoa incrível que sempre tem uma palavra de carinho para me confortar.

Agradeço ao $\mathrm{CNPq}$ o apoio financeiro.

Finalmente, agradeço à Professora $\mathrm{Dr}^{\mathrm{a}}$. Claudia Pio Ferreira e ao Professor Dr. Renato Mendes Coutinho a receptividade em participar da minha banca de mestrado. E às pessoas que não citei, mas que direta ou indiretamente fizeram parte da minha formação e da minha trajetória, o meu muito obrigada. 


\section{Resumo}

Oliveira, S. A. B. Estratégias de controle do mosquito transmissor da dengue e seus impactos financeiros. 2019. 71 f. Dissertação de Mestrado - Instituto de Matemática e Estatística, Universidade de São Paulo, São Paulo, 2019.

A epidemia da dengue, causada pelo mosquito Aedes aegypti, tem feito um verdadeiro estrago nos cofres públicos da cidade de São Paulo. Pensando nisso, criamos um modelo matemático que compreende a dinâmica entre humanos e vetores, e nele incluimos três mecânismos de controle ao vetor: repelente, inseticida e larvicida. Simulamos 8 cenários diferentes, 4 para epidemia e 4 para endemia, ambos para as quatro estações do ano nas estratégias Sem Controle; Restrição do $R_{0}$, que seria o custo para mantermos o $R_{0}$ controlado abaixo de 1 o ano todo; e Restrição de Custo, mantendo o controle da doença com o menor impacto possível na qualidade de vida da população (DALY), limitando o custo. Concluímos que a melhor opção seria a estratégia Restrição do $R_{0}$ diante dos cenários epidêmicos e quando a situação passar para o cenário endêmico manter o controle por meio da estratégia Restrição de Custo.

Palavras-chave: Aedes aegypti, dengue, controle, custo, equações diferenciais ordinárias. 


\section{Abstract}

Oliveira, S. A. B. Control strategies for the transmitter mosquito of dengue and its financial impacts. 2019. $71 \mathrm{f}$. Masters dissertation - Institute of Mathematics and Statistics, University of São Paulo, São Paulo, 2019.

The epidemic of dengue, caused by the mosquito Aedes aegypti, has done a real damage in the coffers of the city of São Paulo. With this in mind, we created a mathematical model that capture the dynamics between humans and vectors, and includes three control mechanisms: repellent, insecticide and larvicide. We simulate 8 different scenarios, 4 for epidemic and 4 for endemic, both for the fourth seasons of the year and the strategies Without Control; Restricted $R_{0}$, consisting in the cost to maintaining $R_{0}$ controlled below 1 in the all year; Cost Restriction, controlling the disease with the lower possible impact in life quality of the population (DALY), with the cost limited. We conclude that the best option will be the strategy Restricted $R_{0}$ for the epidemic scenarios and when we pass to endemic scenarios use to control the strategy Cost Restriction.

Keywords: Aedes aegypti, dengue, control, cost, ordinary differential equations. 


\section{Sumário}

$\begin{array}{ll}\text { Lista de Figuras } & \text { ix }\end{array}$

Lista de Tabelas $\quad$ xi

Introdução $\quad$ xiii

1 Dengue na cidade de São Paulo, evolução e modelagem matemática 1

1.1 A dengue na cidade de São Paulo . . . . . . . . . . . . . . . . . 1

1.2 Mecanismos de controle . . . . . . . . . . . . . . . . . . 3

1.3 Modelos Epidemiológicos . . . . . . . . . . . . . . . . . 4

1.3.1 Modelo simples com vetor e sem controle . . . . . . . . . . . . . 6

1.3.2 Modelo com vetor e com estratégia de controle . . . . . . . . . . . . 8

2 Estruturação de um modelo para dengue com estratégias de controle do vetor 11

2.1 Formulação do modelo . . . . . . . . . . . . . . . . . . . . . 11

2.2 Análise do modelo . . . . . . . . . . . . . . . . . . . 16

2.2 .1 Equilíbrio livre de mosquitos . . . . . . . . . . . . . 18

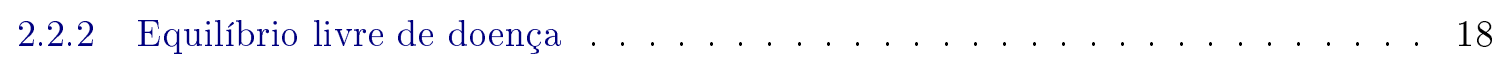

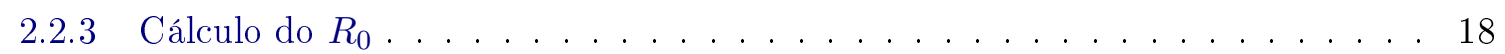

2.2 .4 Equilíbrio endêmico . . . . . . . . . . . . . . . . . . 20

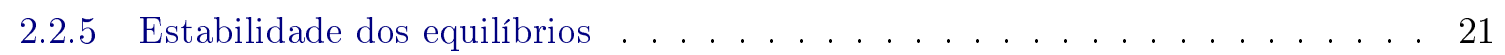

2.3 Busca por estratégias de controles . . . . . . . . . . . . . . . . . 24

3 Resultados Numéricos $\quad 27$

3.1 Resultados numéricos do cenário $1 \ldots \ldots \ldots \ldots \ldots$

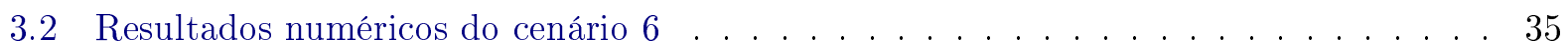

4 Conclusões $\quad 41$

4.1 Sugestões para Pesquisas Futuras . . . . . . . . . . . . . . . . . . . . . . . 42

$\begin{array}{ll}\text { A } & 43\end{array}$

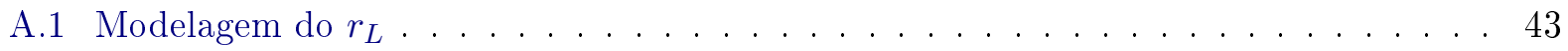

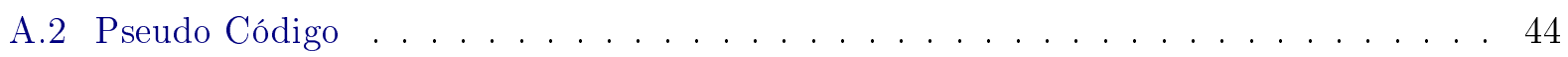

A.3 Resultados numéricos do cenário $2 \ldots \ldots \ldots \ldots \ldots \ldots$

A.4 Resultados numéricos do cenário $3 \ldots \ldots \ldots \ldots \ldots$

A.5 Resultados numéricos do cenário $4 \ldots \ldots \ldots \ldots \ldots \ldots \ldots \ldots \ldots \ldots \ldots$ 
A.6 Resultados numéricos do cenário $5 \ldots \ldots \ldots \ldots \ldots \ldots \ldots$

A.7 Resultados numéricos do cenário $7 \ldots \ldots \ldots \ldots \ldots \ldots$

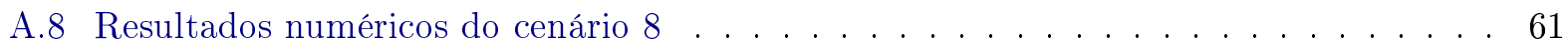

Referências Bibliográficas $\quad 65$ 


\section{Lista de Figuras}

1.1 Notificações de casos de dengue na cidade de São Paulo . . . . . . . . . . . . . . 1

1.2 Mapas de Risco de dengue na cidade de SP de 2015 e 2016 . . . . . . . . . . . . . . 2

1.3 Representação compartimental do modelo de Bernoulli . . . . . . . . . . . . . . . . 5

1.4 Representação compartimenal do modelo SIR . . . . . . . . . . . . . . . . . . 5

1.5 Representação compartimental de um modelo com vetor e sem controle . . . . . . . . 7

2.1 Representação compartimental do modelo epidemiológico . . . . . . . . . . . . . . . . 12

3.1 Melhor combinação de controles . . . . . . . . . . . . . . . . . . . . . . 30

3.2 Uso do inseticida . . . . . . . . . . . . . . . . . . . . . . 30

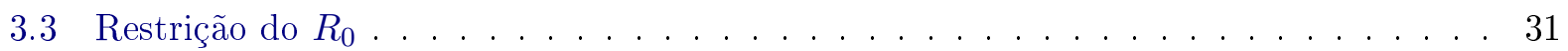

3.4 Humanos suscetíveis, infectados e resistentes . . . . . . . . . . . . . . 32

3.5 Mosquitos suscetíveis e infectados . . . . . . . . . . . . . . . . . . 33

3.6 Larvas suscetíveis e infectados . . . . . . . . . . . . . . . . . . . 33

3.7 Custo Total acumulado e DALYs por dia . . . . . . . . . . . . . . . . 34

3.8 Melhor combinação de controles . . . . . . . . . . . . . . . . . . . . 35

3.9 Uso do Inseticida . . . . . . . . . . . . . . . . . . . . . . . . . 36

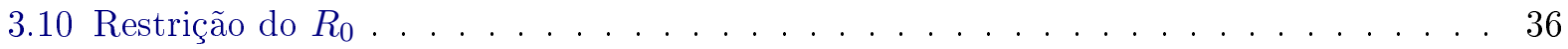

3.11 Humanos suscetíveis, infectados e resistentes . . . . . . . . . . . . . . . . 37

3.12 Mosquitos suscetíveis e infectados . . . . . . . . . . . . . . . . 38

3.13 Larvas suscetíveis e infectados . . . . . . . . . . . . . . . . . . . . . 38

3.14 Custo Total acumulado e DALY por dia . . . . . . . . . . . . . . . . 39

A.1 Melhor combinação - CI $2 \ldots \ldots \ldots$. . . . . . . . . . . 46

A.2 Uso do Inseticida e Repelente - CI $2 \ldots \ldots \ldots$. . . . . . . . . . . . 46

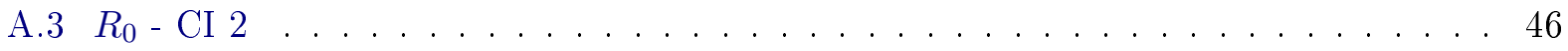

A.4 Humanos suscetíveis, infectados e recuperados - CI $2 \ldots \ldots \ldots \ldots$

A.5 Mosquitos e larvas suscetíveis e infectados - CI $2 \ldots \ldots \ldots$. . . . . . . 47

A.6 Custos e DALY - CI $2 \ldots \ldots \ldots \ldots \ldots \ldots \ldots$

A.7 Melhor combinação - Cenário $3 \ldots \ldots$. . . . . . . . . . . . . . . . 49

A.8 Uso do Inseticida e Repelente - CI $3 \ldots \ldots$. . . . . . . . . . . . . . . . . . 49

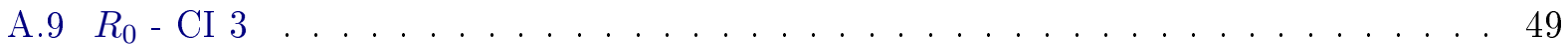

A.10 Humanos suscetíveis, infectados e recuperados - CI $3 \ldots \ldots \ldots$. . . . . . 50

A.11 Mosquitos e larvas suscetíveis e infectados - CI $3 \ldots \ldots \ldots \ldots$

A.12 Custos e DALY - CI $3 \ldots \ldots \ldots \ldots \ldots \ldots \ldots$ 
A.13 Melhor combinação - CI $3 \ldots \ldots \ldots$. . . . . . . . . . . . . 52

A.14 Uso Inseticida e Repelente - CI $4 \ldots \ldots$. . . . . . . . . . . . . . 5 . 52

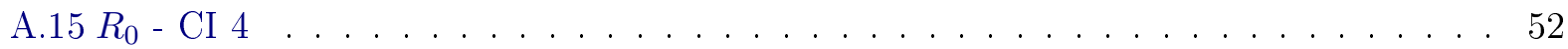

A.16 Humanos suscetíveis, infectados e recuperados - CI $4 \ldots \ldots \ldots$. . . . . . 53

A.17 Mosquitos e larvas suscetíveis e infectados . . . . . . . . . . . . . . 53

A.18 Custos e DALY - CI $4 \ldots \ldots \ldots \ldots \ldots \ldots$

A.19 Melhor combinação - CI $5 \ldots \ldots \ldots \ldots \ldots \ldots \ldots$

A.20 Uso do Inseticida - CI $5 \ldots \ldots \ldots \ldots \ldots \ldots \ldots$

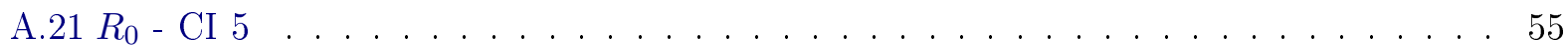

A.22 Humanos suscetíveis, infectados e recuperados - CI $5 \ldots \ldots \ldots 6$

A.23 Mosquitos e larvas suscetíveis e infectados - CI $5 \ldots \ldots \ldots$. . . . . . . . 56

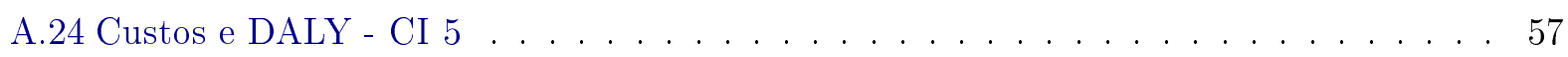

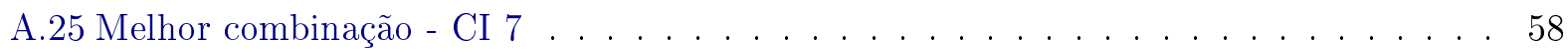

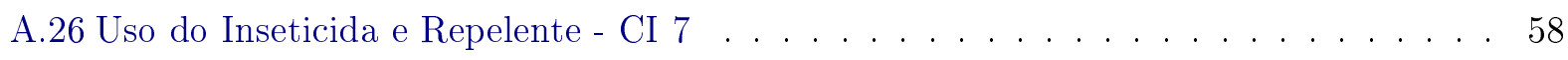

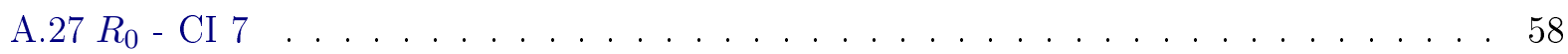

A.28 Humanos suscetíveis, infectados e recuperados - CI $7 \ldots \ldots \ldots$. . . . . . . 59

A.29 Mosquitos e larvas suscetíveis e infectados - CI $7 \ldots \ldots \ldots$. . . . . . . . 59

A.30 Custos e DALY - CI $7 \ldots \ldots \ldots \ldots$. . . . . . . . . . . . . . . . . . . . . . . . . . . 60

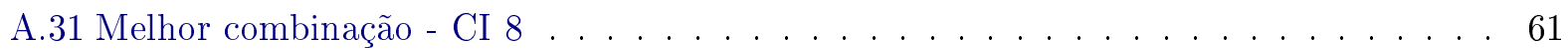

A.32 Uso do Inseticida e Repelente - CI $8 \ldots \ldots \ldots$. . . . . . . . . . . . . . . . . . . . . . .

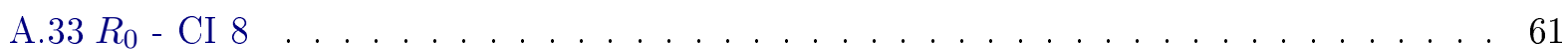

A.34 Humanos suscetíveis, infectados e recuperados - CI $8 \ldots \ldots \ldots 2$

A.35 Mosquitos e larvas suscetíveis e infectados - CI $8 \ldots \ldots \ldots$. . . . . . . . 62

A.36 Custos e DALY - CI $8 \ldots \ldots \ldots \ldots \ldots$ 


\section{Lista de Tabelas}

1 Notificações de casos de dengue no Brasil de 2014 à 2019 . . . . . . . . . . . . . . xiv

1.1 Orçamentos de 2015 à 2019 destinados ao Fundo Municipal da Saúde da cidade de São Paulo (Valores em reais) _ . . . . . . . . . . . . . . . . . 2

1.2 Tabela de variáveis do modelo . . . . . . . . . . . . . . . . . . . 8

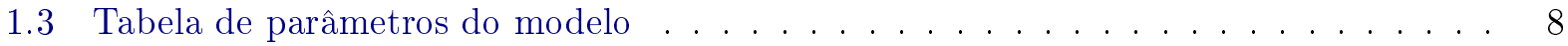

2.1 Tabela de valores dos parâmetros relacionados a dinâmica do modelo . . . . . . . . . 13

2.2 Parâmetros relacionados a custo e DALYs . . . . . . . . . . . . . . . . . . 16

2.3 Tabela de novos parâmetros - reparametrização . . . . . . . . . . . . . . 17

2.4 Tabela de $R_{0}$ conforme estações do ano . . . . . . . . . . . . . . . . . . . . 20

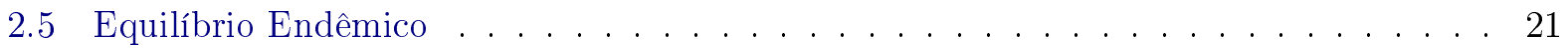

2.6 Critério de Routh-Hurwitz para polinômios de graus 1 a $4 \ldots \ldots$. . . . . . . . 21

2.7 Tabela de estabilidade dos equilíbrios . . . . . . . . . . . . . . . . . 23

3.1 Tabela de condições iniciais nos cenários de Epidemia (1, 3, 5 e 7$)$ e Endemia $(2,4$,

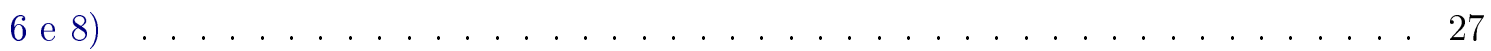

3.2 Tabela de valores dos parâmetros relacionados a dinâmica do modelo . . . . . . . . . 28

3.3 Tabela de valores dos parâmetros relacionados a função custo e DALY . . . . . . . . 29

3.4 Condição inicial do Cenário 1 de Epidemia, com controle distribuído a partir do início

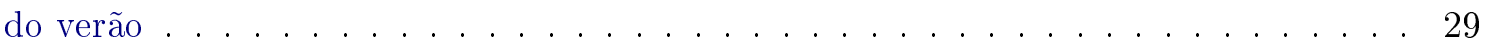

3.5 Comparativo de valores de DALY, Gasto com Controles e Gasto com Hospitais e

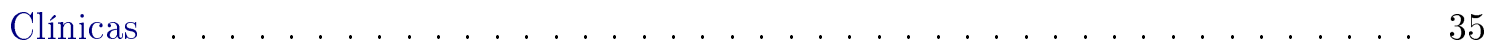

3.6 Condição inicial do Cenário 6 de Endemia, com controle distribuído a partir do início do inverno . . . . . . . . . . . . . . . . . . . 35

3.7 Comparativo de valores - CI $6 \ldots \ldots \ldots \ldots$

A.1 Condição inicial do Cenário 2 de Endemia, com controle distribuído a partir do início

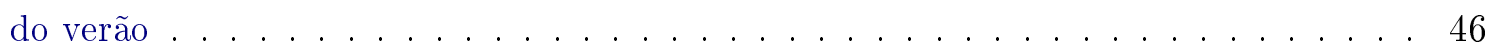

A.2 Comparativo de valores - Condição inicial $2 \ldots \ldots \ldots$. . . . . . . . . 48

A.3 Condição inicial do Cenário 3 de Epidemia, com controle distribuído a partir do início do outono . . . . . . . . . . . . . . . . . . . . . 49

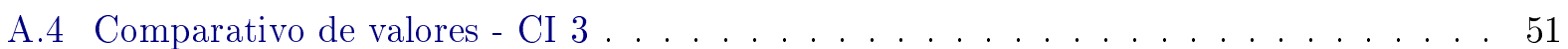

A.5 Condição inicial do Cenário 4 de Endemia, com controle distribuído a partir do início

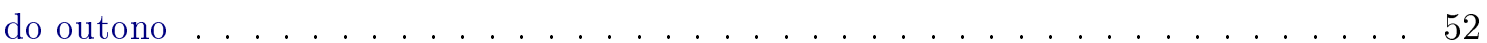

A.6 Comparativo de valores - CI $4 \ldots \ldots \ldots \ldots \ldots$ 
A.7 Condição inicial do Cenário 5 de Epidemia, com controle distribuído a partir do início do inverno . . . . . . . . . . . . . . . . . . . . . . . . . . . 55

A.8 Comparativo de valores - CI 5 . . . . . . . . . . . . . . . . . . . 57

A.9 Condição inicial do Cenário 7 de Epidemia, com controle distribuído a partir do início do primavera . . . . . . . . . . . . . . . . . . . . . . . . . . 58

A.10 Comparativo de valores - CI 7 . . . . . . . . . . . . . . . . . . . . 60

A.11 Condição inicial do Cenário 8 de Endemia, com controle distribuído a partir do início

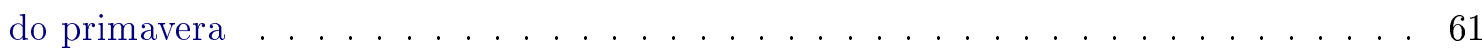

A.12 Comparativo de valores - CI 8 . . . . . . . . . . . . . . . . 63 


\section{Introdução}

A dengue passou a ser considerada uma doença grave após a segunda guerra mundial. A destruição do abastecimento de água das cidades, o alojamento temporário de refugiados, o crescimento explosivo das populações após a guerra, migração rural-urbana e a deterioração constante dos ambientes urbanos levaram a um crescimento no número do mosquito Aedes aegypti, transmissor da doença. Devido a infecções sequenciais com diferentes sorotipos do vírus, surgiram casos mais graves, como o da febre hemorrágica (Halstead, 1992) (Lupi et al., 2007).

É uma doença transmitida pelos mosquitos do gênero Aedes. A espécie Albopictus é de origem asiática, porém, devido as suas características silvestres não teve tanta representatividade na transmissão do vírus nas Américas. A espécie Aegypti é originária de países do continente africano localizados na região ao sul do deserto do Saara, uma das regiões mais pobres do mundo. Devido as suas características urbanas, tornou-se o principal responsável pela transmissão do vírus da dengue (Teixeira et al., 1999). Os mosquitos se proliferam mais facilmente no clima quente e úmido, por isso a dengue atinge principalmente os países de clima tropicais (Herrera-Basto et al., 1992).

No Brasil há relatos de epidemias desde 1846 na cidade de São Paulo e em 1853, na cidade do Rio de Janeiro, embora as primeiras publicações oficiais destes fatos datem de 1916 (Meira, 1916). Em 1928, um navio francês com casos de pessoas com suspeita de dengue desembarcou na cidade de Salvador, porém não houve circulação do vírus na população dessa capital (Soares, 1928).

Os primeiros casos da dengue no Brasil com confirmação laboratorial datam de 1981 - 1982, na cidade de Boa Vista, Roraima, com 11.000 casos cofirmados dos sorotipos DENV1 e DENV4 (Figueiredo et al., 2004).

O Brasil participou da campanha de erradicação continental do Aedes Aegypti em 1955 e teve êxito. Em 1990, foi criada a Fundação Nacional de Saúde (Funasa) e passou a ser responsável pela coordenação das ações de controle da dengue. Em 1996, o Ministério da Saúde elaborou o Plano de Erradicação do Aedes aegypti (PEAa), cuja principal preocupação residia nos casos de dengue hemorrágica. O plano previa uma ação integrada com vários outros ministérios, que foi dividido em nove áreas de atuação: Entomologia; Operações de campo de combate ao vetor; Vigilância de portos, aeroportos e fronteiras; Saneamento; Informação, educação e comunicação social; Vigilância epidemiológica e sistema de informações; Laboratório; Desenvolvimento de recursos humanos; e Legislação de suporte. No entanto, em 1998 o avanço nos casos de dengue demonstrou que a implementação do PEAa não alcançou seu objetivo. Foi criado então um ajuste operacional do PEAa que definiria as áreas de maior infestação de casos de dengue, que ratificaria o que já ocorria na prática, em operações de campo e aplicação de inseticida como forma de controle. Em 1999, o Ministério da Saúde investiu mais de um bilhão de reais nos municípios conveniados na estruturação do combate ao vetor. As principais causas do fracasso do PEAa foram a não-universalização das ações em cada município e a descontinuidade na execução das atividades de combate ao vetor. 
Em 2001, a Funasa abandonou oficialmente a meta de erradicar o Aedes aegypti do país e passou a trabalhar com o objetivo de controlar o vetor (Braga e Valle, 2007).

Desde então ocorreram no país vários surtos de dengue em diferentes estados e municípios do país. Vale destacar o surto em 2002 no estado do Rio de Janeiro, com registro de cerca de 288 mil casos da doença, 1.831 casos de dengue hemorrágica, 91 óbitos a identificação do sorotipo DEN 3. A maioria dos casos foram registrados na cidade do Rio de Janeiro com 246 mil destes casos e 83 óbitos (Nogueira et al., 2005).

Na Tabela 1 temos os números de notificações da doença dos últimos anos no país.

\begin{tabular}{c|c}
\hline Ano & Número de notificações \\
\hline \hline 2014 & 572.408 \\
2015 & 1.587 .080 \\
2016 & 1.487 .673 \\
2017 & 249.056 \\
2018 & 247.393 \\
$2019^{*}$ & 273.193 \\
\hline
\end{tabular}

Tabela 1: Notificações de casos de dengue no Brasil de 2014 à 2019, sendo os dados de 2019 notificados até 25 de março (Ministerio da Saude, 2019b).

Com relação as características entomológicas do vetor, o ciclo de vida do mosquito Aedes aegypti compreende duas etapas: a fase aquática, onde desenvolvem-se ovo, larva e pupa, e a fase aérea, que corresponde a fase adulta do mosquito. Durante a fase aquática, estudos tem apontado uma dependência com relação a variáveis ambientais, como temperatura, precipitação e umidade para o desenvolvimento do vetor para a fase adulta (Massad et al., 2011).

Uma vez adulto, o Aedes aegypti precisa de múltiplas ingestões de sangue humano em um único ciclo gonadotrófico para evitar a morte por inanição e aumentar exponencialmente a sua propagação, por isso tem ampla capacidade de infectar-se e de transmitir o vírus (Scott et al., 1993).

A transmissão do vírus é feita através da picada das fêmeas de mosquitos infectados do gênero Aedes, pois o macho se alimenta apenas de seiva de plantas. Além disso, a fêmea pode depositar entre 150 a 200 ovos em um mesmo ciclo, e para garantir a sobrevivência e dispersão da prole, ela coloca seus ovos em vários recipientes, são os chamados saltos de oviposição (Reiter e Colon, 1991).

O DATASUS-SINAN do Ministério da Saúde é responsável pela divulgação dos dados sobre a dengue. No Brasil circulam os 4 sorotipos da dengue denominados, DENV1, DENV2, DENV3 e DENV4, no entanto, em torno de $1 \%$ dos casos tem a notificação confirmada. Os sintomas da dengue podem ser facilmente confundidos com outras doenças, como gripe ou resfriado. A estimativa do total de casos anuais e dos sorotipos dominantes é feita com base nos casos confirmados. Para cada caso suspeito ou confirmado estima-se que existem 4 outros casos assintomáticos (Wilder-Smith e Schwartz, 2005).

No Brasil, as campanhas populares promovidas pelo governo federal em conjuntos com as prefeituras de cada município tem sido a forma mais importante no combate a dengue, pois é através da conscientização da população que conseguiremos reduzir o número de criadouro do mosquito (Prefeitura de Sao Paulo, 2016b) [(Prefeitura de Sao Paulo, 2016c).

O Aedes aegypti tem provocado um verdadeiro rombo nos cofres públicos do país em gastos com tratamento de pessoas infectadas por doenças causadas pelo esse mosquito, porém o controle do vetor é uma poderosa medida preventiva, que infelizmente não é utilizada em todo seu potencial 
(Bueno et al., 2017).

Em 2016, o país teve quase 1,5 milhões de casos de doenças causadas pelo Aedes aegypti, cujos impactos neste ano com gastos diretos (relacionado ao tratamento das doenças nas fases agudas) foram de 16,4\% e 18,9\% correspondentes a gastos indiretos (falta de trabalhadores e à perda da produtividade), chegando ao total de $\mathrm{R} \$ 2,3$ bilhões, e os gastos com repasses federais e compra de pesticidas representaram $64,6 \%$ do valor total. As regiões Sudeste e Nordeste tiveram os maiores valores de gasto no combate ao mosquito Aedes aegypti (Teich et al., 2017).

A necessidade de se criar estratégias com combinações de mecanismos de controle de combate ao Aedes Aegypti se faz urgente, e também um comparativo de quanto se é gasto com clínicas e hospitais versos os gastos com a implementação dessas estratégias. É isso que propomos no presente trabalho, e para isso nos baseamos nos dados da cidade de São Paulo.

\section{Objetivo}

- Construção de um modelo matemático para a dinâmica da dengue que inclui três mecanismos de combate: dois que reduzem o número de mosquitos (inseticida e larvicida) e um que controla o número de picadas (repelente);

- Construção de uma função custo, atrelada aos mecanismos de combate ao vetor e aos gastos com tratamento das pessoas infectadas em clínicas e hospitais;

- Identificação da estratégia de controle da doença com o menor custo possível e com o $R_{0}$ limitado por um valor fixo abaixo de 1 ;

- Identificação da estratégia de controle da doença com o menor impacto possível na qualidade de vida da população (DALY), mantendo o custo limitado a verba disponível para essa finalidade;

- Fazer comparativos de gastos e DALYs nas várias situações consideradas.

\section{Organização do trabalho}

O presente trabalho está dividido em quatro partes: No capítulo 1 exibiremos os dados do número de casos notificados da dengue na cidade de São Paulo. Apresentaremos um histórico dos modelos epidemiológicos e falaremos sobre a evolução do modelo SIR e suas variações sem e com controle. No capítulo 2 exibiremos a formulação do nosso modelo com o incremento das três formas de controles que usaremos como combate ao vetor: o repelente, o inseticida e o larvicida. Neste modelo acoplamos uma função custo, e também analisaremos o DALY para termos uma noção do quanto se perde em qualidade de vida ao ser infectado pelo vírus da dengue. Faremos uma analise desse modelo, contendo o cálculo do $R_{0}$ e estudos dos pontos de equilíbrio do sistema. Também mostraremos como foi elaborado a busca das melhores estratégias de controle. No capítulo 3 apresentaremos e discutiremos os resultados númericos das estratégias de controle (Sem Controle, com Restrição de Custo e com Restrição do $R_{0}$ ) e seus respectivos custos e DALYs. Finalmente, no capítulo 4 discutiremos as principais conclusões, contribuições do presente trabalho e nossas aspirações para projetos futuros. 


\section{Capítulo 1}

\section{Dengue na cidade de São Paulo, evolução e modelagem matemática}

\subsection{A dengue na cidade de São Paulo}

A cidade conta com uma área de 1521,11 km² uma população de 12.176.866 habitantes, segundo dados do IBGE 2018, com uma densidade de 8.005,25 hab $/ \mathrm{km}^{2}$, altitude de 760 metros e com clima subtropical úmido - ótimas condições para a proliferação do mosquito (Ministerio da Saude, 2019a).

Na Figura 1.1 temos um histórico de notificações de casos da doença na cidade de São Paulo de 2007 à 2019, segundo dados da Prefeitura Municipal (Prefeitura de Sao Paulo, 2019).

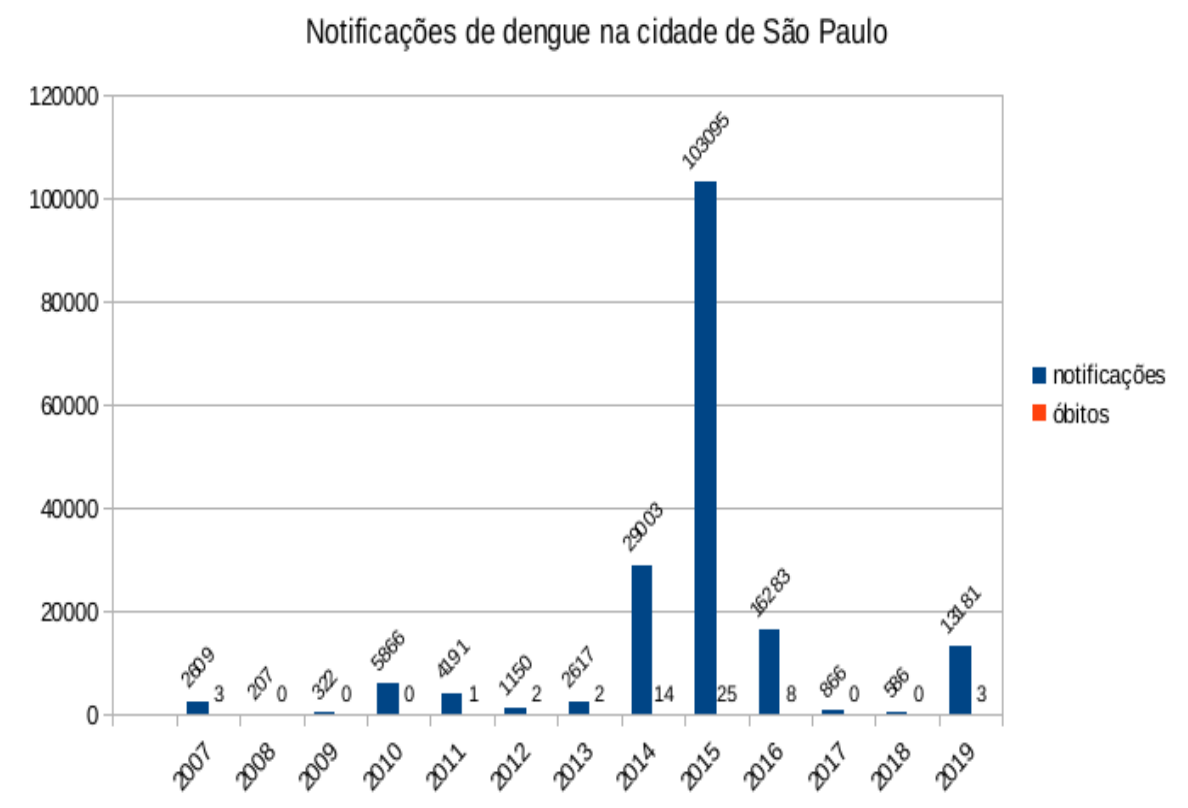

Figura 1.1: Histórico de notificações de casos de dengue na cidade de São Paulo de 2007 à 2019, sendo os dados de 2019 notificados até 20 de junho (Prefeitura de Sao Paulo, 2019).

Um surto é caracterizado quando temos 300 casos para cada 100.000 habitantes. Partindo desse princípio, podemos dizer que em 2014 e 2015 tivemos surtos de dengue na cidade de São Paulo, e estamos vivenciando um em 2019, pois segundo o Ministério da Saúde, dez municípios concentram mais da metade dos casos do estado de São Paulo, e a cidade de São Paulo está entre eles. Daí a importância de se fazer um estudo abrangendo estratégias de controle do mosquito transmissor da doença nesta cidade (Ministerio da Saude, 2019a).

Com base nessas informações é realizado o planejamento das ações de combate e controle do mosquito, tais como identificação de criadouros, campanhas puplicitárias de conscientização, ações 
preventivas e efetivas, priorizando os bairros identificados com os maiores riscos.

O Levantamento Rápido de Índices de Infestação pelo Aedes aegypti (LIRAa), conhecido como Mapa da Dengue, é um instrumento importantíssimo no combate ao mosquito, pois é através do levantamento fornecido pelo LIRAa, que a prefeitura identfica os bairros onde estão concentrados os focos de reprodução do mosquito, bem como o tipo de depósito onde as larvas foram encontradas (Ministerio da Saude, 2017).

A partir de 2012, um Mapa de Risco da doença começou a ser elaborado identificando os locais com maior índice de infestação na cidade. Para a classificação do risco foram considerados três importantes fatores: o número de moradores por região, a temperatura ambiente e a quantidade de depósitos irregulares de lixos e entulhos, e através desses fatores classificou-se os riscos em cinco classes: baixíssimo, baixo, médio, alto e altíssimo (Prefeitura de Sao Paulo, 2016a), como mostra a Figura 1.2. Devido a falta de atualizações, estamos considerando como base os mapa de risco de 2016.

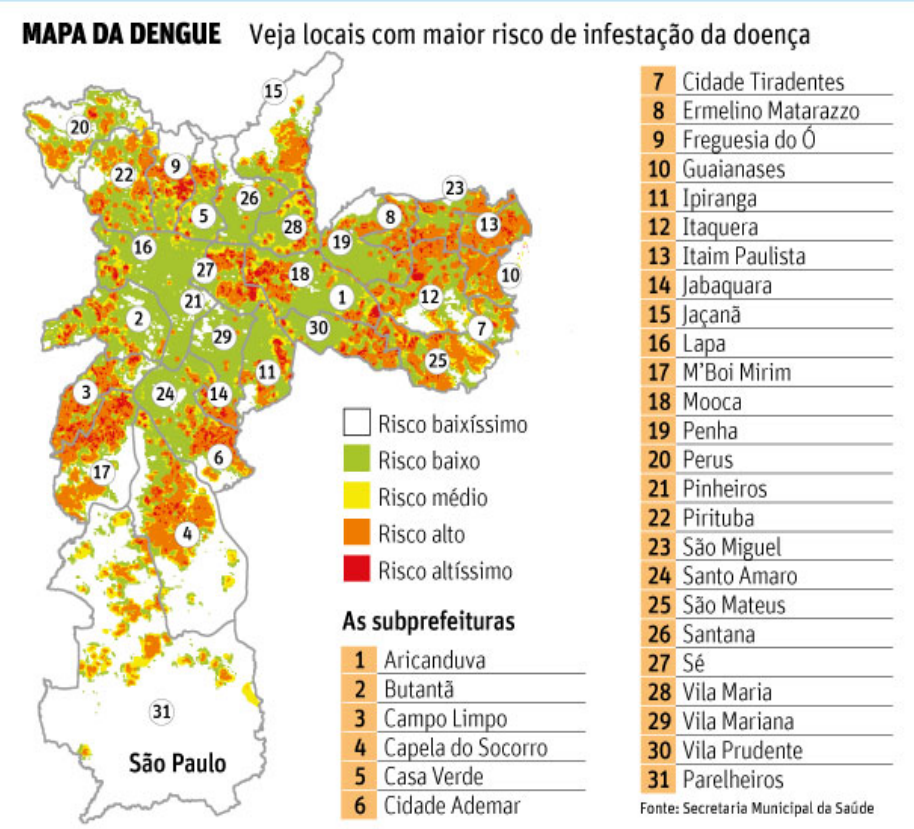

Figura 1.2: Mapa de Risco de dengue na cidade de SP de 2016 (Prefeitura de Sao Paulo, 2016a)

Segundo o Plano anual de orçamento da Prefeitura de São Paulo, os recursos destinados à área da Saúde giram em torno de $11 \%$ a $15 \%$ do orçamento total da cidade. No ano de 2018, o orçamento total aprovado pela Prefeitura foi de R \$ 56,2 bilhões. Esses recursos foram distribuidos entre todas as secretarias, prefeituras regionais, fundos e outros orgãos. Desse total, $\mathrm{R} \$$ 8.138.907.881 foi o valor destinado ao Fundo Municipal de Saúde. Na Tabela 1.1 apresentamos os orçamentos para a cidade de São Paulo de 2014 à 2019 e o valor destinado ao Fundo Municipal da Saúde (Portal transparencia SP, 2019), porém não temos dados oficiais do quanto de fato é gasto pela prefeitura da cidade de São Paulo com mecanismos de controle no combate ao vetor.

\begin{tabular}{c|c|c}
\hline Ano & Orçamento total & Fundo Municipal de Saúde \\
\hline \hline 2014 & 50.7 bilhões & 8.5 bilhões \\
2015 & 51.3 bilhões & 7.6 bilhões \\
2016 & 54.4 bilhões & 7.6 bilhões \\
2017 & 54.6 bilhões & 8.0 bilhões \\
2018 & 56.2 bilhões & 8.1 bilhões \\
2019 & 60.5 bilhões & 8.7 bilhões \\
\hline
\end{tabular}

Tabela 1.1: Orçamentos de 2015 à 2019 destinados ao Fundo Municipal da Saúde da cidade de São Paulo (Valores em reais) 
Outra informação que adicionamos é sobre os gastos por porte de clínicas e hospitais no ano de 2015 (ano de surto) da cidade de São Paulo informados pelo IESS (Instituto de Estudos de Saúde Suplementar). Nesse ano a doença mais recorrente entre todas as clínicas e hospitais (grande, médio e pequeno porte) foi a dengue (Dengue Clássico). Mesmo com variações do custo médio, a internação por esse problema foi a que representou o gasto mais baixo. Ficando atrás de "pneumonia para microrganismo não especificado" para os hospitais de pequeno porte e "infecção de trato urinário de localização não especificado" entre aqueles de médio porte, e "acidente vascular cerebral não especificado" para os de grande porte. A variação de custos médios para as clínicas e hospitais foram de $\mathrm{R} \$ 1.208,92$ para pequeno porte, até $\mathrm{R} \$ 4.954,67$ para grande porte. Já as clínicas e hospitais de médio porte gastaram, em média, $\mathrm{R} \$ 3.367,61$ com as internações por dengue (IESS, 2018).

\subsection{Mecanismos de controle}

Os mecanismos de combate ao vetor transmissor da dengue e prevenção à doença dividem-se em três categorias de controle: físico, biológico e químico.

O controle físico consiste no mapeamento das notificações de dengue e dos locais de oviposição, para classificação do risco e consequente definição de ações localizadas (Kittayapong et al., 2008; Wilder-Smith et al., 2012; Wong et al., 2011).

O controle biológico consiste no método paratrangênese que utiliza bactérias geneticamente modicadas para desregular o ciclo sexual da fêmea do mosquito e reduzir sua capacidade de transmitir o vírus (Ogaugwu e Durvasula, 2017). Uma forma é por meio da liberação de peixes e crustáceos larvórios, como o guppy, recipientes de águas infestadas pelas larvas, pois essas espécies eliminam grande parte das larvas (Seng et al., 2008).

Outra forma é o uso da bactéria wolbachia resulta no nascimento de machos estéreis (Werren et al., 2008). No Brasil é o uso da wolbachia, uma bactéria encontrada em vários tipos de mosquitos, como o Culex conhecido popularmente como pernilongo ou muriçoca. A bactéria é transmitida verticalmente de mãe para filho e estará disseminada a partir de poucas gerações. Sua presença na população de insetos evita a propagação do vírus da dengue, pois machos infectados por essa bactéria são estéreis, diminuindo a população de mosquitos (Flores e ONeill, 2018; Werren et al., 2008).

Um dos projetos que consiste em liberar os mosquitos com a wolbachia nos locais com maior índice de infestação da doença está sob a coordenação de pesquisadores do Instituto Fiocruz do Rio de Janeiro, iniciado em 2014 e expandido em 2016 (Fiocruz, 2017).

Entretanto, esta técnica tem sido questionada em alguns estudos por conta dos efeitos da introdução em mosquitos hospedeiros não-nativos, induzindo a resistência de vários patógenos humanos além do próprio vírus da dengue (de Oliveira e Moreira, 2012).

O controle químico consiste no uso do inseticida como a ciromazina, que impede o crescimento e desenvolvimento das larvas ou o uso de feromônios, que atraem as fêmeas para colocarem seus ovos em locais com um grande número de outras larvas dificultando a progressão do ovo para a larva ou mesmo a larva para a idade adulta (Araújo et al., 2015; Lau et al., 2015; Nagpal et al., 2015; Ong e Jaal, 2015).

Em relação ao controle químico, a pulverização com inseticida ou aplicação de larvicida são as formas mais utilizadas de combate ao mosquito. As reações toxicológicas no organismo dos insetos causadas pelos inseticidas usados em pulverizações são excitação, convulsão, paralisia e morte (Matias, 2014).

O inseticida mais utilizado no Brasil para o combate à dengue é o Malathion GT 96\%, que pertence ao grupo dos organofosforados e atua na inibicão da colinesterase do sistema nervoso do inseto, destruindo a acetilcolina, substância química que age como neurotransmissor de impulsos nervosos, interrompendo as transmissões das atividades musculares voluntárias no sistema nervoso do inseto (Ministerio da Saude, 2014b).

A diluição em água do malathion é a formulação utilizada atualmente no Brasil e sua distribuição é feita somente pelo Governo Federal, que compra o produto e distribui para os Estados, que 
repassam para os municípios (Ministerio da Saude, 2014b).

Alguns estudos nacionais e internacionais mostraram que as populações larvais do mosquito $A e-$ des aegypti tiveram baixos níveis de resistência ao malathion, sugerindo que este composto pode ser eficaz em programas de controle durante surtos de dengue (Andrighetti et al., 2013; Ponlawat et al., 2005).

Outra forma muito utilizada para a redução no número de mosquitos utilizada no Brasil é o uso do larvicida. Os larvicidas utilizados no controle de vetores pertencem aos grupos dos biolarvicidas, e agem como inibidores do crescimento e desenvolvimento das larvas. A Organização Mundial da Saúde tem uma lista bem restrita de larvicidas que podem ser usados em água potável, um desses compostos é o Bacillus thuringiensis israelensis (BTI) (Ministerio da Saude, 2014a).

O larvicida Bt-horus SC que é um dos utilizados e recomendado por especialistas do país. É um larvicida biológico especialmente desenvolvido para controlar as larvas do mosquito transmissor da dengue (Aedes aegypti) e das larvas dos borrachudos (Simulium Spp), e o seu principal ingrediente ativo é o BTI. Esse produto foi desenvolvido por uma empresa privada, em parceria com o Instituto de Pesquisas Tecnológicas (IPT), e pelo Instituto de Tecnologia em Fármacos, da Fiocruz (Embrapa, 2010).

Impedir a criação dos focos do mosquito é a maneira mais eficaz de combate à doença, porém não é o suficiente. O repelente que age como uma película protetora que afasta o mosquito, impedindo que ele pouse na pele do indivíduo, é mais um aliado (Kalyanasundaram e Das, 1985).

Os repelentes recomendados pela OMS são os que possuem de $20 \%$ a $50 \%$ de DEET, $20 \%$ a $25 \%$ de icaridina e 30\% do composto químico IR 353 em seus princípios ativos. Esses produtos têm a capacidade de proteção de até 10 horas. O uso desse produto não é recomendado para bebês de até 6 meses e grávidas (Stefani et al., 2009). Os produtos mais vendidos no Brasil respeitam as recomendações da OMS, e as porcentagens de eficiencia não atingem o máximo, a maioria deles tem capacidade de proteção de até 6 horas (Stefani et al., 2009).

Além das formas de combate já citadas vale lembrar que uma outra forma de proteção direta aos humanos pode ser feita por meio de vacinas, que atuam estimulando a resposta imunológica e protegendo o indivíduo contra a infecção (Qiao et al., 2011).

Desde a vacina contra a varíola, desenvolvida por Edward Jenner em 1796, várias doenças podem ser prevenidas por vacinação (Keeling e Rohani, 2011). Para a dengue, algumas vacinas foram desenvolvidas e aprovadas, por exemplo a vacina da empresa Sanofi Pasteur, que já está pronta e a vacina do Instituto Butantan que encontra-se em sua fase III de teste (Dayan et al., $2014, ?)$.

\subsection{Modelos Epidemiológicos}

Um dos primeiros modelos para doenças infecciosas foi para a varíola, formulado em 1760, por Daniel Bernoulli. Esse modelo foi aplicado para avaliar a eficácia da variolação em pessoas saudáveis com o vírus (Dietz e Heesterbeek, 2002). Em 1855, John Snow publicou um estudo clássico da cólera, e vários estudos quantitativos e estatísticos epidemiológicos surgiram depois disso (Smith et al., 2012).

A Equação 1.2 mostra a estrutura do modelo de Bernoulli. A população é dividida em suscetíveis - indivíduos que ainda não foram infectados, e imunes - indivíduos que foram imunizados após uma infecção. A taxa de mortalidade devido a todas as causas, exceto devido à infecção é denotada por $\mu(a)$. A força da infecção $\lambda(a)$ é a taxa segundo a qual os suscetíveis são infectados. Apenas uma fração $s(a)$ sobrevive para se tornar imunes. O resto $c(a)=1-s(a)$ morre devido à infecção. Tradicionalmente, $c(a)$ é chamado de taxa de letalidade. Como não é uma taxa (com dimensão por unidade de tempo), mas uma probabilidade, ou seja, uma quantidade sem dimensão, vamos nos referir a ela como fatalidade de caso. E $u(a)$ é a probabilidade de um indivíduo recém-nascido estar vivo e suscetível na idade $a$. Então $u(a)$ satisfaz a equação diferencial 


$$
\left\{\frac{d u}{d a}=-[\lambda(a)+\mu(a)] u\right.
$$

com condições iniciais: $u(0)=1$.

A probabilidade de $w(a)$ estar vivo e imune é dada por

$$
\left\{\frac{d w}{d a}=[1-c(a)] \lambda(a) u(a)-\mu(a) w,\right.
$$

com condições iniciais: $w(0)=0$.

A representação compartimental do modelo é:

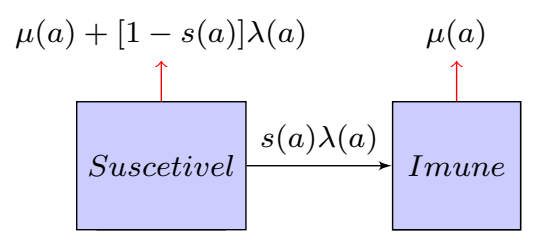

Figura 1.3: Representação compartimental do modelo de Bernoulli

O modelo epidêmico mais simples é o SIR que representa a dinâmica de uma população $N$ composta por indivíduos suscetíveis, infectados e recuperados.

O modelo SIR mostra num certo tempo $t$ os três estados da população total $N(t)$, que são:

S - suscetíveis: indivíduos que não estão infectados, mas podem vir a se infectar.

I - infectados: indivíduos que estão infectados.

$\mathrm{R}$ - resistentes: indivíduos que são resistentes a doença, ou aqueles que adquiriram imunidade devido a uma infecção passada.

As hipóteses do modelo são:

- doença é de transmissão direta $(I \rightarrow S)$;

- a população $N$ é constante, podendo prescindir da variável $R$, em alguns casos;

- a dinâmica de transmissão é definida pelo número de contatos entre $S$ e $I$ e sempre que ocorrer um contato, o indivíduo $S$ se torna infectado.

A representação matemática é dada por um sistema de EDO mostrado na Equação (1.3):

$$
\left\{\begin{array}{l}
\frac{d S(t)}{d t}=\nu N-\mu S(t)-\lambda S(t) I(t) \\
\frac{d I(t)}{d t}=\lambda S(t) I(t)-\mu I(t)-\gamma I(t) \\
\frac{d R(t)}{d t}=\gamma I(t)-\mu R(t)
\end{array}\right.
$$

com condições iniciais: $S\left(t_{0}\right), I\left(t_{0}\right), R\left(t_{0}\right)$.

$\mathrm{N}=\mathrm{S}(\mathrm{t})+\mathrm{I}(\mathrm{t})+\mathrm{R}(\mathrm{t})$ : população total

$\nu=$ taxa de nascimento, no caso $\nu=\mu$, pois $N$ é constante

$\mu=$ taxa de mortalidade, independente da doença, $\mu>0$

$\lambda=$ taxa de transmissão de suscetíveis para infectados, $\lambda>0$

$\gamma=$ taxa de transmissão de infectados para recuperados, $\gamma>0$

A representação compartimental da Equação (1.3) é:

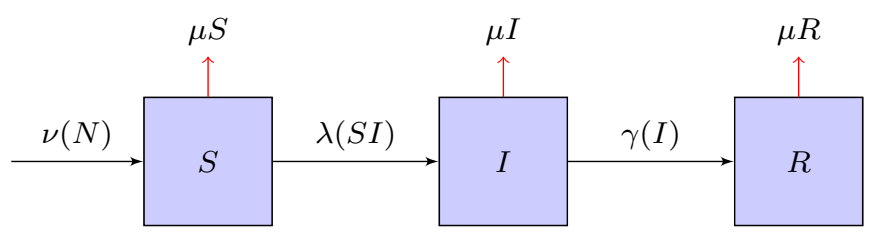

Figura 1.4: Representação compartimenal do modelo SIR 
Os parâmetros $\nu, \mu, \lambda, \gamma$ devem se adequar a cada população e doença. O modelo também pode ser aprimorado incluindo o aumento da taxa de mortalidade devida à doença, e variações sazonais em $\lambda$ e $\gamma$.

Usando a nomenclatura $S, I, R, E, M$, respectivamente para suscetíveis, infectados, recuperados, expostos e imunizados, as variações clássicas do modelo $S I R$ são:

- SIRS: quando a imunização é temporária e os recuperados voltam a ser suscetíveis;

- SEIR: é introduzida a população de expostos $E(t)$, que efetivamente terão contato com os infectados

- SIS: quando a população de suscetíveis não é protegida contra uma reinfecção, voltando a ser suscetível.

- MSEIR: é introduzida a população de imunizados $M(t)$, em geral são os recém nascidos imunizados passivamente.

Todos esses modelos podem ser aprimorados, incluindo algum tipo de controle, por meio de vacinação, aumentando o número de imunizados; e quarentena por meio do isolamento dos infectados.

No caso da dengue e outras doenças transmitidas por vetor é necessário incluir os compartimentos que representam a dinâmica populacional do vetor e sua interação com os humanos.

\subsubsection{Modelo simples com vetor e sem controle}

Ao longo da história sempre houve a suspeita de que os mosquitos eram transmissores de doenças. Essa suspeita foi confirmada em 1877, na China, onde Patrick Manson demonstrou formalmente que os mosquitos transmitem patógenos através do sangue que transportavam com eles quando picavam uma pessoa infectada. Em 1880, Charles Laveran notou que o vírus da malária poderia ser transmitido por mosquitos e, em 1897, Ronald Ross demonstrou que os mosquitos podiam sim transmitir o vírus malária. Depois disso, Ross deu início a estudos que mostravam que as populações de mosquitos poderiam ser reduzidas através do controle das larvas e combinadas com outras medidas para previnir doenças transmitidas por mosquitos (Smith et al., 2012).

No ano de 1990, em Cuba, Walter Reed, Carlos Finlay e James Carrol, mostraram que os mosquitos tramitiam o vírus da febre amarela, e que controlando as populações de mosquitos poderia ser interrompida a transmissão do vírus. Em 1904, em Mian-Mir, cidade do Paquistão, Ross publicou um modelo descrevendo o movimento do mosquito adulto e a escala espacial de controle das larvas que seria necessária para reduzir o número de mosquitos. Já na Australia, em 1906, Thomas Bancroft mostrou que os mosquitos também transmitiam o vírus da dengue (Smith et al., 2012).

Em 1908, Ross formulou e descreveu um modelo para a transmissão de doenças transmitidas por moquitos, e em 1911, ele publicou um segundo modelo de transmissão da malária. Em 1921, discutiu sobre o valor do tratamento repetido com drogas para "curar" as infecções, essa foi sua última contribuição para modelar a malária (Smith et al., 2012).

As ideias de Ross serviram de motivação para uma geração de médicos entomologistas, e a partir de 1950 houve um grande avanço nessa área devido ao trabalho de George Macdonald. O modelo "Ross-Macdonald" foi fortemente estabelecido como base para uma teoria mais ampla da transmissão e controle de doenças transmitidas por mosquitos (Smith et al., 2012).

Ross também estudou uma teoria quantitativa que deu o nome de "força de infecção", onde ele notou que havia uma conexão entre as densidade da população de mosquitos e o número de infecções, mas sem sucesso. Em 1939 Ross mostrou que seria possível matar mosquitos adultos com a utilização de inseticida. Após a Segunda Guerra Mundial com a proliferação dos mosquitos, o produto foi usado em grande escala em programas de controle da malária. A Organização Mundial de Saúde (OMS) fundada em 1948, começou a defender a erradicação global da malária e a erradicação do Aedes aegypti no Ocidente. Logo depois, o Programa Global de Erradicação da Malária (GMEP, 1955 1969) foi formalmente lançado.

Em 1947, Walton usou uma distribuição de Poisson para modelar a multiplicidade de infecções com a malária, isto é, vários tipos de diferente de parasitas sendo transportados ao mesmo tempo no sangue. 
Em 1950, Macdonald inovou matematicamente o modelo de Ross introduzindo a superinfecção, reinfecção daqueles que já estavam infectados, para que eles carregassem vários tipos de parasitas. Mas sua contribuição mais importante foi desenvolver a teoria entomológica e a teoria quantitativa de controle que Ross tinha tentado meio século antes. Em 1952, Macdonald fez uma primeira estimativa da força de infecção para descrever a sobrevivência do mosquito, a alimentação através do sangue e a relação entre a temperatura e o período de incubação extrínseco. Também incluiu a primeira taxa de recuperação da infecção. E em 1956, Macdonald justificou teoricamente o uso do inseticida na erradicação da malária (Smith et al., 2012).

Em 1953, Drapter e Davidson publicaram a primeira estimativa do $R_{0}$, que descreve o número esperado de hospedeiro que seriam infectados por um único hospedeiro infectado em uma população suscetível. Mais tarde, entomologistas da OMS, deram o nome de capacidade vetorial, ou taxa de reprodução diária para conceitos entomológicos de $R_{0}$, que corresponde ao número esperado de picadas de mosquitos infecciosos que picariam uma mesma pessoa em um único dia, ou seja, a intensidade potencial de transmissão por mosquitos.

Em 1969, Macdonald mediu a capacidade vetorial e estimou o tamanho do efeito do inseticida e examinou as mudanças reais de uma endemia. Ele também descreveu a base matemática para mudanças na endemicidade, e relação entre a endemia e o $R_{0}$, e os prazos de resposta para a interrupção da transmissão após o controle. Sua última contribuição foi um modelo estocástico de transmissão da malária, includindo as primeiras simulações de um patógeno transmitido por mosquito já realizada em um computador, publicada após sua morte (Smith et al., 2012).

Muitas doenças são transmitidas por vetores, essas doenças podem ser transmitidas entre os hospedeiros primários (de pessoa para pessoa ou de animal para animal), mas somente através de um hospedeiro ou vetor intermediário de insetos. Quando o inseto infectado se alimenta de um humano suscetível, o patógeno entra na corrente sanguínea do humano e a infecção pode ocorrer, com uma determinada probabilidade, da mesma forma pode ocorrer do inseto suscetível ser infectado por um humano infectado através da picada (Keeling e Rohani, 2011).

Este modelo baseia-se na seguintes hipóteses: a doença é viral ou bacteriana e é transmitida por contato direto, ou seja, de indivíduo para indivíduo; no início da epidemia, apenas uma fração da população é contagiosa, todas os outros indivíduos são suscetíveis; o indivíduo sofre o curso completa da doença para eventualmente se recuperar adquirindo imunidade, ou morrendo; e a população total de indivíduos é constante, e sem dinâmica demográfica (Capasso e Serio, 1978).

Aqui também teremos os compartimentos dos suscetíveis, infectados e recuperados, porém, quando estivérmos nos referindo a humanos usaremos o índice $H$, quando nos referirmos a mosquitos usaremos o índice $M$ e quando nos referirmos a larvas usaremos o índice $L$.

Consideremos um modelo simples para a propagação da infecção entre humanos e mosquitos. Para esse tipo de modelo a dinâmica do SIR é da seguinte forma:

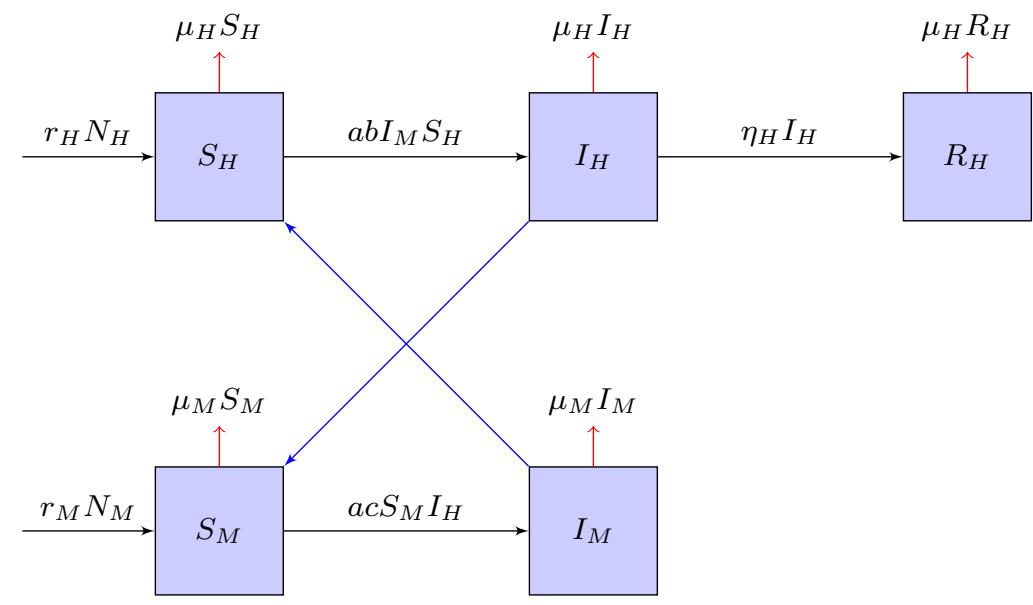

Figura 1.5: Representação compartimental de um modelo com vetor e sem controle

A fórmula para essa dinâmica pressupõe que cada mosquito pica a uma taxa constante $b$ e que 
isso é compartilhado entre todos os hospedeiros humanos dentro de uma área. Assim, as equações para a dinâmica da doença são:

$$
\left\{\begin{array}{l}
\frac{d S_{H}}{d t}=r_{H} N_{H}-a b I_{M} S_{H}-\mu_{H} S_{H} \\
\frac{d I_{H}}{d t}=a b I_{M} S_{H}-\left(\eta_{H}+\mu_{H}\right) I_{H} \\
\frac{d R_{H}}{d t}=\eta_{H} I_{H}-\mu_{H} R_{H} \\
\frac{d S_{M}}{d t}=r_{M} N_{M}-a c S_{M} I_{H}-\mu_{M} S_{M} \\
\frac{d I_{M}}{d t}=a c S_{M} I_{H}-\mu_{M} I_{M}
\end{array}\right.
$$

As variáveis do modelo 1.3 são:

\begin{tabular}{c|c}
\hline Notação & Variável \\
\hline \hline$S_{H}$ & População de humanos suscetíveis \\
$I_{M}$ & População de humanos infectados \\
$R_{H}$ & População de humanos recuperados \\
$S_{M}$ & Populaçãa de mosquitos suscetíveis \\
$I_{M}$ & População de mosquitos infectados \\
\hline
\end{tabular}

Tabela 1.2: Tabela de variáveis do modelo

Hipótese sobre a população total de humanos é $N_{H}$ :

$N_{H}=S_{H}(t)+I_{H}(t)+R_{H}(t)=$ constante.

Os parâmetros do modelos são:

\begin{tabular}{c|c}
\hline Notação & Parâmetro \\
\hline \hline$r_{H}$ & Taxa de nascimento de humanos \\
$\mu_{H}$ & Taxa de mortalidade de humanos \\
$r_{M}$ & Taxa de nascimento de mosquitos \\
$\mu_{M}$ & Taxa de mortalidade de mosquitos \\
$a$ & Média diária de picadsas por mosquito \\
$b$ & Fração diária de picadas por mosquito infectados \\
$c$ & Suscetibilidade do mosquito à doença \\
$\eta_{H}$ & Taxa de recuperação de humanos \\
\hline
\end{tabular}

Tabela 1.3: Tabela de parâmetros do modelo

$a b I_{M} S_{H}$ : representa a probabilidade de um mosquito infectado picar um humano suscetível;

$a c S_{M} I_{H}$ : representa a probabilidade de um mosquito suscetível se infectar ao picar um humano infectado.

Neste modelo não há nenhum controle da infecção. Entretanto, é possível identificar algumas estratégias de combate:

- redução da população de mosquitos promovendo o aumento de $\mu_{M}$ por meio de agentes físicos;

- redução do número de encontros entre $I_{M} S_{H}$ por meio do uso de repelente;

- vacinação de humanos, reduzindo o número de suscetíveis.

Cada forma de controle implica em várias ações envolvendo agentes públicos, populações residente, e, consequentemente, diferentes custos.

\subsubsection{Modelo com vetor e com estratégia de controle}

Para impedir a transmissão e proliferação da doença é importante que sejam tomadas medidas de combate ao vetor, para isso é necessário o uso de alguns mecanismos de controle. As técnicas mais utilizadas são as que matam o mosquito adulto, como o inseticida, as que matam as larvas, 
como os larvicidas, e as que impedem a picada no humano, como o repelente, e algumas que atuam na eliminação do criadouro.

Matematicamente, esses mecanismos de controle são introduzidos nas equações do sistema da seguinte forma:

- Larvicida: atua na redução da população de mosquitos em sua fase aquática promovendo o aumento de mortes de larvas e ovos por meio de controle químico. Os mecanismos de controle são introduzidos como taxas de mortalidade adicionadas em cada uma das fases do vetor em que atuam (Burattini et al., 2008; Erlanger et al., 2008; Ferreira e Yang, 2003; Rigau-Pérez et al., 1998; Yang e Ferreira, 2008).

- Inseticida: atua na redução da população de mosquitos adultos promovendo o aumento de $\mu_{M}$ por meio de controle químico. Os mecanismos de controle são introduzidos como taxas de mortalidade na fase adulta do vetor (Burattini et al., 2008; Esteva e Vargas, 1998; Ponlawat et al., 2005; Rigau-Pérez et al., 1998; Rodrigues et al., 2010).

- Repelente: a população de humanos suscestíveis pode influenciar a taxa de picadas de mosquitos pelo uso do repelente. Para esse propósito, o parâmetro mais importante é a taxa média de picadas, $a$. Neste caso o controle é introduzido na equação de $S_{H}$, reduzindo o número de encontros entre $I_{M} S_{H}$ por meio do uso do repelente (Aldila et al., 2013; Dorsett et al., 2016; Naowarat et al., 2012; Phaijoo e Gurung, 2017).

Nosso modelo será baseado em um modelo SIR simples com a introdução das três formas de controle indicadas acima como mecanismos de combate ao vetor e a maior contribuição desse modelo foi o desenvolvimento das variáveis de controle que são diferentes dos já vistos na literatura atual. 


\section{Capítulo 2}

\section{Estruturação de um modelo para dengue com estratégias de controle do vetor}

Neste capítulo apresentaremos um modelo determinístico SIR de Equações Diferenciais Ordinárias. Para isso adaptamos o modelo apresentado em Burattini et al. (2008) para simular a dinâmica de difusão da doença em humanos e vetores com o incremento de três diferentes controles simultânamente: larvicida, inseticida e repelente. Além disso acoplaremos uma função custo e uma função DALY.

\subsection{Formulação do modelo}

Algumas hipóteses são feitas neste modelo: a população humana total $\left(N_{H}\right)$ é constante, o que significa que não consideramos nascimentos e mortes, a população é homogênea; consideramos apenas um sorotipo; supõe-se que tanto humanos como mosquitos nascem suscetíveis; não há proteção natural; para o mosquito não há fase de resistência, devido ao seu curto tempo de vida.

Cada compartimento representa uma população e as flechas consideram a entrada e saída dos compartimentos de acordo com cada taxa. A transmissão do vírus é feita através de contato direto de humanos suscetíveis com mosquitos infectados e de humanos infectados com mosquitos suscetíveis. Também temos a transmissão vertical de larvas infectadas para mosquitos infectados e a taxa de mortalidade natural está presente em todos os compartimentos.

Neste modelo após um indivíduo suscetível $S_{H}$ se tornar infectado $I_{H}$ a taxa $a b I_{M} \frac{\left(1-p_{H}\right) S_{H}}{N_{H}}$, este se recupera a taxa $\eta_{H} I_{H}$ e passa para o compartimento dos recuperados $R_{H}$ e terá imunidade permanente.

Os mosquitos suscetíveis $S_{M}$ se tornam infectados $I_{M}$ a taxa de transmissão $a c S_{M} \frac{\left(1-p_{H}\right) I_{H}}{N_{H}}$.

As larvas suscetíveis nascem a taxa $r_{M}\left[S_{M}+(1-g) I_{M}\right]\left(1-\frac{S_{L}+I_{L}}{k N_{H}}\right)$, passando para o compartimento $S_{M}$ a taxa $r_{L} S_{L}$, assim como as larvas infectadas $r_{M}\left[g I_{M}\right]\left(1-\frac{S_{L}+I_{L}}{k N_{H}}\right)$ passam para o compartimento $I_{M}$ transmitindo o vírus a uma taxa de $r_{L} I_{L}$. Em todos os compartimentos consideramos a taxa de morte natural.

A representação compartimental do modelo é: 


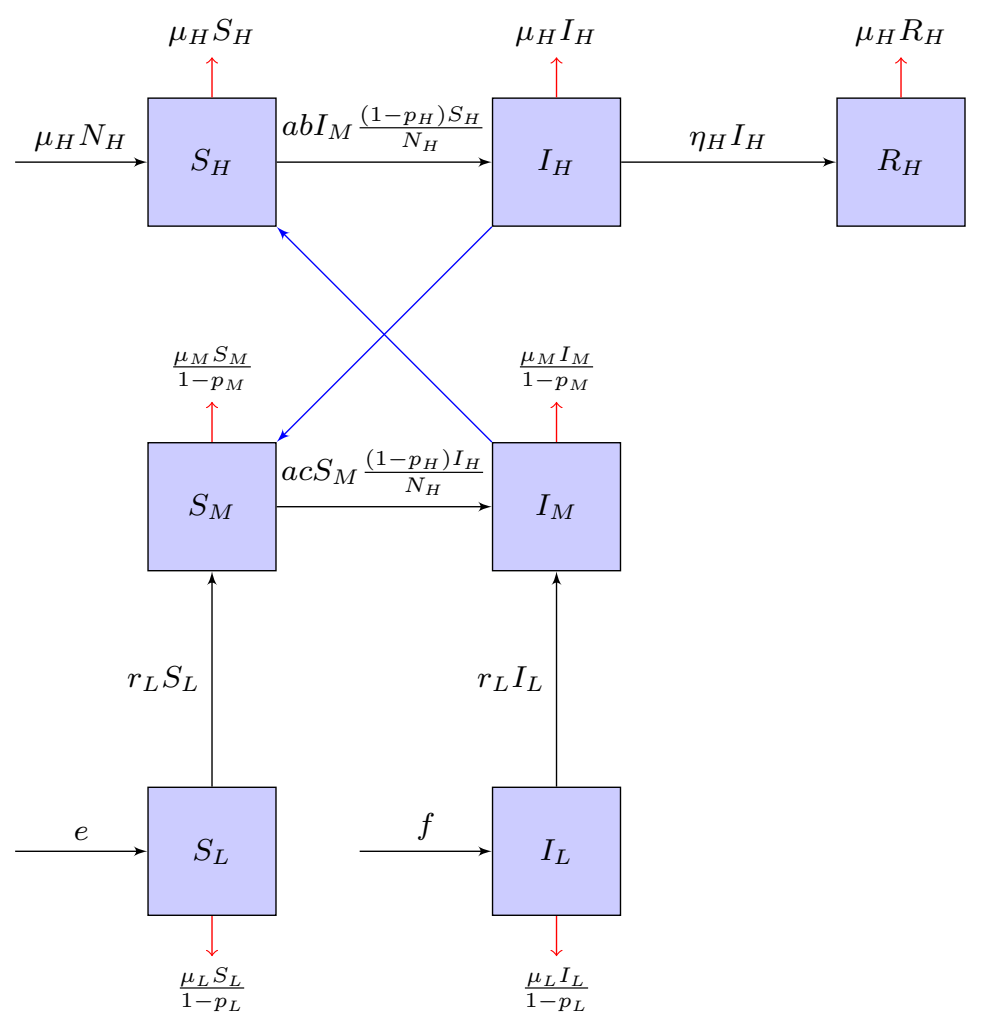

Figura 2.1: Representação compartimental do modelo epidemiológico

onde:

$e=r_{M}\left[S_{M}+(1-g) I_{M}\right]\left(1-\frac{S_{L}+I_{L}}{k N_{H}}\right)$,
$f=r_{M}\left[g I_{M}\right]\left(1-\frac{S_{L}+I_{L}}{k N_{H}}\right)$.

Assim, a representação matemática do modelo é:

$$
\left\{\begin{aligned}
\frac{d S_{H}}{d t} & =\mu_{H} N_{H}-a b I_{M} \frac{\left(1-p_{H}\right) S_{H}}{N_{H}}-\mu_{H} S_{H} \\
\frac{d I_{H}}{d t} & =a b I_{M} \frac{\left(1-p_{H}\right) S_{H}}{N_{H}}-\left(\eta_{H}+\mu_{H}\right) I_{H} \\
\frac{d R_{H}}{d t} & =\eta_{H} I_{H}-\mu_{H} R_{H} \\
\frac{d S_{M}}{d t} & =r_{L} S_{L}-a c S_{M} \frac{\left(1-p_{H}\right) I_{H}}{N_{H}}-\frac{\mu_{M}}{1-p_{M}} S_{M} \\
\frac{d I_{M}}{d t} & =r_{L} I_{L}+a c S_{M} \frac{\left(1-p_{H}\right) I_{H}}{N_{H}}-\frac{\mu_{M}}{1-p_{M}} I_{M} \\
\frac{d S_{L}}{d t} & =r_{M}\left[S_{M}+(1-g) I_{M}\right]\left(1-\frac{S_{L}+I_{L}}{k N_{H}}\right)-\left(r_{L}+\frac{\mu_{L}}{1-p_{L}}\right) S_{L} \\
\frac{d I_{L}}{d t} & =r_{M}\left[g I_{M}\right]\left(1-\frac{S_{L}+I_{L}}{k N_{H}}-\left(r_{L}+\frac{\mu_{L}}{1-p_{L}}\right) I_{L}\right. \\
\frac{d C}{d t} & =\left(\gamma_{C}+\gamma_{H}\right) a b I_{M} \frac{\left(1-p_{H}\right) S_{H}}{N_{H}}+\gamma_{R} N_{H} p_{H}+\gamma_{I} p_{M}+\gamma_{L} p_{L} \\
\frac{d D}{d t} & =\frac{\alpha I_{H}}{365}
\end{aligned}\right.
$$

O parâmetro $r_{L}$ indica a metamorfose das larvas, no caso, as larvas virando mosquitos, e varia em função do tempo, sendo dado pela fórmula

$$
r_{L}(t)=X\left[Y+Z \cos \left\{2 \pi\left(\frac{\mathrm{t}}{365}+\mathrm{t}_{0}\right)\right\}\right]
$$


onde $t_{0}$ indica a época do ano correspondente ao instante $t=0$. O $X$ é o valor máximo do $r_{L}$ no ano, o $Y$ é a razão entre o valor médio e o máximo no ano e $Z$ é $1-Y$ (Burattini et al., 2008).

Os termos de transmissão de dengue são padrões, envolvendo o produto dos infectados e dos suscetíveis. Este termo pode ser deduzido da seguinte forma: se cada mosquito infectado realiza $a$ picadas por dia, então são $a * I_{M}$ picadas; se apenas uma proporção $b$ destas picadas é infecciosa, então temos um total de $a * b * I_{M}$ picadas infecciosas por dia. Mas nem todas estas picadas transmitem a doença, pois a pessoa picada precisa ser suscetível, então apenas uma proporção destas picadas realmente transmite a dengue, sendo que esta proporção é a proporção de suscetíveis na população humana $\frac{S_{H}}{N_{H}}$. Fazendo uma adaptação, o mesmo argumento serve para deduzir o outro termo de transmissão (de humanos infectados para mosquitos suscetíveis). A proporção de larvas nascidas infectados é trivial: o termo corresponde ao total de nascimentos e multiplicado pela proporção $g$ de nascidos infectados e $\eta_{H}$ representa a taxa de recuperação da imunidade em humanos.

\begin{tabular}{c|c}
\hline Notação & Parâmetro \\
\hline \hline$N_{H}$ & População (constante) de humanos \\
$\mu_{H}$ & Taxa de mortalidade de humanos \\
$r_{M}$ & Taxa de depósito de ovos de larvas \\
$k$ & Número máximo de larvas por humano \\
$\mu_{L}$ & Taxa de mortalidade de larvas \\
$r_{L}$ & Taxa de metamorfose de larvas \\
$\mu_{M}$ & Taxa de mortalidade de mosquitos \\
$a$ & Média diária de mordidas por mosquito \\
$b$ & Fração de mordidas de mosquito infecciosas \\
$c$ & Suscetibilidade de mosquitos a dengue \\
$g$ & Proporção de larvas infectadas \\
$\eta_{H}$ & Taxa de recuperação ou cura \\
$p_{H}$ & Proporção de humanos usando repelente \\
$p_{M}$ & Proporção de mosquitos atingidos por inseticida \\
$p_{L}$ & Proporção de ovos atingidos por larvicida \\
\hline
\end{tabular}

Tabela 2.1: Tabela de valores dos parâmetros relacionados a dinâmica do modelo

O termo $p_{H}$ foi criado especialmente para este trabalho, já que não encontramos na literatura algo que fizesse o controle dessa forma. Sabendo, a cada momento, a proporção $p_{H}$ de pessoas que estão com o repelente ainda surtindo efeito, podemos modificar as equações (assumindo que esta proporção $p_{H}$ é a mesma em todos os 3 compartimentos). Assim pegamos os termos de transmissão da dengue e mudamos a proporção de pessoas que podem ser infectadas

$$
\frac{S_{H}}{N_{H}}
$$

para

$$
\frac{\left(1-p_{H}\right) S_{H}}{N_{H}}
$$

e a proporção de pessoas que podem infectar mosquitos para

$$
\frac{\left(1-p_{H}\right) I_{H}}{N_{H}}
$$

pois apenas os que não usam repelente podem estar envolvidos na transmissão da doença.

Para encontrarmos a proporção $p_{H}$, que é a proporção de pessoas com repelente ativo, isto é, 
ainda em efeito, calculamos o seguinte produto

$$
\mathrm{p}_{H}=\frac{N_{C}}{N_{H}} n_{R} T_{R}
$$

onde, $T_{R}$ é o tempo médio de duração do repelente; $n_{R}$ corresponde ao número médio de aplicações de repelente por dia (dentre as pessoas que usam repelente) e sua unidade é dia $^{-1}$ (unidade inversa de $T_{R}$ que é em dia); e $N_{C}$ é o número de pessoas que usam repelente. Com isso, temos que $\frac{N_{C}}{N_{H}}$ é a proporção de pessoas que usa repelente.

Também criamos o parâmetro para modelarmos o uso de inseticida, e para isso usamos a alteração na expectativa de vida dos mosquitos: se a taxa de mortalidade é $\mu_{M}$, então a expectativa de vida é

$$
\frac{1}{\mu_{M}}
$$

mas, se o inseticida mata uma proporção $p_{M}$ dos mosquitos, então estes mosquitos possuem expectativa de vida 0 , enquanto que os outros $\left(1-p_{M}\right)$ continuam com a mesma expectativa de antes, levando a uma expectativa média de

$$
p_{M} * 0+\left(1-p_{M}\right) * \frac{1}{\mu_{M}}=\frac{\left(1-p_{M}\right)}{\mu_{M}}
$$

Como a taxa é o inverso da expectativa de vida, podemos dizer que a taxa de mortalidade dos mosquitos é

$$
\frac{\mu_{M}}{1-p_{M}}
$$

Para determinar esta proporção $p_{M}$, temos mais uma vez um produto

$$
\mathrm{p}_{M}=\frac{A_{C}}{A} \beta_{I}
$$

onde, $A_{C}$ corresponde a área na qual o inseticida é aplicado; mesma unidade de $A\left(\mathrm{~km}^{2}\right)$. Com isso, $\frac{A_{C}}{A}$ é a proporção da área total na qual se usa inseticida.

Os argumentos são exatamente os mesmos para o uso de larvicida, com uma exceção: deve-se trocar "proporção da área total" por "proporção do volume total de águas" no produto da última fórmula, ou seja,

$$
\mathrm{p}_{L}=\frac{V_{C}}{V} \beta_{L}
$$

onde, $V_{C}$ é o volume de águas nas quais o larvicida é aplicado; mesma unidade de $V(L)$. Com isso, $\frac{V_{C}}{V}$ é a proporção do volume total de águas no qual se usa larvicida.

Nosso modelo visa distribuir os métodos de controle de uma forma homogênea em toda cidade de São Paulo, e não por região, por isso estamos trabalhando com um sistema de Equações Diferenciais Ordinárias.

Outro item criado especialmente para este trabalho foi a função do custo total. Para o desenvolvimento dessa função levamos em consideração os gastos com os três controles (repelente, inseticida e larvicida) e os gastos com clínicas e hospitais. Assim, a nossa função custo (equação 8 de 2.1) ficou da seguinte forma: 


$$
\left\{\frac{d C}{d t}=\left(\gamma_{C}+\gamma_{H}\right) a b I_{M} \frac{\left(1-p_{H}\right) S_{H}}{N_{H}}+\gamma_{R} N_{H} p_{H}+\gamma_{I} p_{M}+\gamma_{L} p_{L}\right.
$$

Na equação acima,

$$
\gamma_{C}=v_{C} * q_{C}
$$

onde, $\gamma_{C}$ representa o custo associado a visita à clinicas, $v_{C}$ é o custo por visita a clínica e $q_{C}$ é a proporção de recém-infectados que visitam clínicas

$$
\gamma_{H}=v_{H} * q_{H}
$$

onde, $\gamma_{H}$ corresponde ao custo associado a visita à hospitais, $v_{H}$ é o custo por visita a hospital e $q_{H}$ é a proporção de recém-infectados que visitam hospital

Os outros três termos correspondem ao uso de repelente, inseticida e larvicida, respectivamente.

$$
\gamma_{R}=\frac{1}{\beta_{R}} * \frac{u_{R}}{T_{R}}
$$

onde, $\gamma_{R}$ representa o custo associado ao repelente, $u_{R}$ corresponde ao custo por unidade de repelente e $T_{R}$ corresponde ao tempo total de duração por unidade de repelente

$$
\gamma_{I}=\frac{1}{\beta_{I}} * \frac{u_{I}}{T_{I}} * \frac{A}{A_{I}}
$$

onde, $\gamma_{I}$ representa o custo associado ao uso do inseticida, $\beta_{I}$ é a eficiência do repelente, $u_{I}$ é o custo por unidade de inseticida, $T_{I}$ corresponde ao tempo de duração por unidade do inseticida, $A$ é a área total da região e $A_{I}$ é a área de uso por unidade de repelente

$$
\gamma_{L}=\frac{1}{\beta_{L}} * \frac{u_{L}}{T_{L}} * \frac{V}{V_{L}}
$$

onde, $\gamma_{L}$ representa o custo associado ao uso do larvicida, $\beta_{L}$ é a eficiência do larvicida, $u_{L}$ é o custo por unidade do larvicida, $T_{L}$ corresponde ao tempo de duração por unidade do larvicida, $V$ é o volume total de águas e $V_{L}$ é o volume de águas por unidade de larvicida

O parâmetro $v_{H}$ foi calculado como sendo a média dos três valores 1208.92, 3367.61 e 4954.67, que correspondem aos custos em clínicas e hospitais de pequeno, médio e grande porte, respectivamente (IESS, 2018). Por falta de dados referente ao parâmtro $v_{C}$, assumimos que o valor é zero.

Os parâmetros $T_{R}, T_{I}$ e $T_{L}$ correspondem a períodos de duração de $12 \mathrm{~h}, 8 \mathrm{~h}$ e $6 \mathrm{~h}$, respectivamente. Enquanto que $u_{I}$ corresponde ao custo de aplicação por hectare, dado por

$$
u_{I}=50 \mathrm{R} \$ / \mathrm{L} \times 0.15 \mathrm{~L} / \text { hectare }
$$

Isso quer dizer que uma "unidade" de inseticida é a quantidade necesária para aplicar o produto em 1 hectare (ou seja, $150 \mathrm{~mL}$ ), de forma que $A_{I}$ (a área de uso por unidade) é exatamente 1 hectare. (Ministerio da Saude, 2019c) 


\begin{tabular}{c|c} 
Notação & Parâmetro \\
\hline \hline$q_{C}$ & Proporção de recém-infectados que visitam clínica \\
$q_{H}$ & Proporção de recém-infectados que visitam hospital \\
$v_{C}$ & Custo por visita a clínica \\
$v_{H}$ & Custo por visita a hospital \\
$u_{R}$ & Custo por unidade de repelente \\
$u_{I}$ & Custo por unidade de inseticida \\
$u_{L}$ & Custo por unidade de larvicida \\
$T_{R}$ & Tempo de duração por unidade de repelente \\
$T_{I}$ & Tempo de duração por unidade de inseticida \\
$T_{L}$ & Tempo de duração por unidade de larvicida \\
$\beta_{R}$ & Eficiência do repelente \\
$\beta_{I}$ & Eficiência do inseticida \\
$\beta_{L}$ & Eficiência do larvicida \\
$A$ & Área total da região \\
$A_{I}$ & Área de uso por unidade de inseticida \\
$V$ & Volume total de águas \\
$V_{L}$ & Volume de águas por unidade de larvicida \\
$\gamma_{C}$ & Custo associado a visita a clínica \\
$\gamma_{H}$ & Custo associado a visita a hospital \\
$\gamma_{R}$ & Custo associado a uso de repelente \\
$\gamma_{I}$ & Custo associado a uso de inseticida \\
$\gamma_{L}$ & Custo associado a uso de larvicida \\
$\alpha$ & DALYs perdidos por pessoa (por ano de dengue) \\
\hline
\end{tabular}

Tabela 2.2: Parâmetros relacionados a custo e DALYs

Neste trabalho também faremos a análise do DALY - Disability Adjusted Life Years (equação 9 de 2.1). É uma medida da perda de dias saudáveis em uma sociedade devido à mortalidade e morbidade. Esta medida sumária pode comparar a carga entre as doenças, assim como entre as populações. Ele também serve como uma ferramenta para alocação de recursos e análise econômica (Devleesschauwer et al., 2014) (Krishnamoorthy et al., 2009).

A equação dos DALYs perdidos acumulados para o nosso sistema fica da seguinte forma:

$$
\left\{\frac{d D}{d t}=\frac{\alpha I_{H}}{365}\right.
$$

onde, $\alpha$ representa os DALYs perdidos por pessoa (por ano de dengue).

Aqui, simplesmente multiplicamos o número padrão $\alpha$ de DALY usado para casos de dengue pelo número de pessoas infectadas, e dividimos por 365 dias para termos a quantidade em dias que a pessoa perde em qualidade de vida ao ser infectado pelo vírus.

Para o cálculo do DALY exitem vários pontos a serem considerados, um deles é o peso por incapacidade, ou DW. A tabela nacional de incapacidade por acidente de trabalho e doenças, em Diario da Republica Eletronico (2019), nos mostra qual o DW de cada enfermidade, porém como não conseguimos encontrar o DW da dengue especificamente, assumiremos o mesmo valor usado em Lee et al. (2011).

\subsection{Análise do modelo}

Utilizamos de um recurso matemático seguindo os passos descritos em Strogatz (2018), e definimos novos parâmetros a partir dos já utilizados. Esses parâmetros a princípio não tem nenhum 
significado epidemiológico, foram utilizados apenas para simplificar as contas relativas aos equilíbrios.

\begin{tabular}{c|c|c}
\hline Parâmetro & Fórmula & Regra de Substituição \\
\hline \hline$\theta_{H}$ & $\frac{\eta_{H}}{\mu_{H}}$ & $\eta_{H} \rightarrow \theta_{H} \mu_{H}$ \\
$u$ & $\left(1-p_{H}\right) a$ & $p_{H} \rightarrow 1-\frac{u}{a}$ \\
$v$ & $\frac{b}{\mu_{H}} u$ & $b \rightarrow \frac{v}{u} \mu_{H}$ \\
$w$ & $\frac{c}{r_{L}} u$ & $c \rightarrow \frac{w}{u} r_{L}$ \\
$\psi_{M}$ & $\frac{\mu_{M}}{r_{L}\left(1-p_{M}\right)}$ & $p_{M} \rightarrow 1-\frac{\mu_{M}}{r_{L} \psi_{M}}$ \\
$\psi_{L}$ & $\frac{\mu_{L}}{r_{L}\left(1-p_{L}\right)}$ & $p_{L} \rightarrow 1-\frac{\mu_{L}}{r_{L} \psi_{L}}$ \\
$\phi$ & $\frac{1}{\psi_{M}}-\frac{r_{L}\left(1+\psi_{L}\right)}{r_{M}}$ & $r_{M} \rightarrow r_{L}\left(1+\psi_{L}\right) \frac{\psi_{M}}{1-\psi_{M} \phi}$ \\
\hline
\end{tabular}

Tabela 2.3: Tabela de novos parâmetros - reparametrização

A última coluna da tabela 2.3 indica as substituições que serão feitas nas equações para que o modelo possa ser escrito em função dos novos parâmetros. Além disso, nota-se que o parâmetro $\phi$ é o único que não está restrito a valores positivos, podendo também ser zero ou negativo; apesar disto, a quantidade $\left(1-\psi_{M} \phi\right)$ é sempre positiva.

Aplicando as regras de substituição da tabela anterior no sistema de equações do modelo, obtemos o seguinte sistema reparametrizado:

$$
\text { Humanos }\left\{\begin{aligned}
\frac{d S_{H}}{d t} & =\mu_{H}\left[N_{H}-v I_{M} \frac{S_{H}}{N_{H}}-S_{H}\right] \\
\frac{d I_{H}}{d t} & =\mu_{H}\left[v I_{M} \frac{S_{H}}{N_{H}}-\left(1+\theta_{H}\right) I_{H}\right] \\
\frac{d R_{H}}{d t} & =\mu_{H}\left[\theta_{H} I_{H}-R_{H}\right]
\end{aligned}\right.
$$

$$
S_{H}+I_{H}+R_{H}=N_{H}
$$

$$
\begin{gathered}
\text { Mosquitos }\left\{\begin{array}{l}
\frac{d S_{M}}{d t}=r_{L}\left[S_{L}-w S_{M} \frac{I_{H}}{N_{H}}-\psi_{M} S_{M}\right] \\
\frac{d I_{M}}{d t}=r_{L}\left[I_{L}-w S_{M} \frac{I_{H}}{N_{H}}-\psi_{M} I_{M}\right] \\
\frac{d N_{M}}{d t}=r_{L}\left[N_{L}-\psi_{M} N_{M}\right]
\end{array}\right. \\
\operatorname{Larvas}\left\{\begin{array}{l}
\frac{d S_{L}}{d t}=r_{L}\left(1+\psi_{L}\right)\left[\psi_{M}\left[N_{M}-g I_{M}\right] \frac{1-\frac{N_{L}}{k N_{H}}}{1-\psi_{M} \phi}-S_{L}\right] \\
\frac{d I_{L}}{d t}=r_{L}\left(1+\psi_{L}\right)\left[\psi_{M}\left[g I_{M}\right] \frac{1-\frac{N_{L}}{1-\psi_{M}}}{1-\psi_{M} \phi}-I_{L}\right] \\
\frac{d N_{L}}{d t}=r_{L}\left(1+\psi_{L}\right)\left[\psi_{M} N_{M} \frac{1-\frac{N_{L}}{k N_{H}}}{1-\psi_{M} \phi}-N_{L}\right]
\end{array}\right.
\end{gathered}
$$

Matematicamente, para o sistema acima existem três tipos de equilíbrios: o livre de mosquitos (caso trivial); o livre de doença, onde há mosquitos, porém não há doença; e o endemico. 


\subsubsection{Equilíbrio livre de mosquitos}

Vamos considerar daqui em diante que $r_{L}$ assume algum valor fixo, para que o modelo possa ter pontos de equilíbrio.

Para o sistema acima, temos que

Se $\phi \leq 0$, é o caso trivial, livre de mosquitos e portanto só existe

$$
S_{H}^{*}=N_{H}
$$

Para nossas análises, o caso trivial será descartado e consideraremos apenas o caso não trivial.

\subsubsection{Equilíbrio livre de doença}

Se $\phi>0$, o sistema possui equilíbrios livres de doença, dado por

$$
E_{1}\left\{\begin{array}{lcc}
S_{H}^{*}=N_{H} & I_{H}^{*}=0 & R_{H}^{*}=0 \\
S_{M}^{*}=\phi k N_{H} & I_{M}^{*}=0 & N_{M}^{*}=\phi k N_{H} \\
S_{L}^{*}=\psi_{M} \phi k N_{H} & I_{L}^{*}=0 & N_{L}^{*}=\psi_{M} \phi k N_{H}
\end{array}\right.
$$

Dos resultados acima conseguimos descobrir o significado de alguns dos novos parâmetros, pois podemos deduzir as seguintes relações a partir do equilíbrio $E_{1}$ :

$$
\begin{aligned}
\frac{N_{L}^{*}}{N_{M}^{*}} & =\psi_{M} \\
\frac{N_{M}^{*}}{k N_{H}} & =\phi
\end{aligned}
$$

Isto significa que $\psi_{M}$ indica a quantidade limite de larvas por mosquito, enquanto que a quantidade $k N_{H}$ age como uma capacidade de carga, com $\phi$ relacionando esta quantidade com os valores limites de $N_{M}$ e $N_{L}$.

\subsubsection{Cálculo do $R_{0}$}

O número de reprodutibilidade basal, conhecido por $R_{0}$, foi introduzido em epidemiologia em 1975 por Dietz e em 1976, por Hethcote, e se trata da medida da capacidade máxima da doença para aumentar o número de infectados. Suponha-se que uma pessoa infectada (infecção primária), é introduzida em uma grande população em que todos os indivíduos são suscetíveis. $\mathrm{O} R_{0}$ é o número médio de infecções secundárias causadas pela infecção primária numa população inteiramente suscetível. Se a população for tão grande que se possa desprezar as infecções que vão sendo produzidas, o $R_{0}$ mede a velocidade inicial de crescimento da epidemia, pois cada indíviduo infectado ramifica-se em $R_{0} s$ novos infectados que, por sua vez, originam $R_{0} s$ infectados, e assim sucessivamente. Quando $R_{0}>1$, a doença tem capacidade para invadir toda uma população de suscetíveis, enquanto que, se $R_{0}<1$, a doença acaba desaparecendo (Diekmann et al., 1995; Van den Driessche e Watmough, 2002).

Teorema 1. O número de Reprodução Básico para o sistema de EDO 2.1 é:

$$
R_{0}=\sqrt{\frac{w v|\phi| k}{(1-g) \psi_{M}\left(1+\theta_{H}\right)}}
$$

Demonstração. Nos segundos membros do sistema de equações 2.1 foram incluídas as expressões de controle da população de mosquitos e larvas. Portanto, a expressão de $R_{0}$ dependerá dessas funções 
e será calculada usando o método de operador de próxima geração proposto por Diekmann et al. (1995); Van den Driessche e Watmough (2002).

Sendo assim, obtemos primeiramente que o vetor de componentes infectadas é $x=\left(I_{H}, R_{H}, I_{M}, I_{L}\right)$ e que podemos escrever a derivada de $x$ na forma $f-v$, como

$$
f=\left[\begin{array}{c}
\mu_{H} v I_{M} \frac{S_{H}}{N_{H}} \\
0 \\
r_{L} w S_{M} \frac{I_{H}}{N_{H}} \\
0
\end{array}\right] v=\left[\begin{array}{c}
\mu_{H}\left(1+\theta_{H}\right) I_{H} \\
\mu_{H}\left[R_{H}-\theta_{H} I_{H}\right] \\
r_{L}\left[\psi_{M} I_{M}-I_{L}\right] \\
r_{L}\left(1+\psi_{L}\right)\left[I_{L}-\psi_{M}\left[g I_{M}\right]\left(\frac{1-\frac{N_{L}}{k N_{H}}}{1-\psi_{M \phi}}\right)\right]
\end{array}\right]
$$

Calculando os Jacobianos de $f$ e $v$ com relação às variáveis de $x$ e avaliando-os no ponto de equilíbrio $E_{2}$ (pois o equilíbrio $E_{1}$ não nos interessa, por não conter quantidade alguma de mosquitos ou larvas), obtemos

$$
F=\left[\begin{array}{cccc}
0 & 0 & \mu_{H} v & 0 \\
0 & 0 & 0 & 0 \\
r_{L} w \phi k & 0 & 0 & 0 \\
0 & 0 & 0 & 0
\end{array}\right] \quad V=\left[\begin{array}{cccc}
\mu_{H}\left(1+\theta_{H}\right) & 0 & 0 & 0 \\
-\mu_{H} \theta_{H} & \mu_{H} & 0 & -r_{L} \\
0 & 0 & r_{L} \psi_{M} & r_{L}\left(1+\psi_{L}\right)
\end{array}\right]
$$

de onde conclui-se que

$$
V^{-1}=\left[\begin{array}{cccc}
\frac{1}{\mu_{H}\left(1+\theta_{H}\right)} & 0 & 0 & 0 \\
\frac{\theta_{H}}{\mu_{H}\left(1+\theta_{H}\right)} & \frac{1}{\mu_{H}} & 0 & 0 \\
0 & 0 & \frac{1}{(1-g) r_{L} \psi_{M}} & \frac{1}{(1-g) r_{L}\left(1-\psi_{L}\right) \psi_{M}} \\
0 & 0 & \frac{g}{(1-g) r_{L}} & \frac{1}{(1-g) r_{L}\left(1-\psi_{L}\right)}
\end{array}\right]
$$

Assim, obtemos a matriz de próxima geração

$$
M=F V^{-1}=\left[\begin{array}{cccc}
0 & 0 & \frac{\mu_{H} v}{(1-g) r_{L} \psi_{M}} & \frac{\mu_{H} v}{(1-g) r_{L}\left(1+\psi_{L}\right) \psi_{M}} \\
0 & 0 & 0 & 0 \\
\frac{r_{L} w \phi k}{\mu_{H}\left(1+\theta_{H}\right)} & 0 & 0 & 0 \\
0 & 0 & 0 & 0
\end{array}\right]
$$

e seu polinômio característico

$$
p(\lambda)=\operatorname{det}(\lambda I-M)=\lambda^{2}\left(\lambda^{2}-\frac{w v \phi k}{(1-g) \psi_{M}\left(1-\theta_{H}\right)}\right)
$$

Como $R_{0}$ é igual ao maior módulo dentre todos os autovalores (raízes do polinômio característico), temos que

$$
\mathrm{R}_{0}=\sqrt{\frac{w v|\phi| k}{(1-g) \psi_{M}\left(1+\theta_{H}\right)}}
$$

Além disso, o modelo depende do parâmetro variável 


$$
r_{L}(t)=X\left[Y+Z \cos \left\{2 \pi\left(\frac{\mathrm{t}}{365}+\mathrm{t}_{0}\right)\right\}\right]
$$

A tabela 2.4 indica os valores de $r_{L}$ e $R_{0}$ no início de cada estação do ano, calculados com controles nulos $\left(p_{H}=p_{M}=p_{L}=0\right)$. Nosso $R_{0}$ varia conforme $r_{L}$ que por sua vez, varia com o tempo, ou seja, nas estações quentes ele é maior e nas estações frias ele é menor.

\begin{tabular}{c|c|c}
\hline Estação & $r_{L}$ & $R_{0}$ \\
\hline \hline Verão & 0.150 & 4.324 \\
Outono & 0.081 & 3.173 \\
Inverno & 0.012 & 1.198 \\
Primavera & 0.081 & 3.173 \\
\hline
\end{tabular}

Tabela 2.4: Tabela de $R_{0}$ conforme estações do ano

\subsubsection{Equilíbrio endêmico}

Definindo as constantes

$$
\xi=\frac{w}{(1-g) \psi_{M}\left(1+\theta_{H}\right)} \quad \zeta=v \phi k
$$

temos que $\xi|\zeta|=R_{0}^{2}$. Com isso, chegamos à seguinte conclusão: se $\phi \leq 0$ ou $R_{0} \leq 1$ o modelo não possui equilíbrio endêmico. Por outro lado, se $\phi>0$ e $R_{0}>1$, então o sistema de EDOs possui um equilíbrio endêmico $E_{2}$ dado por

$$
E_{2}\left\{\begin{aligned}
S_{H}^{*} & =\frac{(\xi+1)}{\left(R_{0}^{2}-1\right)+(\xi+1)} N_{H} \\
I_{H}^{*} & =\frac{1}{1+\theta_{H}} \frac{\left(R_{0}^{2}-1\right)}{\left(R_{0}^{2}-1\right)+(\xi+1)} N_{H} \\
R_{H}^{*} & =\frac{\theta_{H}}{1+\theta_{H}} \frac{\left(R_{0}^{2}-1\right)}{\left(R_{0}^{2}-1\right)+(\xi+1)} N_{H} \\
S_{M}^{*} & =\frac{(\zeta+1)}{\left(R_{0}^{2}-1\right)+(\zeta+1)} \phi k N_{H} \\
I_{M}^{*} & =\frac{\left(R_{0}^{2}-1\right)}{\left(R_{0}^{2}-1\right)+(\zeta+1)} \phi k N_{H} \\
S_{L}^{*} & =\frac{(1-g)\left(R_{0}^{2}-1\right)+(\zeta+1)}{\left(R_{0}^{2}-1\right)+(\zeta+1)} \psi_{M} \phi k N_{H} \\
I_{L}^{*} & =\frac{g\left(R_{0}^{2}-1\right)}{\left(R_{0}^{2}-1\right)+(\zeta+1)} \psi_{M} \phi k N_{H}
\end{aligned}\right.
$$

$\operatorname{com} N_{M}^{*}=\phi k N_{H}$ e $N_{L}^{*}=\psi_{M} \phi k N_{H}$.

Além disso, quando $\phi>0$, podemos deduzir que

$$
\left[\xi \frac{S_{H}^{*}}{N_{H}}\right]\left[\zeta \frac{S_{M}^{*}}{N_{M}^{*}}\right]=1=\left[R_{0} \frac{S_{H}^{*}}{N_{H}}\right]\left[R_{0} \frac{S_{M}^{*}}{N_{M}^{*}}\right]
$$

pois $\xi \zeta=R_{0}^{2}$. Este resultado é importante, pois em modelos SIR mais simples um dos resultados que se pode obter é que

$$
R_{0} \frac{S_{H}^{*}}{N_{H}}=1
$$


ou seja, que no caso $R_{0}>1$ a proporção de suscetíveis no equilíbrio endêmico é igual a $\frac{1}{R_{0}}$. Neste modelo, vale algo parecido: o produto das proporções de humanos suscetíveis e mosquitos suscetíveis no equilíbrio é igual a $\frac{1}{R_{0}^{2}}$ (de outra maneira: a média geométrica das proporções de humanos suscetíveis e mosquitos suscetíveis é igual a $\frac{1}{R_{0}}$ ).

Temos também os seguintes valores para o equilíbrio endêmico:

\begin{tabular}{crrr}
\hline Parâmetro & Valor (verão) & Valor (outono/primavera) & Valor (inverno) \\
\hline \hline$S_{H}^{*}$ & 647999.098 & 1203581.185 & 8439133.720 \\
$I_{H}^{*}$ & 2803.945 & 2667.996 & 897.490 \\
$R_{H}^{*}$ & 11456116.957 & 10900670.819 & 3666888.790 \\
$S_{M}^{*}$ & 20518047.591 & 11046763.200 & 1575478.808 \\
$I_{M}^{*}$ & 15610.967 & 7997.322 & 383.678 \\
$N_{M}^{*}$ & 20533658.557 & 11054760.522 & 1575862.486 \\
$S_{L}^{*}$ & 35988662.390 & 35880868.757 & 34533448.354 \\
$I_{L}^{*}$ & 13685.614 & 12983.307 & 4204.469 \\
$N_{L}^{*}$ & 36002348.004 & 35893852.065 & 34537652.822 \\
\hline
\end{tabular}

Tabela 2.5: Equilıbrio Endêmico

\subsubsection{Estabilidade dos equilíbrios}

A análise de estabilidade para esses equilíbrios indica que se $R_{0}<1$, o equilíbrio livre de doença é estável e o equilíbrio endêmico é instável; e se $R_{0}>1$, o equilíbrio livre de doença é instável e o equilíbrio endêmico é estável (Diekmann et al., 1990; Li e Muldowney, 1995; Van den Driessche e Watmough, 2002).

Para demonstrar tais resultados, faremos uma pequena revisão teórica de polinômios.

Um polinômio é estável se todas as suas raízes possuem parte real negativa. Disso pode-se concluir que um produto de polinômios estáveis é um polinômio estável. O critério de RouthHurwitz é uma alternativa para determinar se um dado polinômio é estável ou não, sendo útil principalmente para polinômios de grau baixo.

Em um sistema de EDOs

$$
\frac{d x}{d t}=F(x)
$$

temos que um ponto de equilíbrio $x^{*}$ (isto é, tal que $F\left(x^{*}\right)=0$ ) é localmente assintoticamente estável se a matriz Jacobiana

$$
J\left(x^{*}\right)=\frac{\partial F}{\partial x}\left(x^{*}\right)
$$

tem como polinômio característico um polinômio estável.

Apresentaremos a seguir um resumo do Critério de Routh-Hurwitz para polinômios de graus 1

\begin{tabular}{|c|c|}
\hline Polinômio & Estável se, e somente se,... \\
\hline $\begin{array}{r}\lambda+a_{1} \\
\lambda^{2}+a_{1} \lambda+a_{2}\end{array}$ & $\begin{array}{c}a_{1}>0 \\
a_{1}, a_{2}>0\end{array}$ \\
\hline $\begin{array}{r}\lambda^{3}+a_{1} \lambda^{2}+a_{2} \lambda+a_{3} \\
\lambda^{4}+a_{1} \lambda^{3}+a_{2} \lambda^{2}+a_{3} \lambda+a_{4}\end{array}$ & $\begin{array}{cc}a_{1}, a_{2}, a_{3}>0 & a_{1} a_{2}>a_{3} \\
a_{1}, a_{2}, a_{3}, a_{4}>0 & a_{1} a_{2}>a_{3}^{2}+a_{1}^{2}+a_{4}\end{array}$ \\
\hline
\end{tabular}
a 4

Tabela 2.6: Critério de Routh-Hurwitz para polinômios de graus 1 a 4 
Considerando o sistema de EDOs na forma $\frac{d x}{d t}=F(x) \operatorname{com} x=\left(S_{H}, I_{H}, R_{H}, S_{M}, I_{M}, S_{L}, I_{L}\right)$, temos que a matriz Jacobiana é dada por

$$
\left[\begin{array}{ccccccc}
-\mu_{H}\left(1+v \frac{I_{M}}{N_{H}}\right) & 0 & 0 & 0 & -\mu_{H} v \frac{S_{H}}{N_{H}} & 0 & 0 \\
\mu_{H} v \frac{I_{M}}{N_{H}} & -\mu_{H}\left(1+\theta_{H}\right) & 0 & 0 & \mu_{H} v \frac{S_{H}}{N_{H}} & 0 & 0 \\
0 & \mu_{H} \theta_{H} & -\mu_{H} & 0 & 0 & 0 & 0 \\
0 & -r_{L} w \frac{S_{M}}{N_{H}} & 0 & -r_{L}\left(\psi_{M}+w \frac{I_{H}}{N_{H}}\right) & 0 & r_{L} & 0 \\
0 & r_{L} w \frac{S_{M}}{N_{H}} & 0 & r_{L} w \frac{I_{H}}{N_{H}} & -r_{L} \psi_{M} & 0 & r_{L} \\
0 & 0 & C_{1} C_{2} C_{3} & (1-g) C_{1} C_{2} C_{3} & -C_{1}\left[1+C_{2} C_{4}\right] & -C_{1} C_{2} C_{4} \\
0 & 0 & 0 & 0 & g C_{1} C_{2} C_{3} & -C_{1} C_{2} C_{5} & -C_{1}\left[1+C_{2} C_{5}\right]
\end{array}\right]
$$

onde, foram definidas as constantes

$$
C_{1}=r_{L}\left(1+\psi_{L}\right) \quad C_{2}=\frac{\psi_{M}}{1-\psi_{M} \phi} \quad C_{3}=1-\frac{N_{L}}{k N_{H}} \quad C_{4}=\frac{N_{M}-g I_{M}}{k N_{H}} \quad C_{5}=\frac{g I_{M}}{k N_{H}}
$$

Com isso, temos que o polinômio característico de $J(x)$ é dado por

$$
p(\lambda)=\operatorname{det}[\lambda I-J(x)]=\left[\lambda+\mu_{H}\right]\left[\lambda^{2}+A_{1} \lambda+A_{2}\right] q(\lambda)
$$

onde,

$q(\lambda)=\left[\lambda+\mu_{H}\left(1+v \frac{I_{M}}{N_{H}}\right)\right]\left[\lambda+\mu_{H}\left(1+\theta_{H}\right)\right]\left[\lambda^{2}+B_{1} \lambda+B_{2}\right]-\mu_{H} r_{L} v w \frac{S_{H}}{N_{H}} \frac{S_{M}}{N_{H}}\left[\lambda+\mu_{H}\right]\left[\lambda+r_{L}\left(1+\psi_{L}\right)\right]$

é um polinômio de quarto grau e as constantes $A_{1}, A_{2}, B_{1}, B_{2}$ são dadas por

$$
\begin{aligned}
& A_{1}=r_{L}\left[\frac{1+\psi_{L}}{1-\psi_{M} \phi}\left\{1-\psi_{M}\left(\phi-\frac{N_{M}}{k N_{H}}\right)\right\}+\psi_{M}\right] \\
& A_{2}=r_{L}^{2}\left(1+\psi_{L}\right) \frac{\psi_{M}}{1-\psi_{M} \phi}\left[\frac{N_{L}}{k N_{H}}-\psi_{M}\left(\phi-\frac{N_{M}}{k N_{H}}\right)\right] \\
& B_{1}=r_{L}\left[\left(1+\psi_{L}\right)+\psi_{M}+w \frac{I_{H}}{N_{H}}\right] \\
& B_{2}=r_{L}^{2}\left(1+\psi_{L}\right)\left[\left(1-g \frac{1-N_{L} / k N_{H}}{1-\psi_{M} \phi}\right) \psi_{M}+w \frac{I_{H}}{N_{H}}\right]
\end{aligned}
$$

Assim, no equilíbrio que chamamos de livre de mosquitos, temos que

$$
p(\lambda)=\left[\lambda+\mu_{H}\right]^{2}\left[\lambda+\mu_{H}\left(1+\theta_{H}\right)\right]\left[\lambda^{2}+A_{1} \lambda+A_{2}\right]\left[\lambda^{2}+B_{1} \lambda+B_{2}\right]
$$

com,

$$
\begin{aligned}
& A_{1}=B_{1}=r_{L}\left(1+\psi_{L}+\psi_{M}\right)>0 \\
& A_{2}=r_{L}^{2}\left(1+\psi_{L}\right) \frac{\psi_{M}}{1-\psi_{M} \phi}\left(-\psi_{M} \phi\right) \\
& B_{2}=r_{L}^{2}\left(1+\psi_{L}\right) \frac{\psi_{M}}{1-\psi_{M} \phi}\left[1-g-\psi_{M} \phi\right]
\end{aligned}
$$

Quando $\phi<0$, temos que $A_{2}$ e $B_{2}$ são positivos, portanto o equilíbrio livre de mosquitos é localmente assintoticamente estável. Por outro lado, no caso $\phi>0$ obtemos $A_{2}<0$, logo o equilíbrio livre de mosquitos é instável.

No equilíbrio $E_{1}$ (que ocorre apenas quando $\phi>0$ ), temos que

$$
p(\lambda)=\left[\lambda+\mu_{H}\right]^{2}\left[\lambda^{2}+A_{1} \lambda+A_{2}\right]\left[\lambda^{3}+\alpha_{1} \lambda^{2}+\alpha_{2} \lambda+\alpha_{3}\right]
$$

com,

$$
\begin{aligned}
& A_{1}=r_{L}\left[\frac{1+\psi_{L}}{1-\psi_{M} \phi}+\psi_{M}\right]>0 \\
& A_{2}=r_{L}^{2}\left(1+\psi_{L}\right) \frac{\psi_{M}}{1-\psi_{M}}\left(\psi_{M} \phi\right)
\end{aligned}
$$




$$
\begin{aligned}
& \alpha_{1}=\mu_{H}\left(1+\sigma_{H}\right)+r_{L}\left(1+\psi_{L}+\psi_{M}\right)>0 \\
& \alpha_{2}=(1-g) r_{L}^{2}\left(1+\psi_{L}\right) \psi_{M}+\mu_{H}\left(1+\theta_{H}\right) r_{L}\left[1+\psi_{L}+\psi_{M}\{1-(1-g) \xi \zeta\}\right] \\
& \alpha_{3}=(1-g) \mu_{H}\left(1+\theta_{H}\right) r_{L}^{2}\left(1+\psi_{L}\right) \psi_{M}(1-\xi \zeta)
\end{aligned}
$$

Como $\phi>0$, temos que $A_{2}$ e $\zeta$ são positivos e $\xi \zeta=R_{0}^{2}$. Se $R_{0}<1$, então $\alpha_{2}$ e $\alpha_{3}$ são positivos e, além disso, temos que

$$
\begin{gathered}
\alpha_{1}>\mu_{H}\left(1+\sigma_{H}\right) \\
\alpha_{2}>(1-g) r_{L}^{2}\left(1+\psi_{L}\right) \psi_{M}
\end{gathered}
$$

portanto,

$$
\alpha_{1} \alpha_{2}-\alpha_{3}>(1-g) \mu_{H}\left(1+\theta_{H}\right) r_{L}^{2}\left(1+\psi_{L}\right) \psi_{M} R_{0}^{2}>0
$$

logo $E_{1}$ é localmente assintoticamente estável. Por outro lado, se $R_{0}>1$, então $\alpha_{3}<0$, logo o equilíbrio é instável.

No equilíbrio $E_{2}$ (que ocorre apenas quando $\phi>0$ e $R_{0}>1$ ), temos que

$$
p(\lambda)=\left[\lambda+\mu_{H}\right]\left[\lambda^{2}+A_{1} \lambda+A_{2}\right]\left[\lambda^{4}+\alpha_{1} \lambda^{3}+\alpha_{2} \lambda^{2}+\alpha_{3} \lambda+\alpha_{4}\right]
$$

onde,

$$
\begin{aligned}
A_{1} & =r_{L}\left[\frac{1-\psi_{L}}{1-\psi_{M} \phi}+\psi_{M}\right]>0 \\
A_{2} & =r_{L}^{2}\left(1+\psi_{L}\right) \frac{\psi_{M}}{1-\psi_{M} \phi}\left(\psi_{M} \phi\right)>0 \\
\alpha_{1} & =r_{L}\left[1+\psi_{L}+\psi_{M}+(1-g) \psi_{M} \frac{\xi \zeta-1}{\zeta+1}\right]+\mu_{H}\left[1+\theta_{H}+\xi \frac{\zeta+1}{\xi+1}\right]>0 \\
\alpha_{2} & =(1-g) r_{L}^{2}\left(1+\psi_{L}\right) \psi_{M} \zeta \frac{\xi+1}{\zeta+1}+\mu_{H}^{2}\left(1+\theta_{H}\right) \frac{\zeta+1}{\xi+1}+\mu_{H} r_{L}\left\{\left(1+\psi_{L}\right)\left[1+\theta_{H}+\xi \frac{\zeta+1}{\xi+1}\right]+\psi_{M}[g(1+\right. \\
\left.\theta_{H}\right)+ & \left.\left.(1-g)\left(1+\theta_{H}+\xi\right) \frac{\xi \zeta-1}{\xi+1}+\xi \frac{\zeta+1}{\xi+1}\right]\right\}>0 \\
\alpha_{3} & =\mu_{H} r_{L}\left[(1-g) r_{L}\left(1+\psi_{L}\right) \psi_{M}\left\{\left(1+\theta_{H}\right) \frac{\xi \zeta-1}{\zeta+1}+\xi \zeta\right\}+\mu_{H}\left(1+\theta_{H}\right)\left\{\left(1+\psi_{L}\right) \xi \frac{\zeta+1}{\xi+1}+\psi_{M}[g+\right.\right. \\
\left.\left.\left.(1+(1-g) \xi) \frac{\xi \zeta-1}{\xi+1}\right]\right\}\right]>0 & \\
\alpha_{4} & =(1-g) \mu_{H}^{2}\left(1+\theta_{H}\right) r_{L}^{2}\left(1+\psi_{L}\right) \psi_{M}(\xi \zeta-1)>0, \text { pois } \xi \zeta=R_{0}^{2}>1 .
\end{aligned}
$$

Além disso, temos que $\alpha_{1} \alpha_{2} \alpha_{3}>\alpha_{3}^{2}+\alpha_{1}^{2} \alpha_{4}$.

Portanto, o equilíbrio $E_{2}$ é localmente assintóticamente estável.

A Tabela 2.7 resume os resultados obtidos acima, onde "estável" significa "localmente assintóticamente estável":

\begin{tabular}{c|c|c|c}
\hline Equilíbrio & $\phi<0$ & $\phi>0, R_{0}<1$ & $\phi>0, R_{0}>1$ \\
\hline \hline$E_{1}$ & - & estável & instável \\
$E_{2}$ & - & - & estável \\
\hline
\end{tabular}

Tabela 2.7: Tabela de estabilidade dos equilíbrios

Desta análise, pode-se concluir que o caso $\phi<0$ corresponde à extinção de mosquitos e larvas (portanto não corresponde ao observado), enquanto que o caso $\phi>0$, por sua vez, é o realista, no qual o equilíbrio livre de mosquitos (correspondente à extinção) é instável (ou seja, mesmo em uma situação em que o número de mosquitos e larvas esteja bem próximo de zero, ambas as populações tendem a retornar aos valores anteriores, sem extinção). Nesta situação, o valor de $R_{0}$ dita a existência do equilíbrio endêmico $E_{2}$ : para $R_{0}<1$, não há equilíbrio endêmico, restando apenas o equilíbrio livre de doença $E_{1}$ para ser estável; no caso em que $R_{0}>1$ (que é o mais comum), existe um equilíbrio endêmico $E_{2}$ estável, enquanto $E_{1}$ por sua vez é instável. 
Como este último caso $\left(\phi>0, R_{0}>1\right)$ é o mais comum, esta análise nos permite prever o que é observado com diferentes estratégias de controle: enquanto tivermos $R_{0}>1$ o sistema tenderá ao equilíbrio endêmico $E_{2}$ correspondente (lembrando que os equilíbrios, assim como o $R_{0}$, também variam com os parâmetros do modelo); se, por outro lado, tivermos $R_{0}<1$, então o sistema tenderá ao equilíbrio livre de doença $E_{1}$ (pois não há equilíbrio endêmico) ou mesmo equilíbrio livre de mosquitos. Para isto ocorrer, é necessário termos $\phi<0$; como

$$
\begin{aligned}
\psi_{M} & =\frac{\mu_{M}}{r_{L}\left(1-p_{M}\right)} \\
\psi_{L} & =\frac{\mu_{L}}{r_{L}\left(1-p_{L}\right)}
\end{aligned}
$$

temos que

$$
\phi=\frac{1}{\psi_{M}}-\frac{r_{L}\left(1+\psi_{L}\right)}{r_{M}}=\frac{r_{L}\left(1-p_{M}\right)}{\mu_{M}}-\frac{1}{r_{M}}\left(r_{L}+\frac{\mu_{L}}{1-p_{L}}\right)
$$

logo é possível obter $\phi<0$ com valores suficientemente altos de $p_{M}$ e $p_{L}$, pois a expressão acima é decrescente em $p_{M}$ e em $p_{L}$ separadamente.

\subsection{Busca por estratégias de controles}

Problemas em que a qualidade de uma resposta pode ser medida por um número, é o que a otimização matemática busca solucionar. Para solucionar um desses problemas é preciso formular uma função objetivo, que é uma função que associa cada ponto no espaço de soluções a um número real. Quando é possível prever todos os passos conhecendo o ponto de partida, temos um método de otimização determinística. Já os métodos onde o caráter aleatório de vários processos é simulado, chamamos de métodos estocásticos ou aleatórios.

Para uma melhor compreensão do método utilizado para nossa busca de estratégias de controles, começaremos apresentando alguns conceitos relacionados à otimização.

- Variáveis do problema: são as que podem ser alteradas durante o processo de otimização, sendo de natureza contínua ou discreta.

- Restrições: são as funções de igualdade ou desigualdade que restringem ou relacionam as variáveis do problema.

- Função objetivo: é a função dependente de uma ou mais variáveis do problema que se pretende maximizar/minimizar.

- Espaço de busca: é o conjunto que compreende as possíveis soluções sobre as variáveis do problema a ser otimizado, delimitado pelas funções de restrição.

- Ponto ótimo: é o conjunto de valores para as variáveis do problema que permite maximizar/minimizar a função objetivo satisfazendo as restrições.

- Ótimo local: é o conjunto de valores para as variáveis do problema que maximiza/minimiza a função objetivo em uma vizinhança do espaço de busca.

- Ótimo global: é o maximizador/minimizador da função objetivo no espaço de busca inteiro (em comparação com os ótimos locais, que são os máximos/mínimos da função objetivo em suas respectivas vizinhanças)

Em um problema de otimização local, busca-se o minimizador local de uma função real $F(x)$ onde $x$ é um vetor de variáveis reais. Para funções reais diferenciáveis, o critério de primeira derivada 
nula indica a existência de um extremos, e o sinal da segunda derivada indica se este extremos é um máximo ou mínimo local. Já na otimização global não existem critérios que permitam identificar um mínimo global (Törn e Žilinskas, 1989).

Os algoritmos em geral buscam o ótimo local, e não garantem um ótimo global. A garantia que os teoremas nos dão é de encontrar um ótimo local, que pode ou não ser global.

Como nosso trabalho abrange um problema de otimização global, desenvolvemos um algoritmo para encontrar o controle sub-ótimo que envolve um revezamento entre otimização e busca aleatória, pois os artigos Tang (1994) e Törn e Žilinskas (1989) usaram essa metodologia e os resultados se mostraram satisfatórios. Estamos chamado de controle sub-ótimo, pois o melhor controle provavelmente varia continuamente com o tempo, enquanto que estamos buscando controles constantes por partes com valores que podem mudar de uma semana para outra, mas que são constantes em cada semana, que possam ser aplicados/implementados com um custo total abaixo da verba disponível para o controle da doença. Dentre estas estratégias de controle, buscamos aquele que minimiza o total de DALYs perdidos por dengue no período de um ano.

Temos dois diferentes critérios de escolha dentre as estratégias de controle:

\section{- Restrição de $R_{0}$}

Fixado o valor máximo $\epsilon$ para o $R_{0}$, queremos encontrar a estratégia de controle de menor custo que mantém $R_{0} \leq \epsilon$. Para isto, buscamos minimizar o custo instantâneo que corresponde à derivada $d C / d t$ da função custo. Como, em um dado instante $t$, o termo correspondente ao custo com tratamentos em clínicas e hospitais independe da estratégia de controle aplicada no mesmo instante, podemos ignorar este termo e considerar que o custo no instante $t$ depende apenas do valor dos controles neste mesmo instante, logo podemos determinar o melhor controle separadamente em cada instante de tempo. Para minimizar o custo instantâneo, tomamos o conjunto de todos os controles possíveis, dado por $\left(p_{H}, p_{M}, p_{L}\right) \in\left[0, \beta_{R}\right] \times\left[0, \beta_{I}\right] \times\left[0, \beta_{L}\right]$ e discretizamos o mesmo com espaçamento uniforme de $0.01 \mathrm{em}$ cada dimensão. Descartando os pontos $\left(p_{H}, p_{M}, p_{L}\right)$ que correspondem a $R_{0}>\epsilon$ e calculando o valor de $d C / d t$ nos pontos restantes (ignorando o termo referente a clínicas e hospitais), obtém-se uma estimativa para a estratégia de menor custo no instante $t$ sujeita à restrição $R_{0} \leq \epsilon$. Esta estimativa é passada como ponto inicial para uma rotina de otimização, com o objetivo de encontrar um ótimo local. Devido ao tamanho do espaçamento uniforme, fica praticamente garantido que o ótimo local encontrado é de fato o ótimo global desejado.

\section{- Restrição de Custo}

O que queremos é minimizar o DALY com restrição de custo, porém desta vez, não temos como fazer um instante por vez porque o valor a ser gasto é valido para todo o ano. O DALY vai variar com o que acontece nos outros instantes de tempo, então não temos como fazer isso separadamente, e temos que trabalhar com o ano todo de vez. O algoritmo é composto de duas partes: busca local e busca global.

A busca local, consiste em otimizar a função objetivo (DALYs perdidos no ano), mas realizando tal busca com uma variável por vez, travando todas as outras. Mais explicitamente, sendo $f(x)$ nossa função objetivo, começamos com um chute inicial $x^{*}$ e percorremos todas as variáveis indefinidamente (após a última variável voltamos para a primeira), sendo que se estivermos na variável $i$, então vamos minimizar a função $f\left(x_{1}^{*}, x_{2}^{*}, \ldots, x_{i-1}^{*}, z, x_{i+1}^{*}, \ldots, x_{156}^{*}\right.$ ) em $z$ (ou seja, a $i$-ésima coordenada é variável, mas as outras estão fixas com o valor da respectiva coordenada de $x^{*}$ ). Achando o minimizador $z^{*}$ desta função, atualizamos a $i$-ésima coordenada de $x^{*} \operatorname{com}$ o valor $z^{*}$.

Já a busca global consiste em gerar um controle aleatório e testar se ele é melhor do que o melhor encontrado até o momento. Para gerar um controle aleatório, primeiro escolhemos um número inteiro uniformemente distribuído de 1 a 156 (como o ano tem 52 semanas e estamos lidando com 3 controles, o número de variáveis é $3 \times 52=156)$. Chamando este número de $N$, vamos agora escolher $N$ das 156 variáveis (todas com mesma probabilidade). A ideia é 
considerar um controle aleatório com $N$ variáveis não-nulas e as outras $156-N$ variáveis sendo iguais a zero (pois, na prática, uma estratégia de controle só irá agir em algumas semanas do ano, provavelmente não seria proposto algo que envolva usar sempre algum tipo de controle o ano todo). Tendo escolhidas estas $N$ variáveis $\left(i_{1}, i_{2}, \ldots, i_{N}\right)$, geramos $N$ valores com distribuição exponencial e multiplicamos todos estes valores por uma mesma constante (para que o custo desta estratégia seja exatamente a verba disponível.

No caso da restrição de custo, aumentando uma das variáveis, o custo total passará a ser maior que o máximo permitido; por outro lado, diminuindo uma das variáveis, o custo total será menor que o máximo, o que significa que este controle certamente não será ótimo (pois podemos aumentar os valores das outras variáveis para usar toda a verba disponível). Baseado nessas observações, sempre que mudarmos uma das variáveis, mudamos todas as outras também, mas de maneira proporcional (multiplicando todas as outras por um mesmo valor, de forma que o custo total continue sendo o mesmo). Isso nos permite variar cada coordenada como quisermos, mantendo a propriedade de usar toda a verba disponível e também o que realmente importa sobre as outras variáveis (que é seu valor com relação às outras, pois se investimos mais em uma temos que deixar de investir nas outras).

O algoritmo de otimização é interrompido quando passarmos uma vez por cada uma das variáveis sem modificação do valor ótimo. Em nosso caso, isso ocorre se tivermos 156 iterações seguidas sem mudança no valor ótimo. Neste caso, estamos em um ponto estacionário do algoritmo. Com isso, temos que o algoritmo de busca do controle sub-ótimo é o seguinte: revezamos entre uma iteração de otimização (isto é, otimizando apenas em uma das variáveis) e uma iteração de simulação (isto é, gerando um único controle aleatório), mas pulando o passo de otimização sempre que estivermos em um ponto estacionário (ou seja, quando já tivermos rodado 156 iterações sem melhora no valor ótimo).

Para a implementação desse algoritmo usamos o programa $\mathrm{R}$, rodado em uma máquina com processador Intel Core i3, com 2,93GHz, Windows 8.1 e os pacotes utilizados para as resoluções foram: deSolve, usado para resolução das EDOs; foreach e doParallel, usados para fazer os ciclos em paralelo; bigstatsr e flock, usados para verificar o número de processadores para fazer a computação paralela e travar o arquivo, impedindo que o programa use mais do que uma condição inicial por vez, ou seja, impedindo que dois processadores usem a mesma condição inicial.

Nessa máquina, os tempos de duração das principais operações foram:

- resolução do modelo (sistema de EDOs) para um único controle especificado: 20 a 30 segundos

- otimização do custo sujeito a restrição do $R_{0}$ - cálculo do controle ótimo: 40 minutos

- otimização dos DALYs perdidos no ano sujeito a restrição de custo: 8 a 10 minutos (por variável otimizada)

- ciclo completo de 156 iterações de otimização (uma para cada variável), incluindo revezamento com controles aleatórios entre otimizações: 20 a 25 horas 


\section{Capítulo 3}

\section{Resultados Numéricos}

Neste capítulo apresentaremos os resultados númericos onde analisamos as combinações de formas de contenção de uma epidemia, estratégias de controle e seus custos. A princípio vamos analisar qual a melhor combinação de mecanismos de controle sujeitos à estratégia de restrição de custo. Depois descreveremos a forma mais eficaz de aplicar essa combinação ao longo do ano. Usando o $R_{0}$ como indicador do avanço da epidemia, mostraremos a vantagem de usar os mecanismos de controle em contraposição com não usá-los. Considerando três estratégias (Sem Controle, Restição de Custo e Restrição do $R_{0}$ ) compararemos como variam as dinâmicas das subpopulações de humanos, mosquitos e larvas nos estágios da infecção: suscetíveis, infectados e recuperados. Além disso, usando o DALY como critério de custo, os gastos com controles e os gastos com hospitais e clínicas, estudaremos o custo total de cada estratégia.

Para as simulações pressuporemos a aplicação dos controles de forma homogênea em toda a cidade de São Paulo.

Para esclarecer melhor o algoritmo numérico usado em cada uma das estratégias mencionadas: Sem Controle $\left(p_{H}(t)=p_{M}(t)=p_{L}(t)=0\right.$ para todo $t$ ), Restrição de Custo (limite superior do gasto com controles, igual a $5 \%$ do orçamento destinado à Saúde - $\mathrm{R} \$ 405$ milhões), e Restrição do $R_{0}$ (usar os controles limitando superiormente $R_{0}$ a 0.9 ); no apêndice desse trabalho estão descritos seus Pseudo-Código.

Como estamos trabalhando com um sistema de EDOs, cuja solução depende das condições iniciais é importante comprovar que nossos resultados são independentes do momento do ano em que começamos a simulação, e também é interessante estudar sua robustez para diferentes condições iniciais. Com esse objetivo, para cada estação rodamos o código com condições iniciais distintas: epidemia (equilíbrio livre de doença, mas com a adição de 1.000 mosquitos infectados. Testamos com 500 e 1.500, mas achamos que a adição de 1.000 moquitos infectados já nos deu um resultado satisfatório) e endemia (equilíbrio endêmico com o valor de $r_{L}$ na estação correspondente). Essas condições iniciais encontram-se na tabela 3.1.

\begin{tabular}{c|r|r|r|r|r|r|r}
\hline Condições Iniciais & $S_{H}$ & $I_{H}$ & $R_{H}$ & $S_{M}$ & $I_{M}$ & $S_{L}$ & $I_{L}$ \\
\hline \hline 1 & 12.106 .920 & 0 & 0 & 20.533 .659 & 1.000 & 36.002 .348 & 0 \\
2 & 647.999 & 2.804 & 11.456 .117 & 20.518 .048 & 15.611 & 35.988 .662 & 13.686 \\
3 & 12.106 .920 & 0 & 0 & 11.054 .760 & 1.000 & 35.893 .852 & 0 \\
4 & 1.203 .581 & 2.668 & 10.900 .671 & 11.046 .763 & 7.997 & 35.880 .869 & 12.983 \\
5 & 12.106 .920 & 0 & 0 & 1.575 .863 & 1.000 & 34.537 .653 & 0 \\
6 & 8.439 .134 & 897 & 3.666 .889 & 1.575 .479 & 384 & 34.533 .448 & 4.205 \\
7 & 12.106 .920 & 0 & 0 & 11.054 .760 & 1.000 & 35.893 .852 & 0 \\
8 & 1.203 .581 & 2.668 & 10.900 .671 & 11.046 .763 & 7.997 & 35.880 .869 & 12.983 \\
\hline
\end{tabular}

Tabela 3.1: Tabela de condições iniciais nos cenários de Epidemia (1, 3, 5 e 7) e Endemia (2, 4, 6 e 8)

Como nosso sistema não tem equilíbrio, pois varia com o tempo, as condições iniciais foram obtidas da seguinte forma: primeiro fixamos o $r_{L}$ correspondente a cada estação (valor mais alto), então o $r_{L}$ deixou de ter um valor no tempo para ter um valor constante, depois consideramos 
essa situação e calculamos o equilíbrio livre de doença, e obtivemos os cenários de Epidemia. Já os cenários de Endemia, foram obtidos através do equilíbrio endêmico encontrado no capítulo 2 desse trabalho. Para cada condição inicial teremos as simulações nas 4 estações do ano (verão, outono, inverno e primavera), onde as condições iniciais 1, 3, 5 e 7 representam Epidemia e as condições iniciais 2, 4, 6 e 8 representam Endemia. Para sermos mais sucintos, apresentaremos nesta seção apenas os resultados obtidos para o cenário 1 - epidemia começando a aplicação dos controles no verão, e do cenário 6 - endemia começando a aplicação dos controles no inverno. Para o restante dos cenários fizemos um breve comentário das particularidades de cada cenário e seus resultados numéricos estão expostos no apêndice desse trabalho.

Como vemos na tabela 3.1, alguns cenários são fictícios, com números de suscetíveis bem menores que os de recuperados, isso significa que a maioria das pessoas já tiveram a doença e se recuperaram, o que não acontece na realidade. Esses cenários foram analisados apenas para sabermos como seria a aplicação dos mecanismos de controle caso tal situação realmente acontecesse.

A seguir temos as tabelas com todos os parâmetros e seus respectivos valores usados para nossas simulações:

\begin{tabular}{c|c|c}
\hline Parâmetro & Valor & Fonte bibliográfica \\
\hline \hline$N_{H}$ & 12.106 .920 & IBGE \\
$\mu_{H}$ & $3.5 \times 10^{-5} /$ dia & (Burattini et al., 2008) \\
$r_{M}$ & $50 /$ dia & (Burattini et al., 2008) \\
$\mathrm{k}$ & 3 & (Rodrigues et al., 2014) \& (Burattini et al., 2008) \\
$\mu_{L}$ & $0.1 /$ dia & (Burattini et al., 2008) \\
$r_{L}$ & variável & - \\
$\mu_{M}$ & $0.263 /$ dia & (Burattini et al., 2008) \\
$\mathrm{a}$ & $0.8 /$ dia & (Rodrigues et al., 2014) \\
$\mathrm{b}$ & $0.6 /$ dia & (Burattini et al., 2008) \\
$\mathrm{c}$ & $0.54 /$ dia & (Burattini et al., 2008) \\
$\mathrm{g}$ & $0.5 /$ dia & (Burattini et al., 2008) \\
$\eta_{H}$ & $0.143 /$ dia & (Burattini et al., 2008) \\
$p_{H}$ & uma função & - \\
$p_{M}$ & uma função & - \\
$p_{L}$ & uma função & - \\
$X$ & 0.15 & (Burattini et al., 2008) \\
$Y$ & 0.54 & (Burattini et al., 2008) \\
$Z$ & 0.46 & (Burattini et al., 2008) \\
\hline
\end{tabular}

Tabela 3.2: Tabela de valores dos parâmetros relacionados a dinâmica do modelo. Na tabela, onde não constam as referências são os parâmetros que foram criados para este trabalho, em particular, e suas respectivas fórmulas encontram-se no Capítulo 2 (Materiais e Métodos). 


\begin{tabular}{|c|c|c|}
\hline Parâmetro & Valor & Fonte bibliográfica \\
\hline$p_{C}$ & 0.35 & (IESS, 2018) \\
\hline$p_{H}$ & 0.05 & (IESS, 2018) \\
\hline$v_{C}$ & $0 \mathrm{R} \$ /$ por pessoa & (IESS, 2018) \\
\hline$v_{H}$ & $3177 \mathrm{R} \$ /$ por pessoa & (IESS, 2018) \\
\hline$u_{R}$ & $25 \mathrm{R} \$$ & (Guia de Compras.org, 2019) \\
\hline$u_{I}$ & $50 \mathrm{R} \$$ & (Loja Agropecuaria, 2019) \\
\hline$u_{L}$ & $109 \mathrm{R} \$$ & (Embrapa, 2010) \& (Mercado Livre, 2019) \\
\hline$T_{R}$ & $0.5 / \mathrm{dia}$ & (Stefani et al., 2009) \& (Guia de Compras.org, 2019) \\
\hline$T_{I}$ & $0.33 / \mathrm{dia}$ & (Ministerio da Saude, 2014b) \\
\hline$T_{L}$ & $0.25 / \mathrm{dia}$ & (Ministerio da Saude, 2014a) \\
\hline$\beta_{R}$ & 1 & (Kumar et al., 2011) \& (Fradin e Day, 2002) \\
\hline$\beta_{I}$ & 0.95 & (Marini et al., 2019) \\
\hline$\beta_{L}$ & 0.96 & (Santos et al., 2008) \\
\hline$A$ & $1521 \mathrm{~km}^{2}$ & IBGE \\
\hline$A_{I}$ & $0.01 \mathrm{~km}^{2}$ & - \\
\hline$V$ & $10^{8} \mathrm{~L}$ & - \\
\hline$V_{L}$ & $40 L$ & - \\
\hline$\gamma_{C}$ & $160 \mathrm{R} \$ /$ por pessoa & - \\
\hline$\gamma_{H}$ & $160 \mathrm{R} \$ /$ por pessoa & - \\
\hline$\gamma_{R}$ & $50 \mathrm{R} \$ / \mathrm{dia} / \mathrm{pessoa}$ & - \\
\hline$\gamma_{I}$ & $3.6 \times 10^{6} \mathrm{R} \$ / \mathrm{dia}$ & - \\
\hline$\gamma_{L}$ & $1.1 \times 10^{9} \mathrm{R} \$ / \mathrm{dia}$ & - \\
\hline$\alpha$ & 0,197 & (Lee et al., 2011) \\
\hline
\end{tabular}

Tabela 3.3: Tabela de valores dos parâmetros relacionados a função custo e DALY. Na tabela, onde não constam as referências são os parâmetros e valores criados para este trabalho, em particular, e suas respectivas fórmulas encontram-se no Capítulo 2 (Materiais e Métodos).

\subsection{Resultados numéricos do cenário 1}

Os resultados dessa simulação são consequência da primeira condição inicial referente ao cenário 1 de Epidemia.

\begin{tabular}{c|r|r|r|r|r|r|r}
\hline Condição Inicial & $S_{H}$ & $I_{H}$ & $R_{H}$ & $S_{M}$ & $I_{M}$ & $S_{L}$ & $I_{L}$ \\
\hline \hline 1 & 12.106 .920 & 0 & 0 & 20.533 .659 & 1.000 & 36.002 .348 & 0
\end{tabular}

Tabela 3.4: Condição inicial do Cenário 1 de Epidemia, com controle distribuído a partir do início do verão

Das três estratégias consideradas, começaremos com a análise da Restrição de Custo, pois ela é a que melhor representa a realidade, considerando o verba de dinheiro disponível para usar com mecanismos de controle. A figura 3.1 nos mostra a melhor combinação dos três tipos de controle (repelente, inseticida e larvicida) considerado no nosso modelo com a Restrição de Custo. 


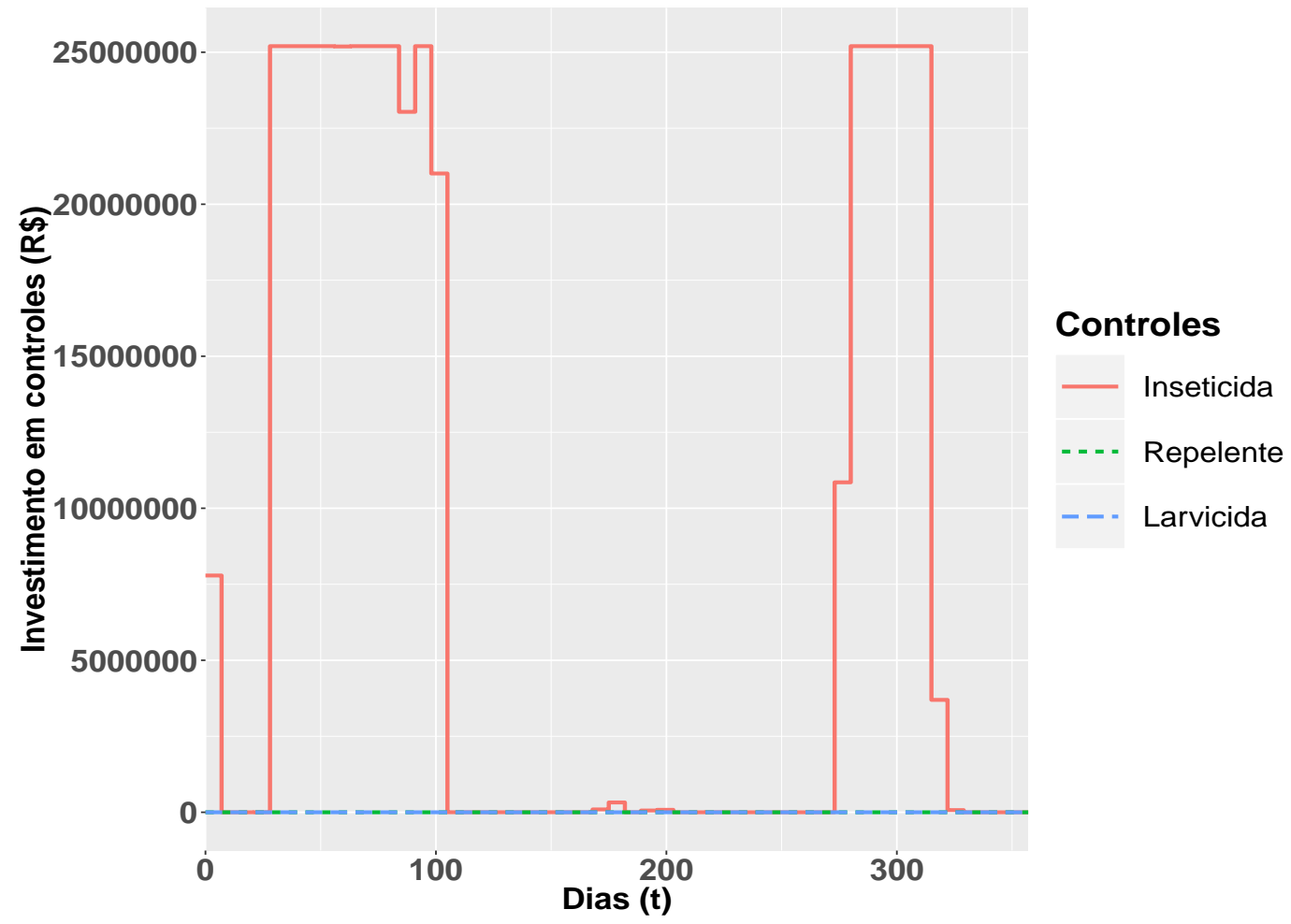

Figura 3.1: Melhor combinação de controles - Cada curva do gráfico representa o montante gasto em cada um dos três mecânismos de controle: repelente (curva verde pontilhada), inseticida (curva vermelha sólida) e larvicida (curva azul tracejada).

Na figura 3.1 o eixo y representa a quantia em dinheiro usada em cada um dos controles ao longo do ano. Nela notamos que quase todo o dinheiro é usado com o inseticida, o que nos sugere que o uso do inseticida é a melhor opção para controlar a epidemia. Isto não nos surpreende, pois o inseticida é eficaz matando os mosquitos e dentre os três controles é o mais barato.

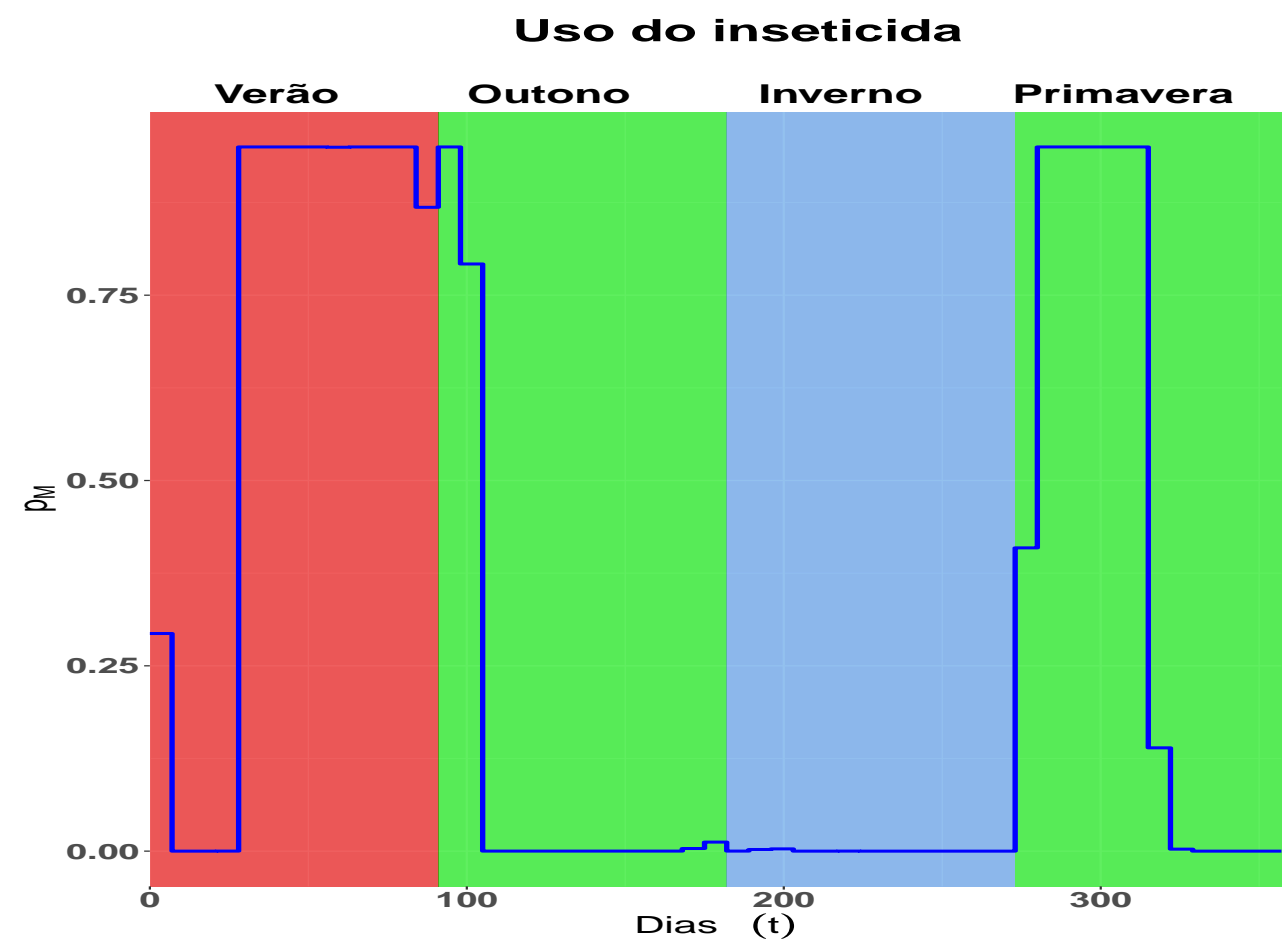

Figura 3.2: Uso do Inseticida - Este gráfico nos apresenta a melhor forma de aplicar o inseticida ao longo do ano. 
Na figura 3.2 temos a melhor forma de aplicar o controle Inseticida ao longo de um ano. Como podemos notar, o algoritmo sugere aplicar uma quantidade maior de inseticida logo após o primeiro mês do verão até as primeiras semanas do outono e também desde o começo até metade da primavera. Isso está em concordância com o conhecimento já estabelecido de que os surtos de epidemias acontecem nas estações quentes. Também no começo do verão, no gráfico, se aplica uma pequena quantidade de inseticida, que corresponde a uma condição inicial onde a quantidade de mosquitos é alta e precisa ser reduzida. Fato que se pode comprovar nos gráficos da dinâmica das populações de mosquitos mostrados na figura 3.5.

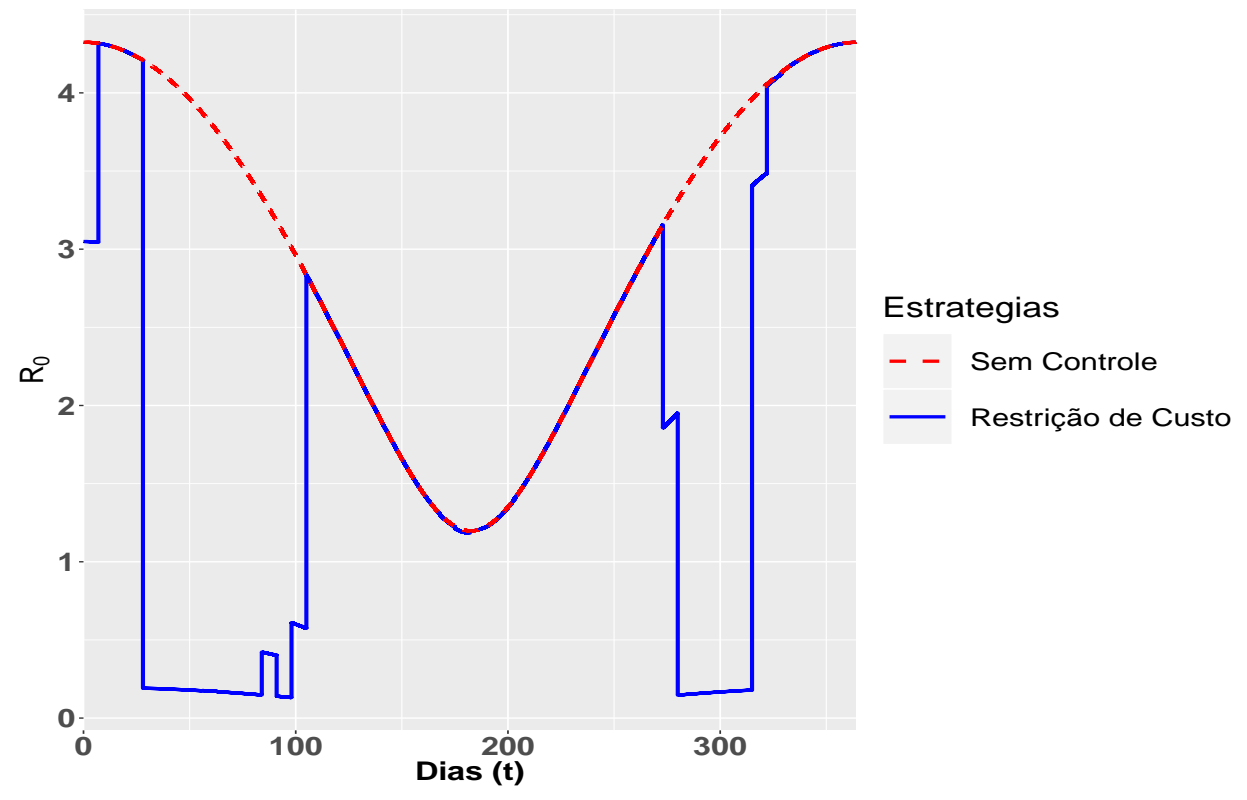

Figura 3.3: Simulação do comportamento das situações "Sem Controle"e "Restrição de Custo"quando o $R_{0}$ está controlado.

Quando mantemos o $R_{0}$ controlado o ano todo, vemos que a estratégia Restrição de custo (curva azul) tem o comportamento parecido com a mesma estratégia na figura 3.2, ou seja, quanto mais aplicamos o controle, mais o $R_{0}$ diminui, e quanto menos aplicamos o controle, mais o $R_{0}$ aumentará, o que é esperado, já que é essa a função do controle. A estratégia Sem Controle (curva vermelha), nos mostra que sua curva se comporta de modo muito parecida com a curva do $r_{L}$, ou seja, aumenta nas estações quentes e diminui nas estações frias. 

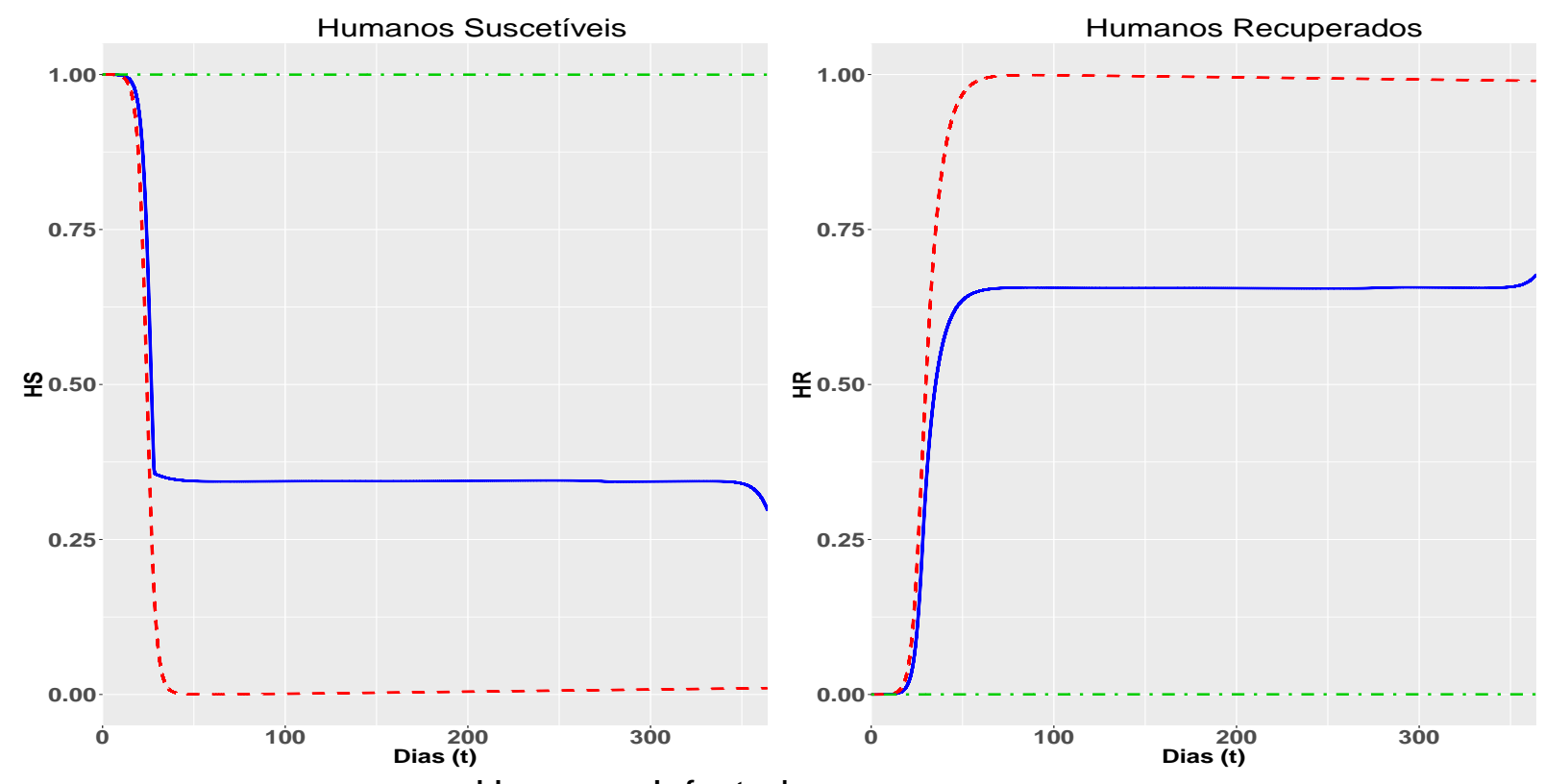

Humanos Infectados

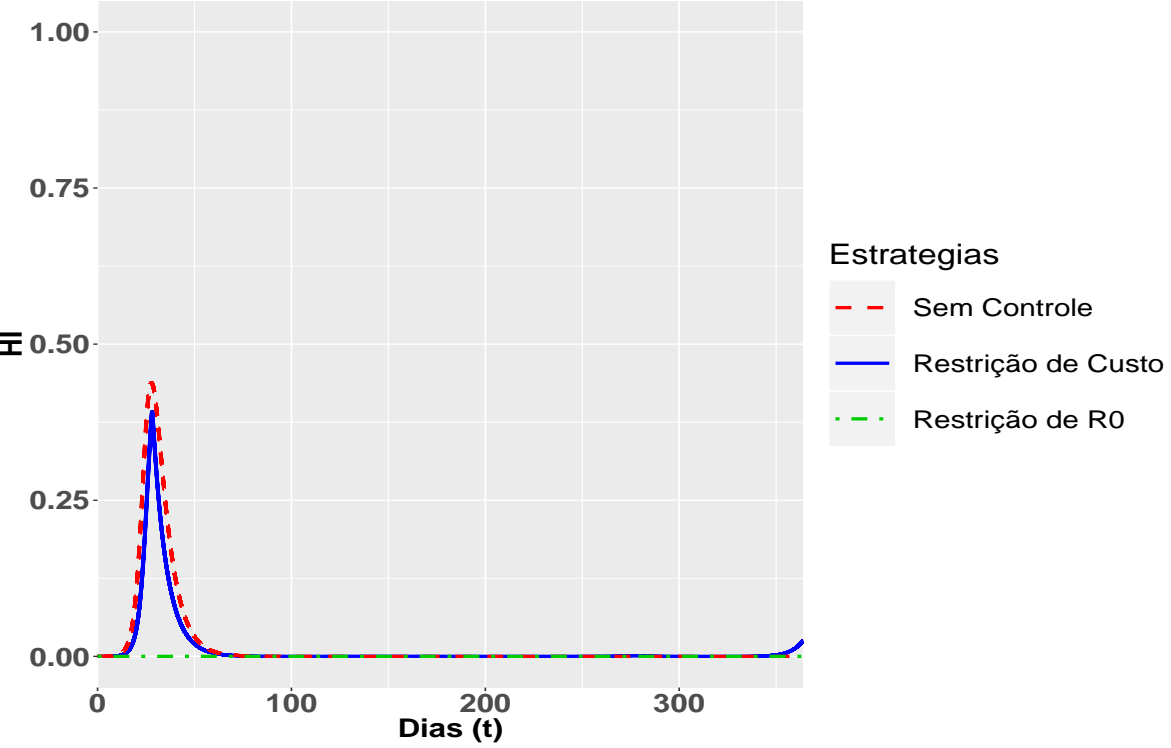

Figura 3.4: Gráfico da dinâmica das populações de humanos suscetíveis, infectados e recuperados para cada uma das três estratégias de controle simuladas - Sem Controle (linha vermelha tracejada), Restrição do $R_{0}$ (linha verde pontilhada) e Restrição de custo (linha azul sólida). Os gráficos estão em escala relativa ao número total de população que é de 12.106.920.

Os três gráficos mostram que a estratégia de Restrição de $R_{0}$ (curva verde), representa uma situação ideal no cenário de epidemia, onde a população de suscetíveis coincide com a população total ao longo ao ano, e portanto, não há humanos infectados nem recuperados. Esses resultados correspondem a teoria apresentada no Capítulo 2: quando $R_{0}<1$ a epidemia não se desenvolve. Para a Restrição de Custo (curva azul) a quantidade de humanos suscetíveis diminui, pois o $R_{0}$ é maior que 1 em quase todo o ano, logo, a população de infectados aumenta juntamente com a de recuperados. Já a estratégia Sem Controle (curva vermelha) nos mostra um decrescimento muito maior na população de suscetíveis acompanhado com o crescimento da população de infectados. Isso é consequente com a figura 3.3 , onde o indicador da evolução da epidemia, $R_{0}$, é maior quando não é usado o controle que quando usado. 

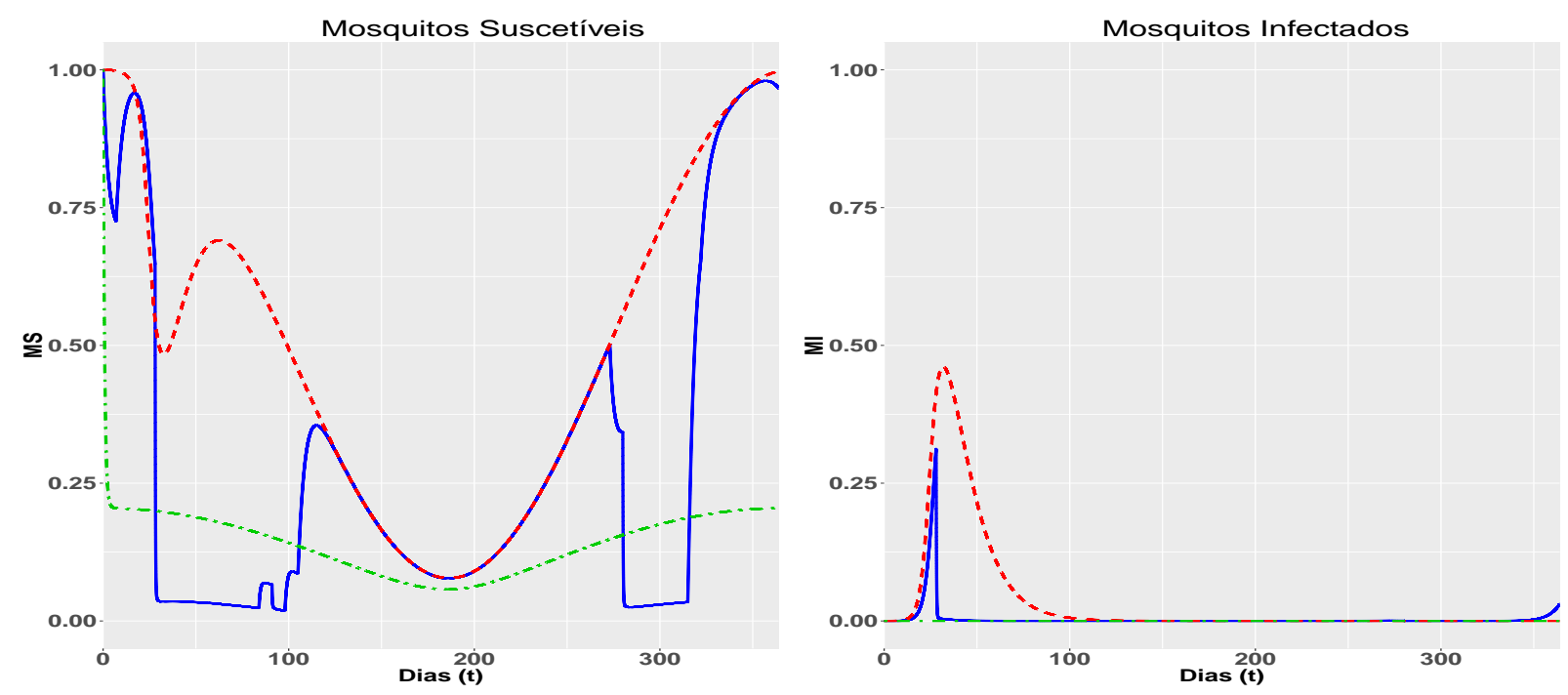

Figura 3.5: Gráfico da dinâmica das populações de mosquitos suscetíveis e infectados para cada uma das três estratégias de controle simuladas - Sem Controle (linha vermelha tracejada), Restrição do $R_{0}$ (linha verde pontilhada) e Restrição de custo (linha azul sólida).

Na figura 3.5, com a estratégia Restrição do $R_{0}$ (curva verde), a população de mosquitos infectados é zerada em todo o ano, o que explica porque não há humanos infectados na figura 3.4. Além disso, a população de mosquitos suscetíveis é a mais baixa em média quando comparado com as outras estratégias. Nas curvas correspondentes a estratégia Restrição de Custo (curva azul), a população de mosquitos suscetíveis tem um decaimento no começo do ano que corresponde com a aplicação de inseticida mostrada na figura 3.2. Além de outros decrescimento abruptos da população de mosquitos suscetíveis que também coincidem com a aplicação de inseticida do mesmo gráfico, figura 3.2. Para a estratégia Sem Controle (curva vermelha), a população de mosquitos suscetíveis e infectados é maior que nas outras estratégias o tempo todo, o que é esperado. Em particular, é interessante notar que no gráfico de mosquitos infectados o tempo de vida médio dos mosquitos com estratégias Sem Controle é aproximadamente 3 vezes maior que na estratégia Restrição de custo.
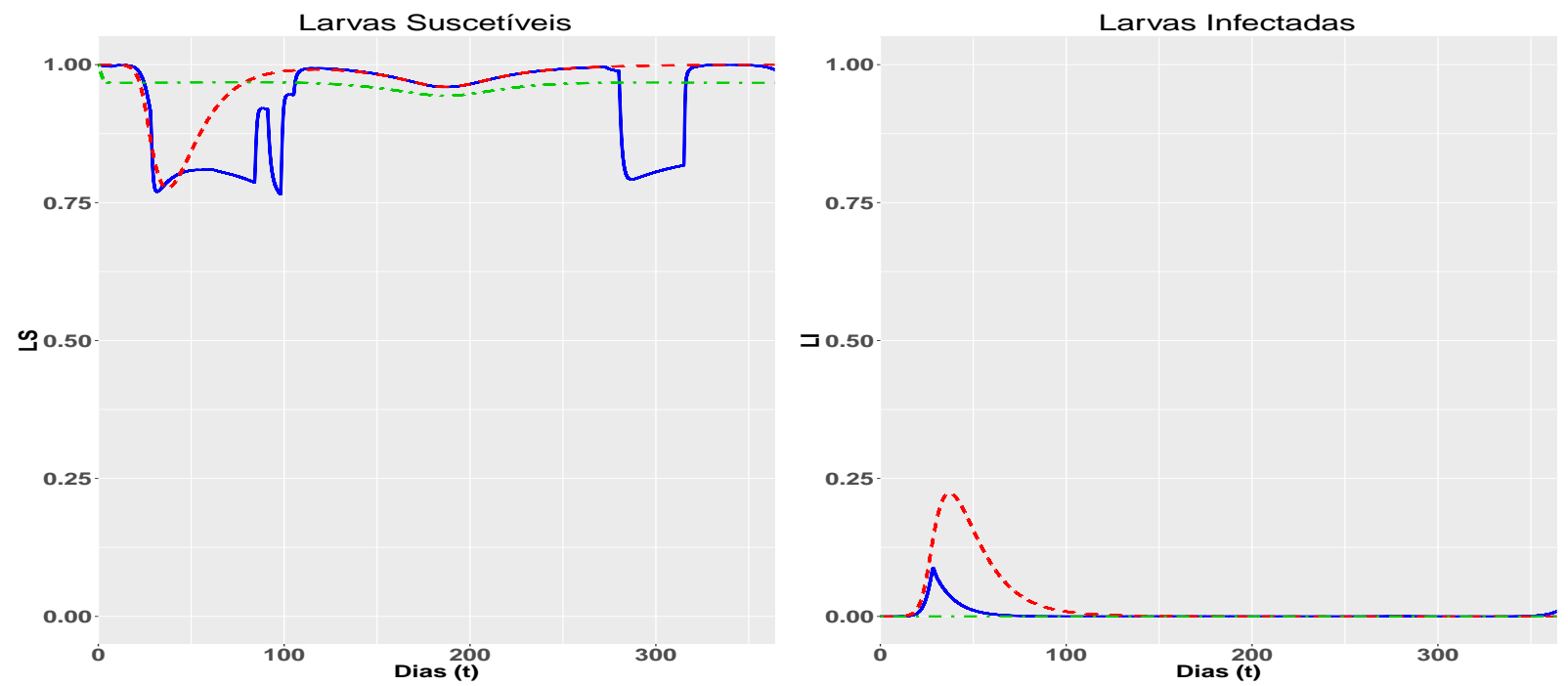

Figura 3.6: Gráfico da dinâmica das populações de larvas suscetíveis e infectados para cada uma das três estratégias de controle simuladas - Sem Controle (linha vermelha tracejada), Restrição do $R_{0}$ (linha verde pontilhada) e Restrição de custo (linha azul sólida).

O comportamento das populações de larvas é muito parecido com o das populações de mosquitos da figura 3.5, porém as larvas não são tão afetadas como os mosquitos. Na estratégia Restrição do $R_{0}$ (curva verde), a população de larvas infectadas é nula durante o ano. A população de larvas 
não infectadas praticamente não varia em relação às outras estratégias, e na maior parte do ano é a mais baixa. Nas curvas correspondentes a estratégia Restrição de Custo (curva azul), a população de mosquitos suscetíveis começa um pouco diferente, pois segundo a nossa condição inicial não há larvas no início do período, porém com a adição de mosquitos no início, geram as larvas e depois o comportamento da linha fica parecida com a do gráfico dos mosquitos 3.5, e coincide também com a aplicação de inseticida mostrada na figura 3.2, por isso diminui também o número de larvas, pois quanto menos mosquitos, menos larvas. As quedas na população de larvas suscetíveis são explicadas também pelo uso de inseticida na população de mosquitos. Já para a estratégia Sem Controle (curva vermelha), a população de larvas não infectadas e infectadas também é maior do que nas outras estratégias durante todo o período.
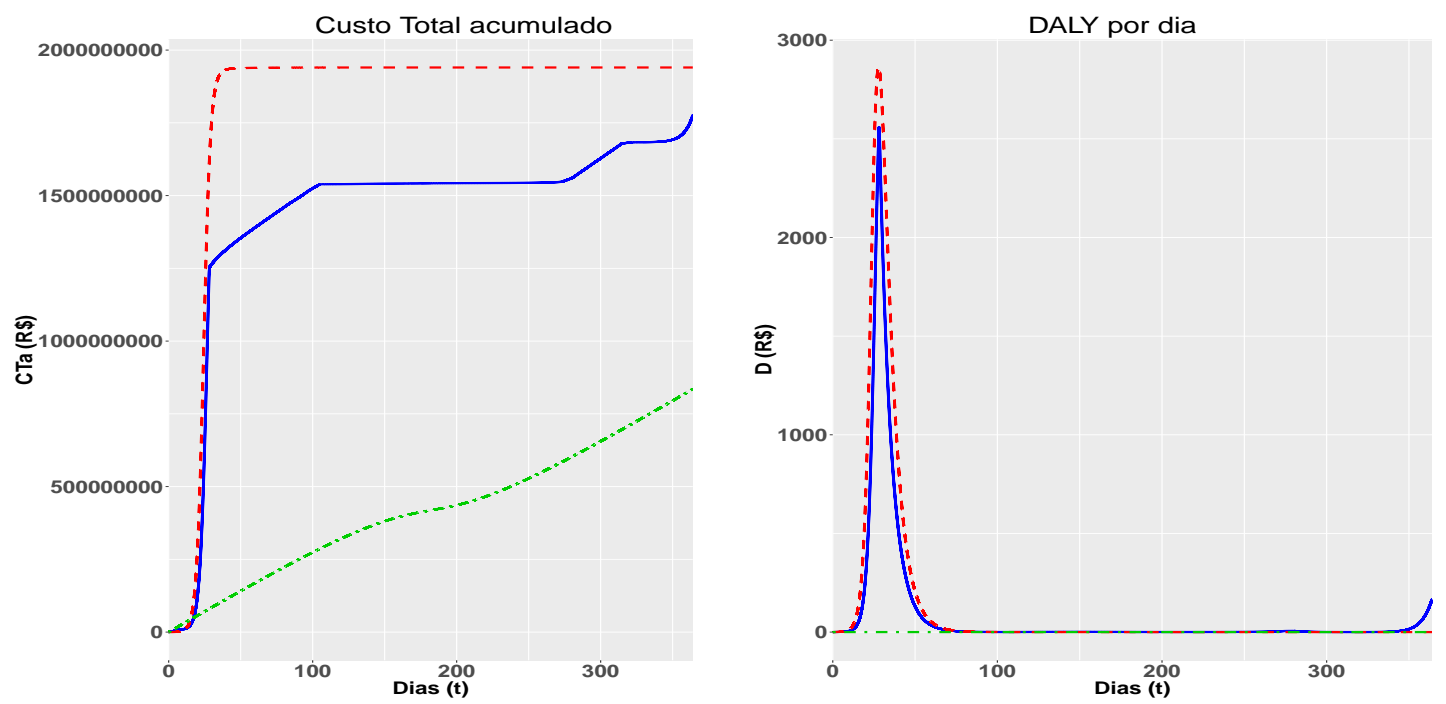

Figura 3.7: Gráficos do Custo Total acumulado e DALYs por dia para cada uma das três estratégias de controle simuladas - Sem Controle (linha vermelha tracejada), Restrição do $R_{0}$ (linha verd) e Restrição de custo (linha azul sólida).

A análise dos gráficos 3.7 é baseada nos resultados das figuras 3.3 e 3.4. A figura 3.3 representa os gastos por tipo de controle e a figura 3.4 mostra a quantidade de pessoas infectadas que geram o custo com internações em clínicas e hospitais. No gráfico de custo, a estratégia Sem Controle (curva vermelha) é a maior geradora de custos, que em sua totalidade são os gastos com clínicas e hospitais, pois o que caracteriza essa estratégia é precisamente não investir em controles. A estratégia de Restrição do $R_{0}$ (curva verde) é a única que não tem um pico no gráfico de custo por dia, isso é explicado porque é a situação em que a epidemia não se desenvolve, não obstante, ela sim gera custo na aplicação dos controles. Porém observando o gráfico de custos acumulados, ela representa a melhor estratégia financeira. A estratégia Restrição de custo (curva azul) reflete o melhor panorama investindo uma quantidade limitada de dinheiro nos mecânismos de controle, sugerindo que quando essa quantidade fica abaixo do real necessário para controlar de forma eficaz a população de mosquitos, os custos continuam sendo muito maiores do que se investirmos o dinheiro para um controle efetivo da epidemia, que é a estratégia Restrição de $R_{0}$.

$\mathrm{Na}$ análise do gráfico do DALY, a situação Sem Controle (linha vermelha) mostra que não há gasto com controles, apenas com clínicas e hospitais. A Restrição de custo ( linha azul) tem um aumento juntamente com a linha vermelha, pois, como observamos no gráfico 3.4, é justamente o momento onde há um pico de humanos infectados causado pela epidemia. Já a Restrição do $R_{0}$ (linha verde) está equilibrada, pois estamos usando o inseticida o ano todo. Com isso, podemos concluir que o caro não é o gasto com controles, e sim, os gastos com clínicas e hospitais, custo este gerado por tratar pessoas infectadas. 
Análise dos custos

\begin{tabular}{lrrrr}
\hline & DALY Acumulado & Controles & Hospitais e Clínicas & Gasto Total \\
\hline Sem Controle & $45.757,24$ & 0 & $1.940 .210 .271,35$ & $1.940 .210 .271,35$ \\
Restrição do $R_{0}$ & 11,62 & $834.235 .179,76$ & $493.081,07$ & $834.728 .260,84$ \\
Restricão de Custo & $31.279,32$ & $400.001 .691,75$ & $1.375 .254 .447,08$ & $1.775 .256 .138,84$ \\
\hline
\end{tabular}

Tabela 3.5: Comparativo de valores de DALY, Gasto com Controles e Gasto com Hospitais e Clínicas (valores em reais)

Fazendo um comparativo dos valores da primeira coluna (DALY acumulado), observa-se que a Restrição do $R_{0}$ seria a estratégia mais viável, com apenas 11,62 DALYs. Analisando a segunda coluna, vemos que o custo por Restrição de custo parou em $\mathrm{R} \$ 400$ milhões enquanto que a Restrição por $R_{0}$ gerou um gasto com controles em torno de $\mathrm{R} \$ 834$ milhões. Porém observando e comparando com a coluna 3 que corresponde aos gastos com clínicas e hospitais, temos um gasto de 493 mil para Restrição do $R_{0}$, contra 1.3 bilhões de gastos para Restrição de custo, o que corresponde a $77 \%$ do gasto total, isso significa que, nas condições iniciais do cenário 1, o mais viável, seria investir mais em controles para restringir o $R_{0}$, pois além de ser a estratégica mais economica a longo prazo, temos também um maior impacto positivo na qualidade de vida das pessoas, que embora seja uma variável subjetiva, é também muito importante.

\subsection{Resultados numéricos do cenário 6}

Os resultados dessa simulação são consequência da segunda condição inicial referente ao cenário 6 de Endemia.

\begin{tabular}{c|r|r|r|r|r|r|r}
\hline Condição Inicial & $S_{H}$ & $I_{H}$ & $R_{H}$ & $S_{M}$ & $I_{M}$ & $S_{L}$ & $I_{L}$ \\
\hline \hline 6 & 8.439 .134 & 897 & 3.666 .889 & 1.575 .479 & 384 & 34.533 .448 & 4.205
\end{tabular}

Tabela 3.6: Condição inicial do Cenário 6 de Endemia, com controle distribuído a partir do início do inverno

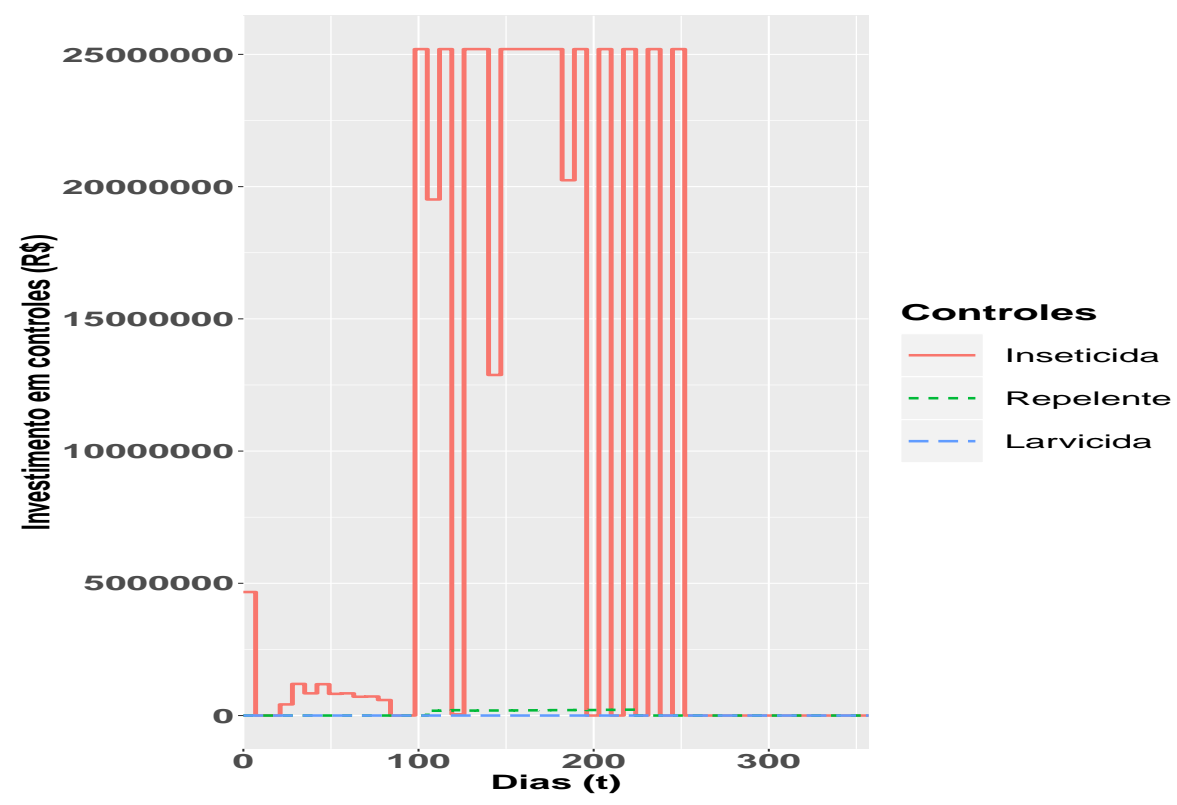

Figura 3.8: Melhor combinação de controles - Cada curva do gráfico representa o montante gasto em cada um dos três mecânismos de controle: repelente (curva verde pontilhada), inseticida (curva vermelha sólida) e larvicida (curva azul tracejada).

Na figura 3.8 o eixo y representa a quantia em dinheiro usada em cada um dos controles ao 
longo do ano. Neste cenário também notamos que todo o dinheiro a ser gasto com controles é usado com o inseticida.

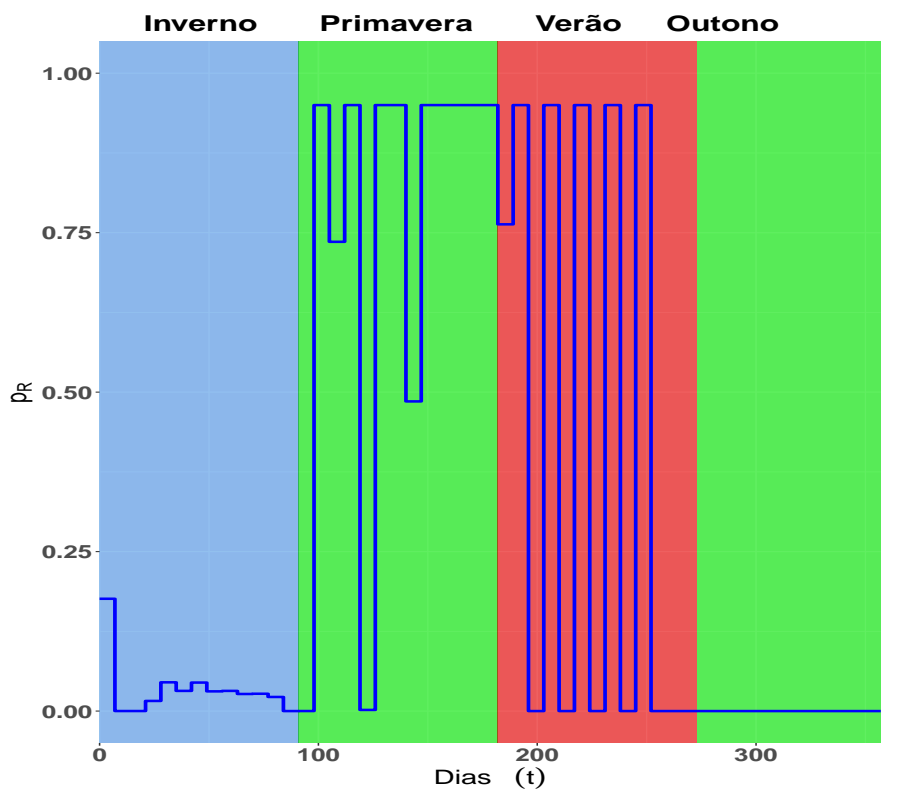

Figura 3.9: Uso do Inseticida - Este gráfico apresenta a melhor forma de aplicar o inseticida ao longo do ano.

Na figura 3.9 temos a melhor forma de aplicar o controle Inseticida ao longo de um ano. Como podemos notar, o algoritmo sugere aplicar uma pequena quantidade de inseticida durante todo o inverno onde há uma pequena concentração de mosquitos e uma quantidade bem maior nas estações primavera e verão até se esgotar toda a verba.

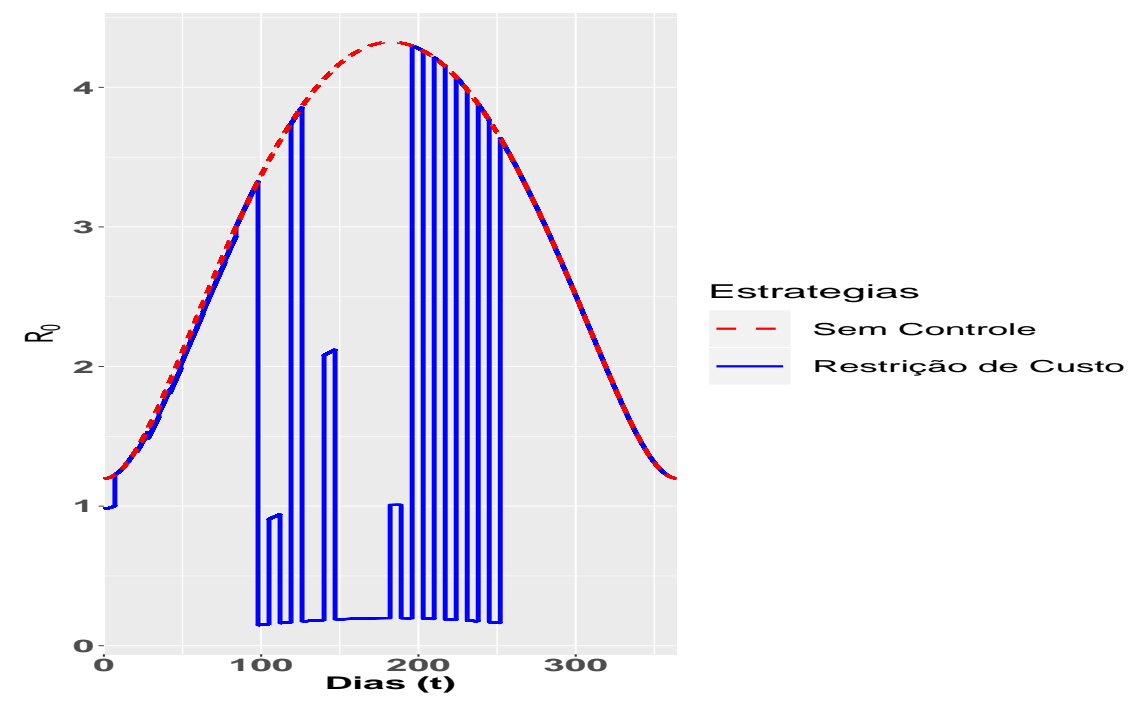

Figura 3.10: Simulação do comportamento das situações "Sem Controle"e "Restrição de Custo"quando o $R_{0}$ está controlado.

Assim como na figura 3.2, esse gráfico nos mostra que quando mantemos o $R_{0}$ controlado o ano todo, vemos que a estratégia Restrição de custo (curva azul) nos confirma que quanto mais aplicamos o controle, mais o $R_{0}$ diminui e vice-versa. A estratégia Sem Controle (curva vermelha), nos mostra, conforme o esperado, que o $R_{0}$ aumenta nas estações quentes e diminui nas estações frias. 


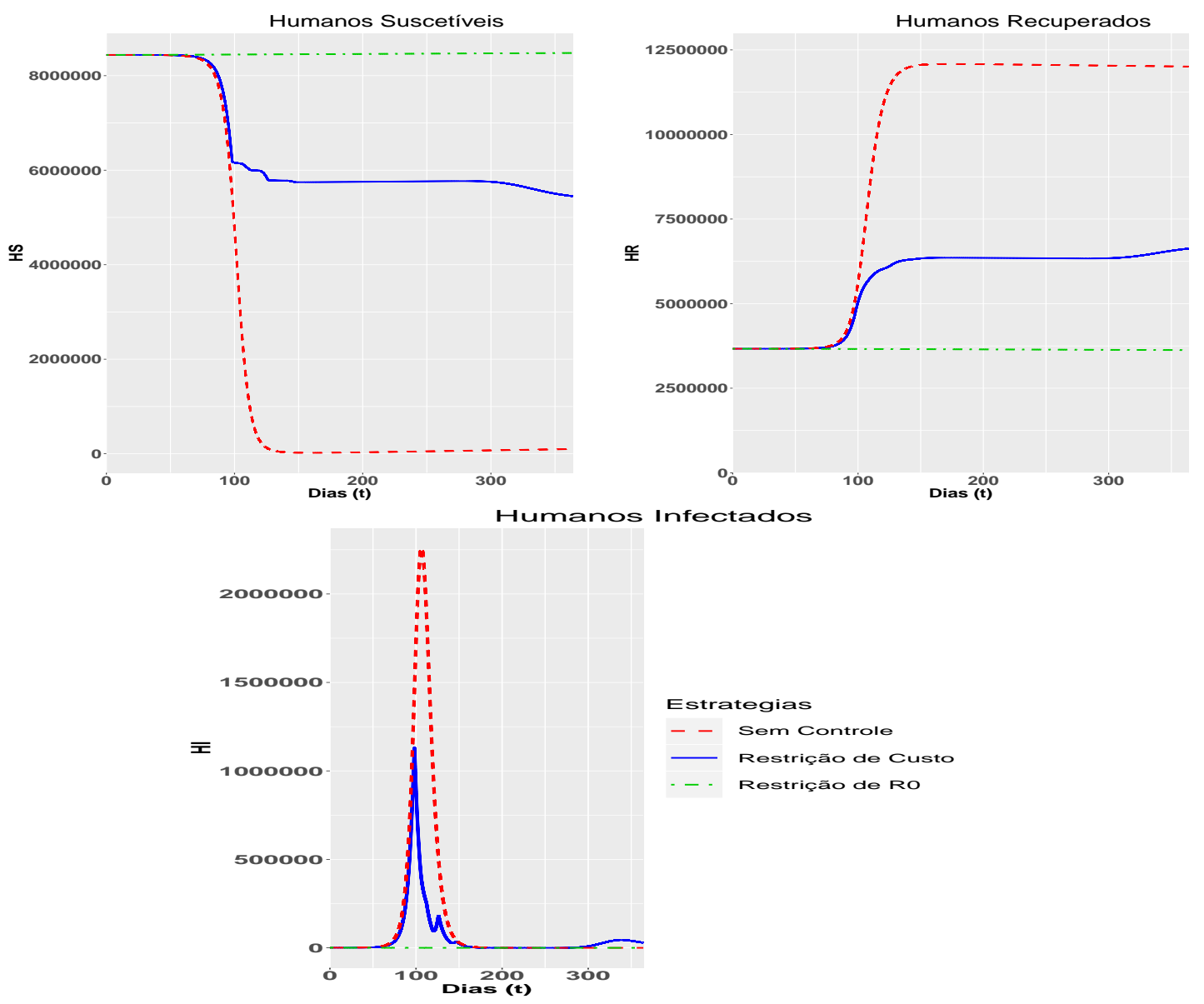

Figura 3.11: Gráfico da dinâmica das populações de humanos suscetiveis, infectados e recuperados para cada uma das três estratégias de controle simuladas - Sem Controle (linha vermelha tracejada), Restrição do $R_{0}$ (linha verde tracejada com pontos) e Restrição de custo (linha azul sólida). Nestes gráficos a escala está em valor absoluto para uma melhor visualização.

No gráfico dos humanos suscestíveis e recuperados, a estratégia Restrição de custo (curva azul) se estabilizam em níveis diferentes, pois os suscetíveis depende da quantidade de pessos que foram infectadas e os recuperados correspondem ao restante das pessoas. A estratégia Sem Controle (curva vermelha) nos mostra que passado a estação inverno, já no início da primavera grande parte dos humanos são infectados e depois passam a se recuperar. A Restrição do $R_{0}$ (curva verde), nos mostra que todos são suscetíveis e não há infectados. No gráfico de infectados notamos que estratégia Restrição de custo (curva azul) fica abaixo da estratégia Sem Controle (linha vermelha), pois corresponde ao número de pessoas infectadas que é representada pela área abaixo da curva azul. Também notamos uma pequena elevação nessa curva depois do centésimo dia, isso corresponde aos dias que deixamos de usar o controle, como podemos observar na figura 3.9. 

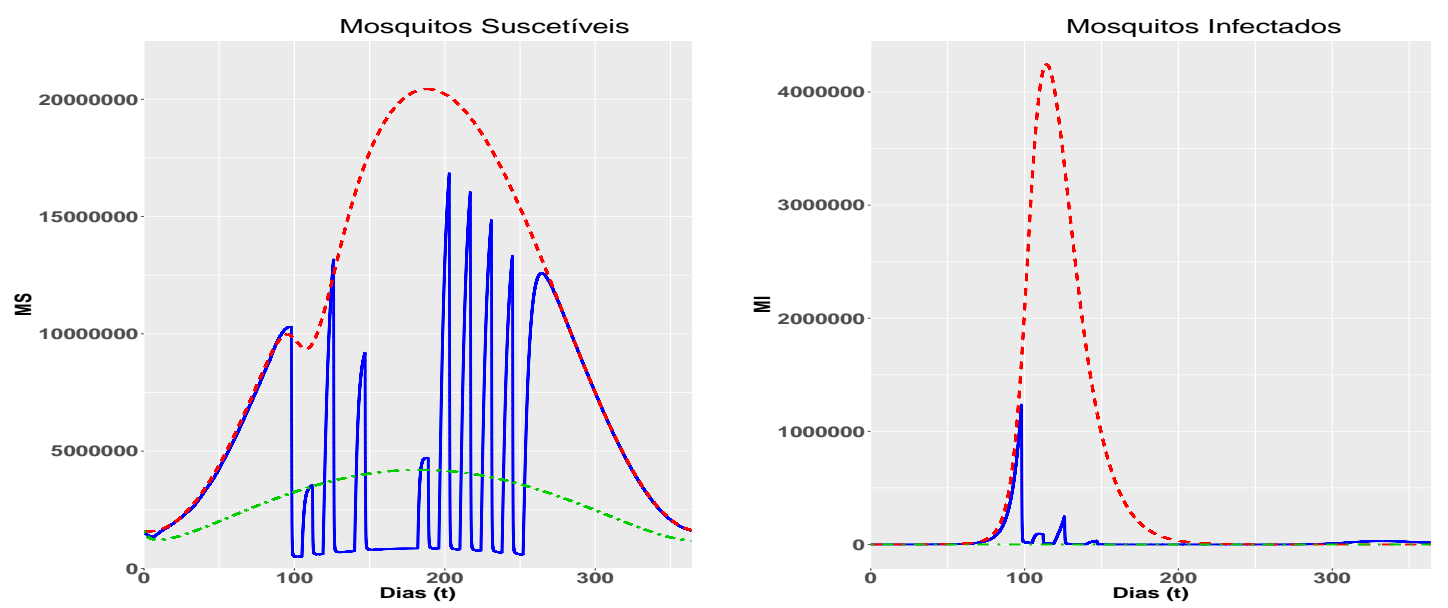

Figura 3.12: Gráfico da dinâmica das populações de mosquitos suscetíveis e infectados para cada uma das três estratégias de controle simuladas - Sem Controle (linha vermelha tracejada), Restrição do $R_{0}$ (linha verde tracejada com pontos) e Restrição de custo (linha azul sólida). Nestes gráficos a escala está em valor absoluto para uma melhor visualização.

Observando o gráfico de mosquitos infectados na figura 3.12, com a estratégia Restrição Sem Controle (curva vermelha), vemos que o número de infectados é bem alto, pois é justamente no período da primavera onde as pessoas deixam de pertencer ao compartimento dos suscetíveis para irem para o compartimento dos infectados. A estratégia Restrição de Custo (curva azul) depende do quanto de controle estamos usando, isso devemos comparar com o gráfico 3.9. Já no gráfico de suscetíveis que na estratégia Sem Controle o número de mosquito sobe nas estações quentes e que quando aplicamos o controle (curva azul) o número de mosquitos diminui.
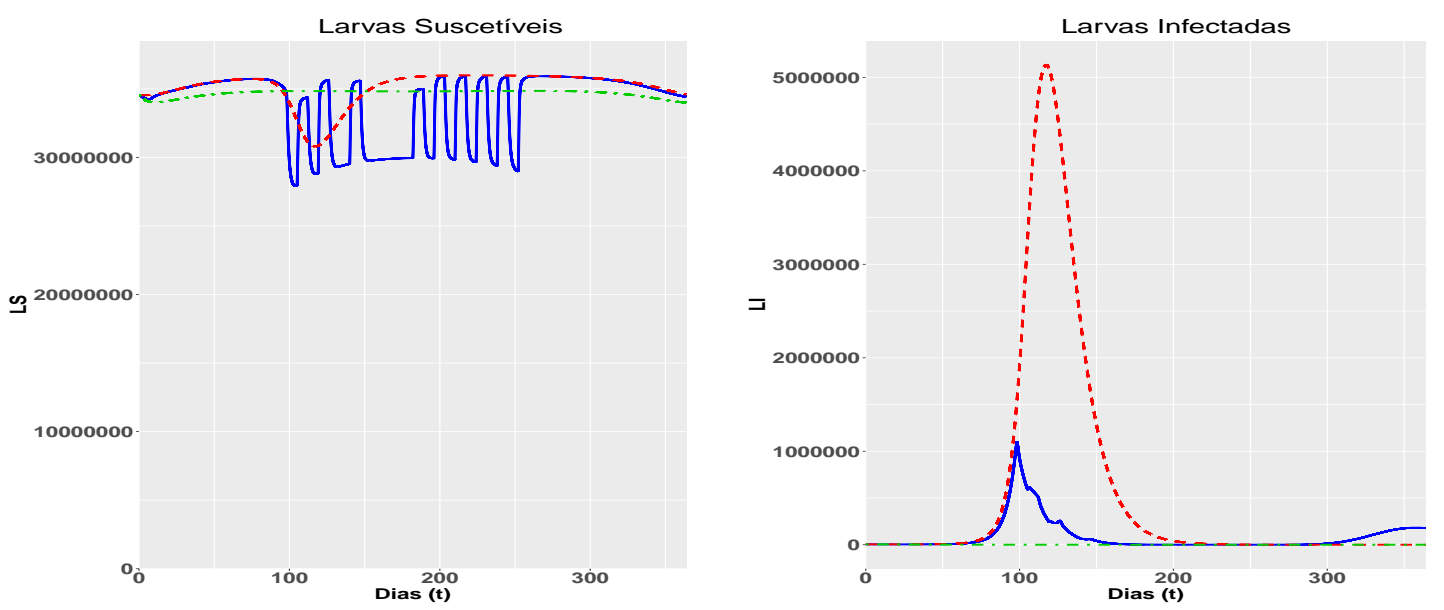

Figura 3.13: Gráfico da dinâmica das populações de larvas suscetíveis e infectados para cada uma das três estratégias de controle simuladas - Sem Controle (linha vermelha tracejada), Restrição do $R_{0}$ (linha verde tracejada com pontos) e Restrição de custo (linha azul sólida). Nestes gráficos a escala está em valor absoluto para uma melhor visualização.

O comportamento das populações de larvas é muito parecido com o das populações de mosquitos da figura 3.12 , porém as larvas não são tão afetadas como os mosquitos. 

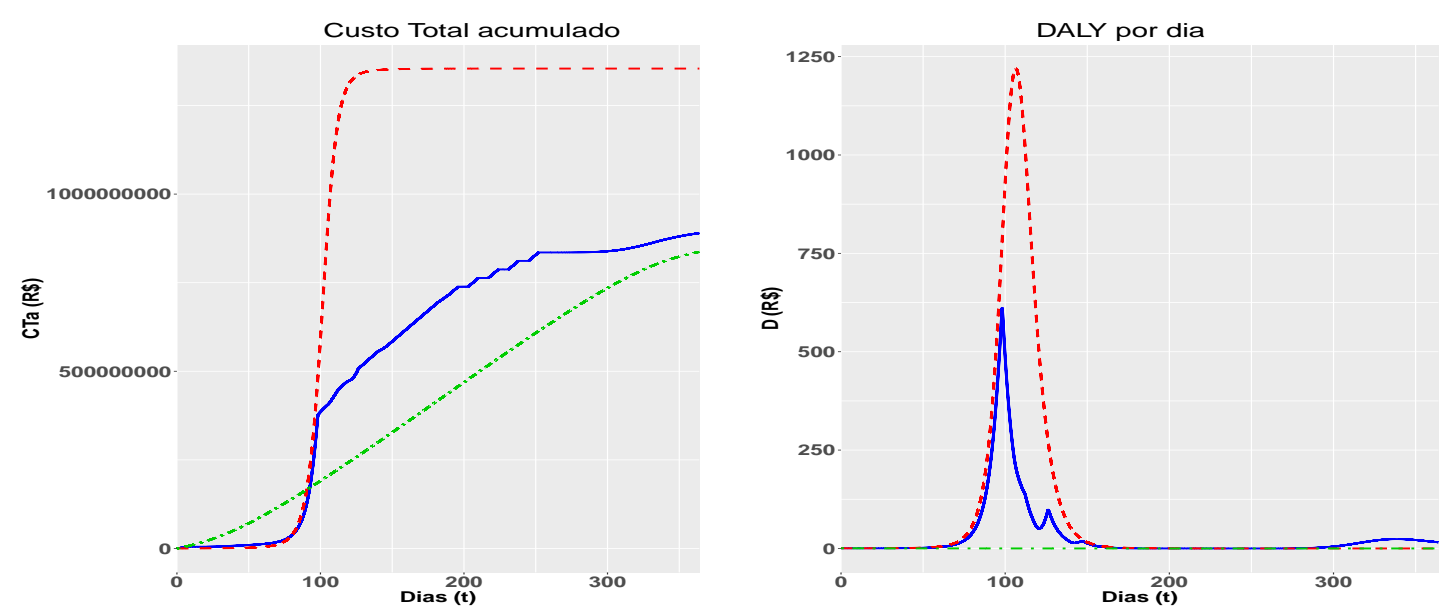

Figura 3.14: Gráficos do Custo Total acumulado e DALYs por dia para cada uma das três estratégias de controle simuladas - Sem Controle (linha vermelha tracejada), Restrição do $R_{0}$ (linha verde tracejada com pontos) e Restrição de custo (linha azul sólida).

No gráfico de Custo Acumulado, a estratégia Sem Controle (curva vermelha) sobe no início da primavera, essa curva também nos indica os custos gerados com clínicas e hospitais e isso depende do número de infectados, já que nessa estratégia não usamos controle. A estratégia Restrição de Custos (curva azul) nos mostra uma subida no início da primavera indicando os gastos com clinicas e hospitais juntamento com o gasto com controles e depois seu comportamento nos mostra os gastos apenas com controles. Já a estratégia Restrição do $R_{0}$ nos mostra os custos gerados somente por controles. O gráfico do DALY é muito parecido com o gráfico dos infectados indicado na figura 3.11, pois esse custo está diretamente ligado ao número de humanos infectados.

Análise dos custos

\begin{tabular}{lrrrr}
\hline & DALY Acumulado & Controles & Hospitais e Clínicas & Gasto Total \\
\hline Sem Controle & $31.941,20$ & 0 & $1.354 .235 .312,74$ & $1.354 .235 .312,74$ \\
Restrição do $R_{0}$ & 22,37 & $836.200 .006,26$ & $804.868,82$ & $837.004 .875,08$ \\
Restrição de Custo & $11.448,15$ & $400.001 .056,36$ & $489.932 .373,85$ & $889.933 .430,21$ \\
\hline
\end{tabular}

Tabela 3.7: Comparativo com valores de DALY, Gasto Total, Gasto com Controles e Gasto com Hospitais e Clinicas - CI 6 .

Fazendo um comparativo dos valores da primeira coluna (DALY acumulado), observa-se que a Restrição do $R_{0}$ seria a estratégia mais viável, com apenas 22,37 DALYs. Analisando a segunda coluna, vemos que o custo por Restrição de custo parou em $\mathrm{R} \$ 400$ milhões enquanto que a Restrição por $R_{0}$ gerou um gasto com controles em torno de $\mathrm{R} \$ 837$ milhões. Porém observando e comparando com a coluna 3 que corresponde aos gastos com clínicas e hospitais, temos um gasto de $\mathrm{R} \$ 804$ mil para Restrição do $R_{0}$, contra $\mathrm{R} \$ 889$ milhões de gastos para Restrição de custo, o que corresponde apenas $6,32 \%$ de diferente entre uma estratégia e outra. Neste cenário, podemos dizer que as duas estratégias são interessantes. 


\section{Análise dos resultados dos outros cenários}

O comportamento dos gráficos dos cenários epidêmicos 3,5 e 7 são muito parecidos com o cenário 1, e em todos o melhor controle recomendado foi o uso do Inseticida.

Nos cenários 2, 4 e 8, as simulações das populações de humanos, mosquitos e larvas estão em valor absoluto para uma melhor visualização da dinâmica da doença.

Uma situação de endemia é bem diferente de uma situação de epidemia. Um cenário de epidemia tem que ser controlado via mecânismos de controle, já no caso endêmico, mesmo não usando nenhum tipo de mecanismo de controle, a endemia se dissiparia com o tempo.

O primeiro gráfico nos mostra que a melhor opção de mecânismos de controle seria fazer uma combinação do uso do Inseticida com o Repelente. Como começamos com um número de pessoas infectadas, aplicamos o inseticida e repelente desde o ínicio do período até o fim do primeiro mês da estação, e também distribuindo o repelente à população, gastando assim todo o recurso financeiro destinado aos controles. Isso também é o que vemos no gráfico do $R_{0}$, quando usamos os controles, o $R_{0}$ fica abaixo de 1 .

No gráfico de humanos suscetíveis vemos que o número de pessoas vai aumentando ao longo do ano devido a quantidade de pessoas que estão nascendo, e consequentemente, suscetíveis. No gráfico de humanos infectados vemos que o número de pessoas que começam infectadas diminui bruscamente com o uso dos controles e logo se estabiliza.

Nos gráficos referente a custo vemos que o maior custo é com o repelente, pois a maior parte dos recursos foi utilizada logo na primeira semana, e o gasto no restante do mês foi somente com o inseticida.

O que fica claro analisando as tabelas de custos, é que a estratégia de Restrição de custo, nestes casos é a melhor opção, já que no cenário endêmico o $R_{0}$ sempre estará controlado.

O algoritmo nos mostra que em todos os cenários o controle mais recomendado é o uso do Inseticida, isso não nos supreende já que o Inseticida é uma forma eficaz de eliminação dos mosquitos, além de ser o controle mais barato, dentro os três. O uso do repelente é indicado nos cenários endêmicos 2, 4 e 8, e esses devem aplicados durante o verão não importando a estação em que começamos a aplicar os controles, e notamos que mesmo distuibuindo pouca quantidade desse controle, nos gera um custo muito alto, bem maior do que a grande quantidade de inseticida que usaremos. 


\section{Capítulo 4}

\section{Conclusões}

A dengue tem causado uma grande preocupação à saúde pública do país. A cidade de São Paulo, em particular, vem tendo um alto gasto com clínicas e hospitais devido às internações de pessoas infectadas pelo virus da dengue. Uma das formas mais eficaz para impedir a proliferação da doença é o combate ao Aedes Aegypti. Porém, o controle do vetor é uma medida preventiva importantíssima, que não é utilizada em todo seu potencial.

Neste trabalho mostramos o quanto o investimento no controle é necessário e pode melhorar a qualidade de vida das pessoas, e, a longo prazo se tornar uma medida até mesmo econômica. Para isso, utilizamos um modelo matemático onde introduzimos três diferentes mecanismos de controle químico: repelente, inseticida e larvicida, para analisar qual a melhor combinação de mecanismos de forma a controlar o vetor, e como em qualquer situação financeira, obter a maior eficiência com o menor custo. Para isso também acoplamos ao sistema uma função custo e uma função DALY.

No capítulo 2 apresentamos nosso modelo SIR discreto. Para esse modelo analisamos seus estados de equilíbrio endêmico e livre de doença. A análise dos pontos de equilíbrio para esse modelo é relacionada com o número de reprodutibilidade basal - $R_{0}$, de tal forma que, para equilíbrios com $R_{0}<1$, as soluções do sistema tenham equilíbrio livre de doença, e para $R_{0}>1$, estas soluções tendem ao equilíbrio endêmico, e através das simulações numéricas verificamos nossos resultados analíticos.

Simulamos oito cenários com as condições iniciais encontradas através do cálculo do equilíbrio endêmico. Os cenários 1, 3, 5 e 7 correspondem a situação de epidemia com controles distribuidos no início das estações verão, outono, inverno e primavera, respectivamente, e os cenários 2, 4, 6 e 8 correspondem a situação de endemia com controles distribuídos no início das estações verão, outono, inverno e primavera, respectivamente. Utilizando três estratégias distintas: Sem Controle, Restrição do $R_{0}$ e Restrição de custo, o algoritmo nos dá a melhor combinação de mecanismos a ser usada para cada cenário, visando cumprir as estratégias de controle determinadas. No caso dos cenários endemicos 2,4 , e 8 , a melhor opção foi usar um pouco de repelente durante o período de verão e investir todo o restante do dinheiro em uso com o inseticida. Já nos cenários de epidemia 1 , 3,5 e 7 e no cenário endêmico 6 , a melhor estratégia encontrada foi o controle somente com o uso do inseticida. O algoritmo nos forneceu um direcionamento estratégico de como aplicar o controle ao longo do ano de uma maneira eficiente e otimizada para os diferentes cenários. Também nos mostrou o comportamento das populações de humanos, mosquitos e larvas mediante da aplicação desses controles. Além de nos fornecer um panorama geral dos gastos com DALY acumulados, controles, e clínicas e hospitais para cada estratégia utilizada.

Concluímos que nos cenários epidêmicos a estratégia Restrição do $R_{0}$ é a melhor. De certo que gastaremos o dobro do valor estipulado para controlar a epidemia usando os mecanismos de controle, porém teremos menos pessoas infectadas, gerando assim gastos com clínicas e hospitais bem menores, e o valor gasto no primeiro ano com controles iria diminuir ao longo dos anos, gerando DALYs cada vez menores. Já nos cenários endêmicos a estratégia Restrição de custo é a melhor, pois como nessa situação não temos tantas pessoas infectadas, e o valor que estipulamos para tal estratégia é o suficiente para manter a situação controlada. 
Portanto o melhor seria tratar com a estratégia de Restrição do $R_{0}$ diante dos cenários epidêmicos e quando passar para o cenário endêmico manter o controle por meio da estratégia de Restrição de custo.

\subsection{Sugestões para Pesquisas Futuras}

No presente trabalho fizemos as simulações para um ano. Nossa intenção é estender esse período e propor uma estratégia de controle do vetor, visando a diminuição no número de infectados, e, consequentemente, diminuindo o número de gastos com clínicas e hospitais. No caso, começaríamos com um valor para o controle do vetor e iríamos diminuindo gradualmente para ver qual o efeito na população de humanos e mosquitos.

Também estamos supondo a aplicação dos mecanismos de controle de forma homogênea. Para um próximo trabalho poderíamos restringir o uso dos mecanismos para as regiões de maior risco, minimizando ainda mais o custo com controles. 


\section{Apêndice A}

\section{A.1 Modelagem do $r_{L}$}

O parâmetro $r_{L}$ indica a metamorfose das larvas, no caso, as larvas virando mosquitos, e varia em função do tempo, sendo dado pela fórmula

$$
\mathrm{r}_{L}(t)=0.15\left[0.54+0.46 \cos \left\{2 \pi\left(\frac{\mathrm{t}}{365}+\mathrm{t}_{0}\right)\right\}\right]
$$

onde $t_{0}$ indica a época do ano correspondente ao instante $t=0$.

No artigo Burattini et al. (2008) - "Modelling the control strategies against dengue in Singapore", o sistema de EDOs usa os termos $p_{S} c_{S}(t) S_{E}$ e $p_{S} c_{S}(t) I_{E}$ para indicar a metamorfose dos ovos em mosquitos (por isso usam a letra E, de "eggs"). Em nosso modelo, estes termos correspondem a $r_{L} S_{L}$ e $r_{L} I_{L}$ (trocando E por L, de "larvas"), onde $r_{L}(t)=p_{S} c_{S}(t)=p_{I} c_{S}(t)$ pois, como considerado no artigo, os parâmetros $p_{S}$ e $p_{I}$ para ovos suscetíveis e infectados, respectivamente, são ambos iguais a 0.15. Além disso, o artigo define $c_{S}(t)=\left(d_{1}-d_{2} \sin (2 \pi f t-\phi)\right) \theta\left(d_{1}-d_{2} \sin (2 \pi f t+-\phi)\right)$ com $f=1 / 365, d_{1}=0.07, d_{2}=0.06$ e com $\theta$ sendo a função de Heaviside

$$
\theta= \begin{cases}1 & \text { se } x>0 \\ 0 & \text { se } x<0\end{cases}
$$

Mas, como os valores mínimo e máximo da expressão $\left(d_{1}-d_{2} \sin (2 \pi f t+\phi)\right)$ são, respectivamente, $d_{1}-d_{2}=0.01$ e $d_{1}+d_{2}=0.13$, temos que esta expressão é sempre positiva, portanto $\theta=$ $\left(d_{1}-d_{2} \sin (2 \pi f t+\phi)\right)$ é sempre igual a 1 , de forma que

$$
c_{S}(t)=d_{1}-d_{2} \sin (2 \pi f t+\phi)
$$

Fazendo a substituição

$$
-\sin (x)=\cos \left(x+\frac{\pi}{2}\right)
$$

temos que

$$
c_{S}(t)=d_{1}+d_{2} \cos \left(2 \pi f t+\phi \frac{\pi}{2}\right)=0.07+0.06 \cos \left\{2 \pi\left(\frac{t}{365}+t_{0}\right)\right\}
$$

onde

$$
t_{0}=\frac{1}{2 \pi}\left(\phi+\frac{\pi}{2}\right)
$$

é um parâmetro usado para fazer com que o máximo desta função ocorra no momento certo do ano, 
ou seja, no verão. Isso quer dizer que

$$
r_{L}(t)=p_{S} c_{S}(t)=0.15\left[0.07+0.06 \cos \left\{2 \pi\left(\frac{t}{365}+t_{0}\right)\right\}\right]
$$

Finalmente, para que o valor 0.15 seja realmente o valor máximo de $r_{L}(t)$ durante o ano, é necessário que o valor máximo da expressão entre colchetes seja 1 , o que não ocorre (o valor máximo é $0.07+0.06=0.13)$. Dividindo a expressão entre colchetes por 0.13 , obtemos a nova fórmula

$$
r_{L}(t)=0.15\left[0.54+0.46 \cos \left\{2 \pi\left(\frac{t}{365}+t_{0}\right)\right\}\right]
$$

que mantém a proporcionalidade entre as constantes $d_{1}$ e $d_{2}$, mas faz com que o valor máximo seja o valor de referência 0.15 (na fórmula original, o valor máximo de $r_{L}(t)$ era $0.15 \times 0.13=0.02$, bem menor que 0.15).

\section{A.2 Pseudo Código}

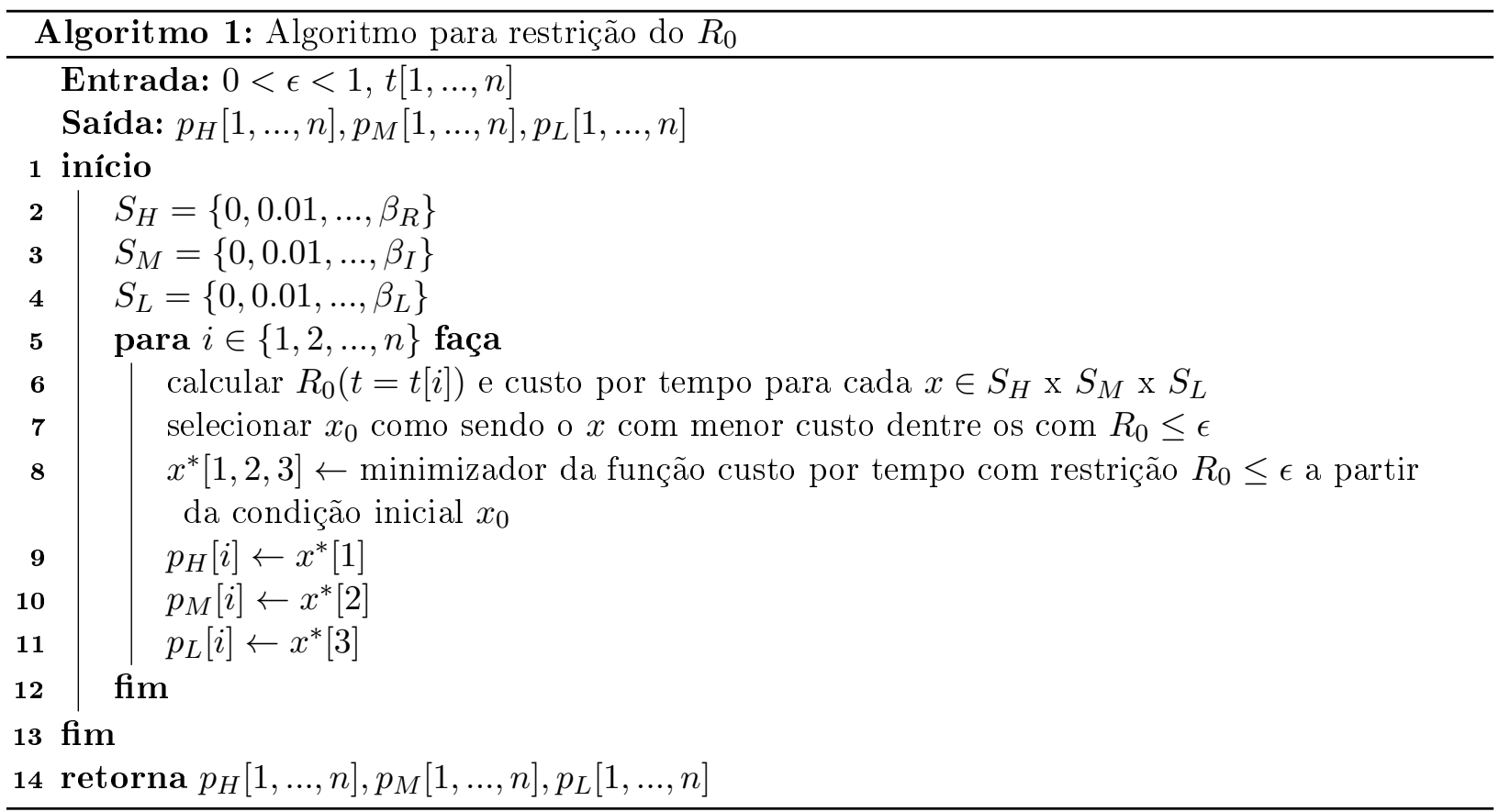


Função custo por tempo: $\left(p_{H}, p_{M}, p_{L}\right) \rightarrow \gamma_{R} N_{H} p_{H}+\gamma_{I} p_{M}+\gamma_{L} p_{L}$

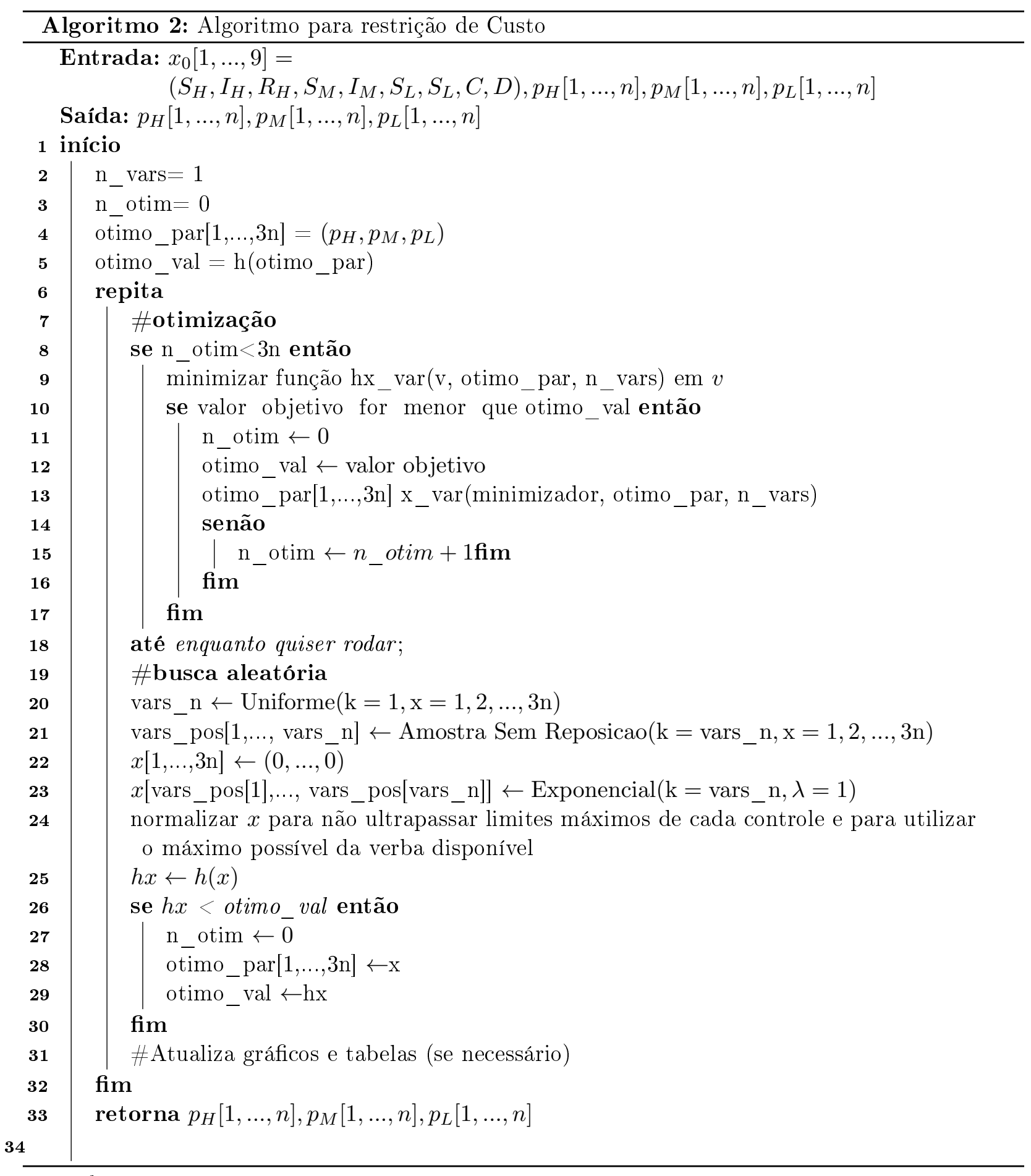

onde:

Função $h(x)$ : retorna DALYs acumulados (ou $+\infty$ se algum dos valores dos controles for inválido ou se custo total exceder verba disponível)

Função $x \_v a r(v, x$, ind $)$ : troca $x[i n d]$ por $v$ e normaliza todas as outras entradas de $x$ para que o custo total seja igual a verba disponível (eliminando valores inválidos para os controles)

Função $h x \_v a r:(v, x$, ind $) \rightarrow h\left(x \_v a r(v, x\right.$, ind $\left.)\right)$ 


\section{A.3 Resultados numéricos do cenário 2}

Os resultados dessa simulação são consequência da sexta condição inicial referente ao cenário 2 de Endemia.

\begin{tabular}{c|r|r|r|r|r|r|r}
\hline Condição Inicial & $S_{H}$ & $I_{H}$ & $R_{H}$ & $S_{M}$ & $I_{M}$ & $S_{L}$ & $I_{L}$ \\
\hline \hline 2 & 647.999 & 2.804 & 11.456 .117 & 20.518 .048 & 15.611 & 35.988 .662 & 13.686
\end{tabular}

Tabela A.1: Condição inicial do Cenário 2 de Endemia, com controle distribuído a partir do início do verão

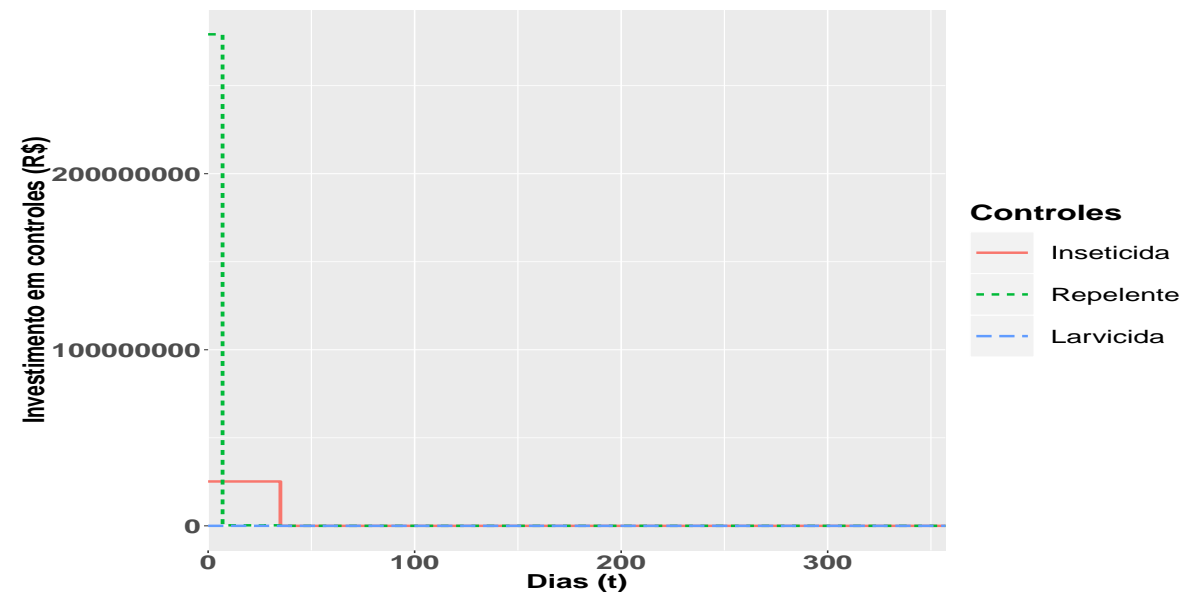

Figura A.1: Melhor combinação - CI 2
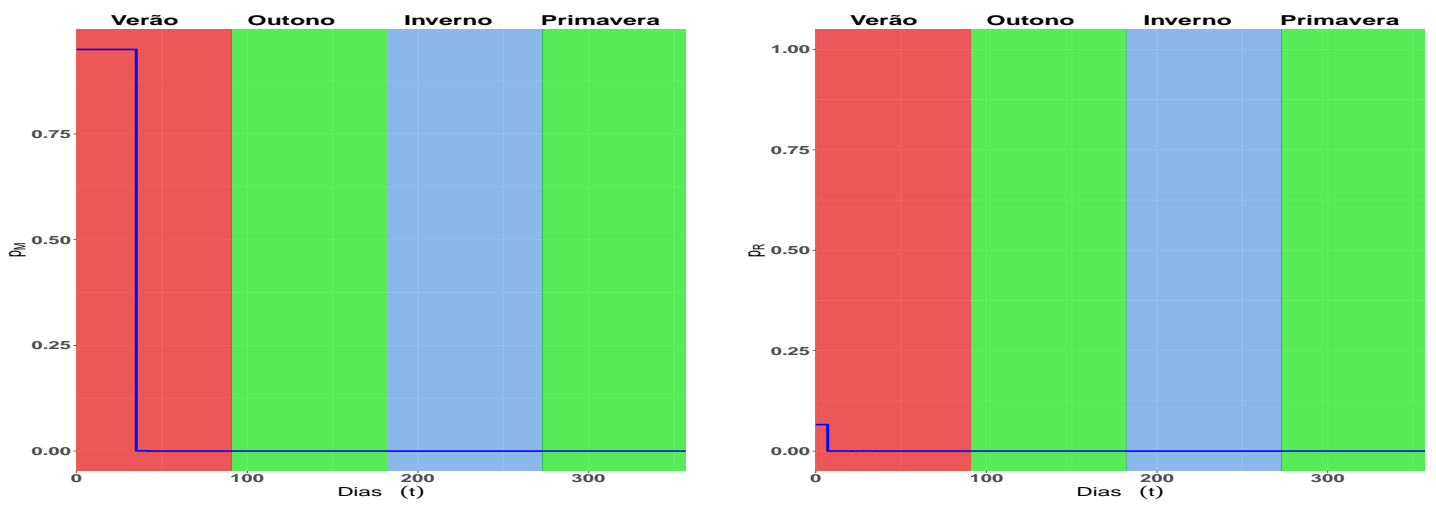

Figura A.2: Uso do Inseticida e Repelente - CI 2

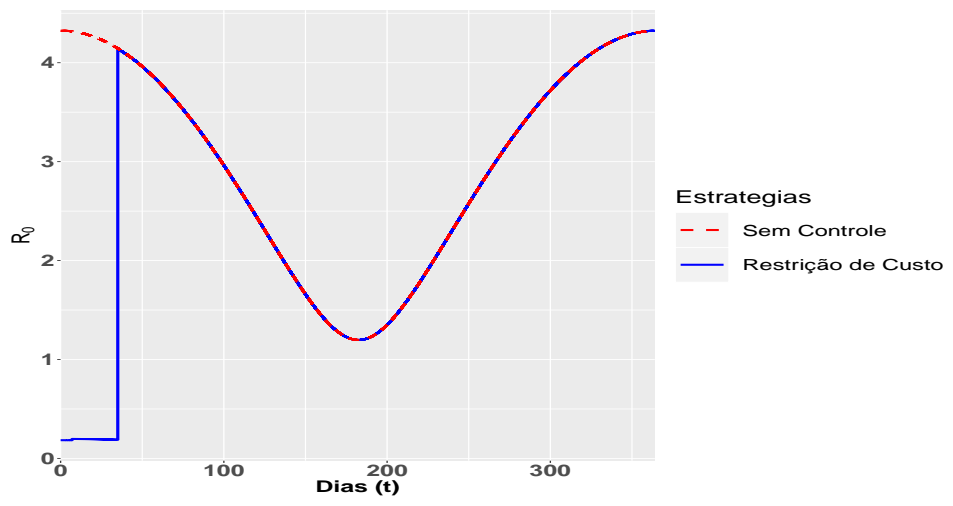

Figura A.3: $R_{0}-C I 2$ 


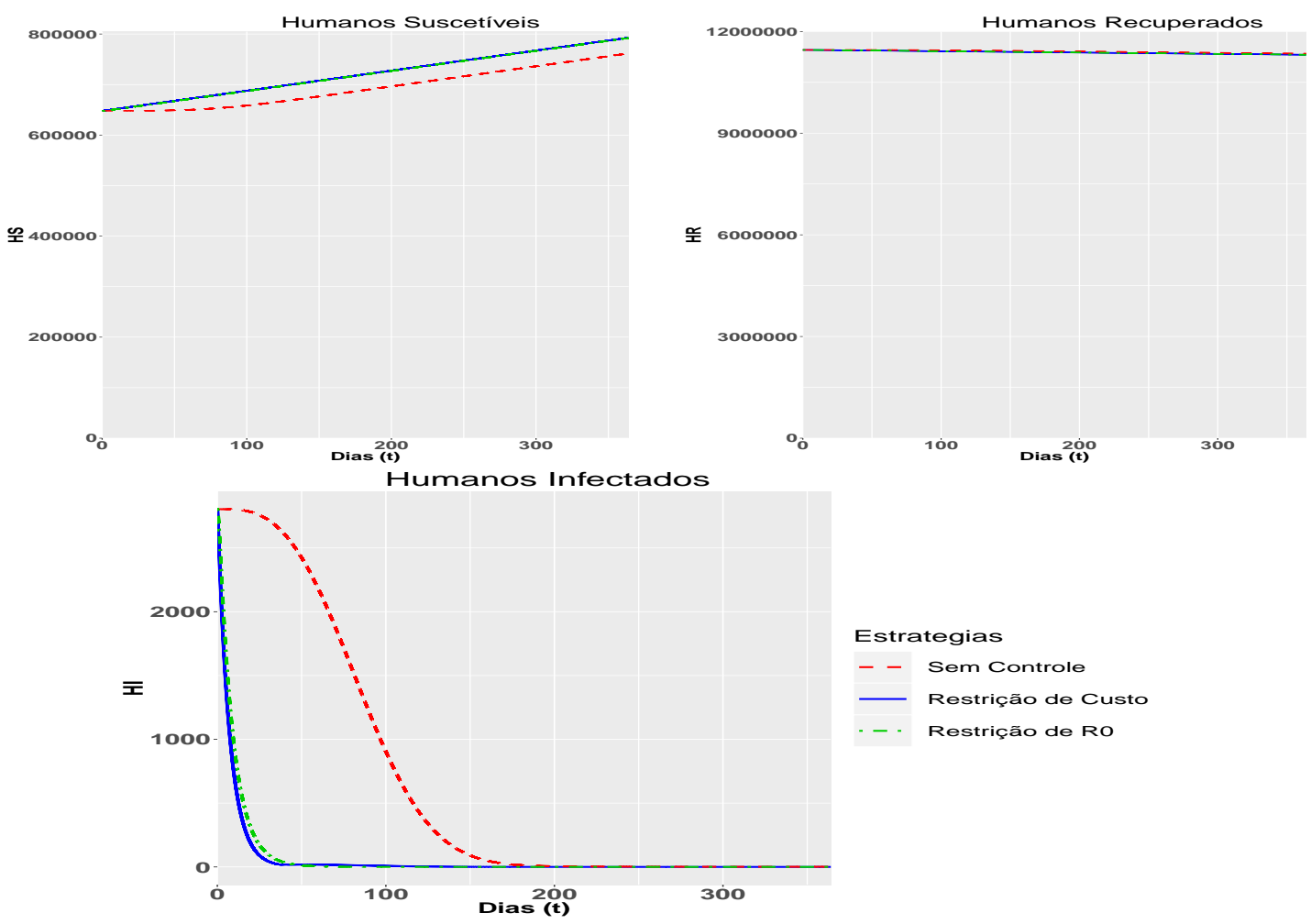

Figura A.4: Humanos suscetiveis, infectados e recuperados - CI 2
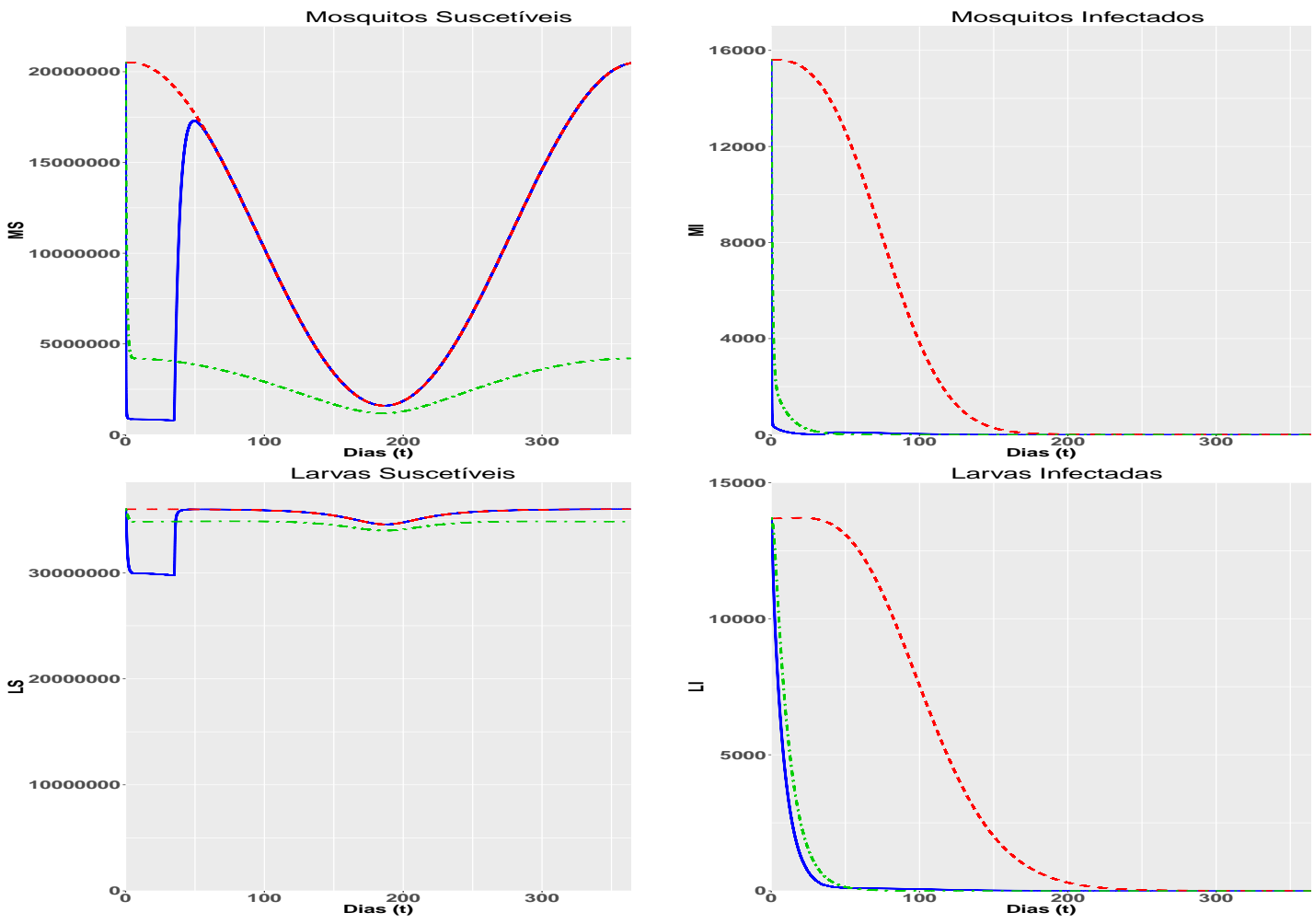

Figura A.5: Mosquitos e larvas suscetiveis e infectados - CI 2 

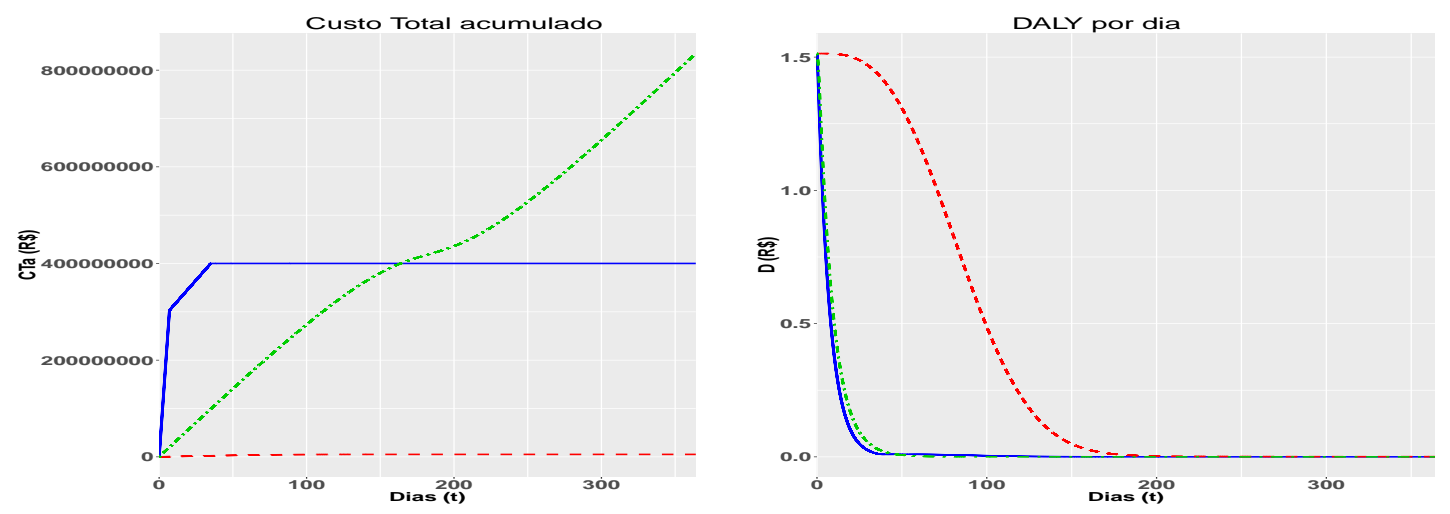

Figura A.6: Custos e DALY - CI 2

\section{Análise dos custos}

\begin{tabular}{lrrrr}
\hline & DALY Acumulado & Controles & Hospitais e Clínicas & Gasto Total \\
\hline Sem Controle & 130,45 & 0 & $5.082 .853,78$ & $5.082 .853,78$ \\
Restrição do $R_{0}$ & 14,19 & $834.235 .179,76$ & $153.116,97$ & $834.388 .296,73$ \\
Restrição de Custo & 11,70 & $400.072 .166,59$ & $47.633,99$ & $400.119 .800,58$ \\
\hline
\end{tabular}

Tabela A.2: Comparativo com valores de DALY, Gasto Total, Gasto com Controles e Gasto com Hospitais e Clínicas - Condicão inicial 2. 


\section{A.4 Resultados numéricos do cenário 3}

Os resultados dessa simulação são consequência da terceira condição inicial referente ao cenário 3 de Epidemia.

\begin{tabular}{c|r|r|r|r|r|r|r}
\hline Condição Inicial & $S_{H}$ & $I_{H}$ & $R_{H}$ & $S_{M}$ & $I_{M}$ & $S_{L}$ & $I_{L}$ \\
\hline \hline 3 & 12.106 .920 & 0 & 0 & 11.054 .760 & 1.000 & 35.893 .852 & 0
\end{tabular}

Tabela A.3: Condição inicial do Cenário 3 de Epidemia, com controle distribuído a partir do início do outono

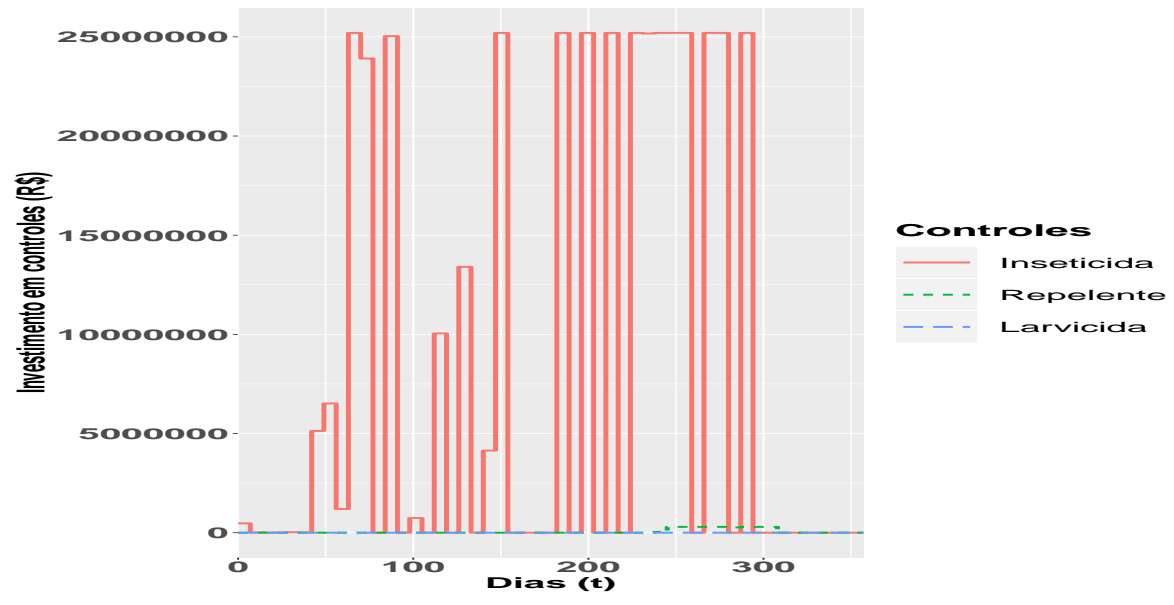

Figura A.7: Melhor combinação - Cenário 3

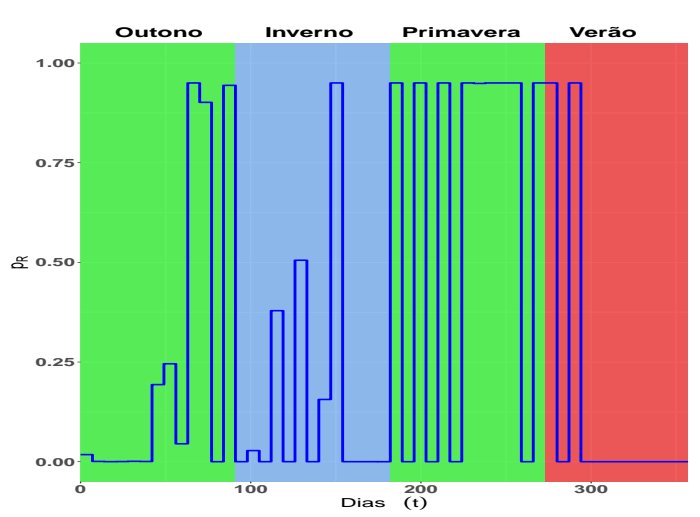

Figura A.8: Uso do Inseticida e Repelente - CI 3

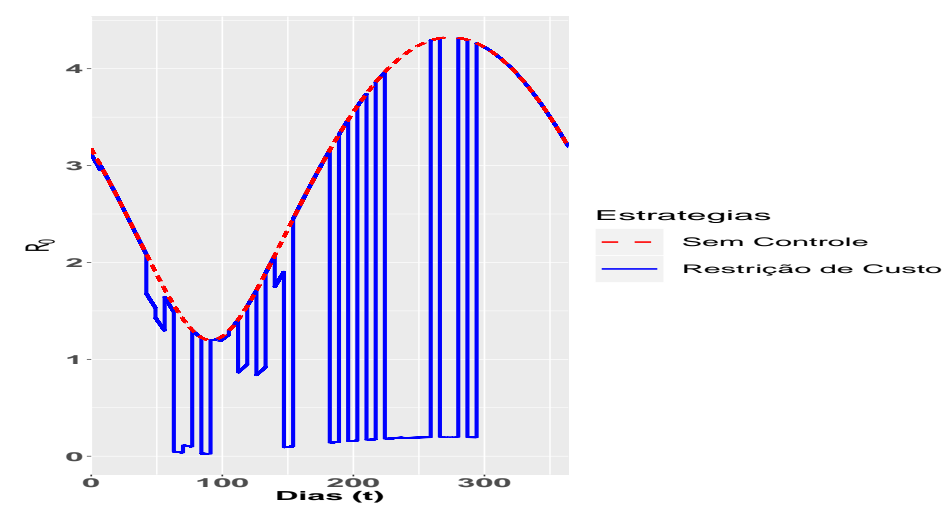

Figura A.9: $R_{0}-C I 3$ 

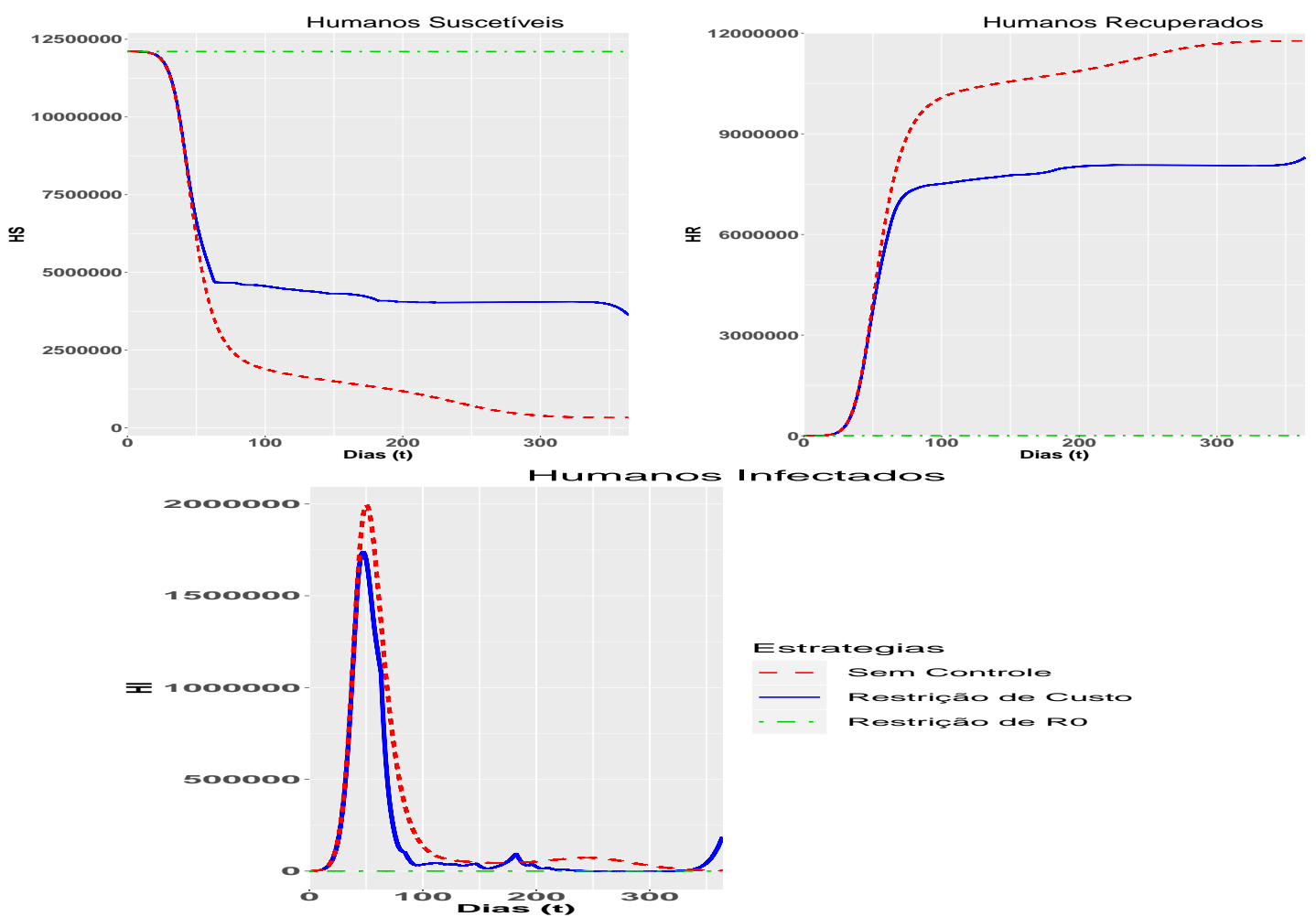

Estrategias

- Sem Contralo

Restricão de Custo

Restricão de Ro

Figura A.10: Humanos suscetiveis, infectados e recuperados - CI 3
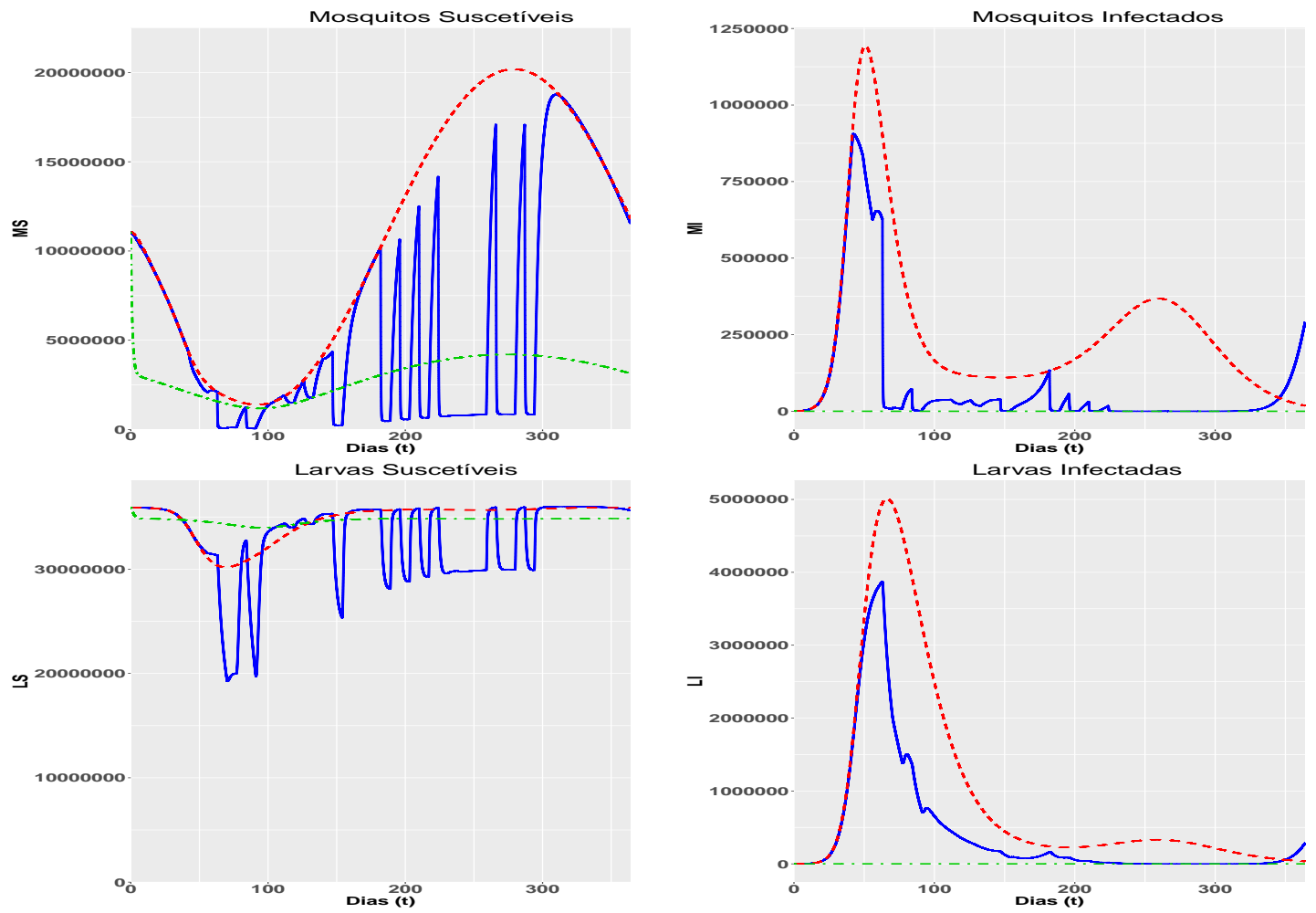

Figura A.11: Mosquitos e larvas suscetiveis e infectados - CI 3 

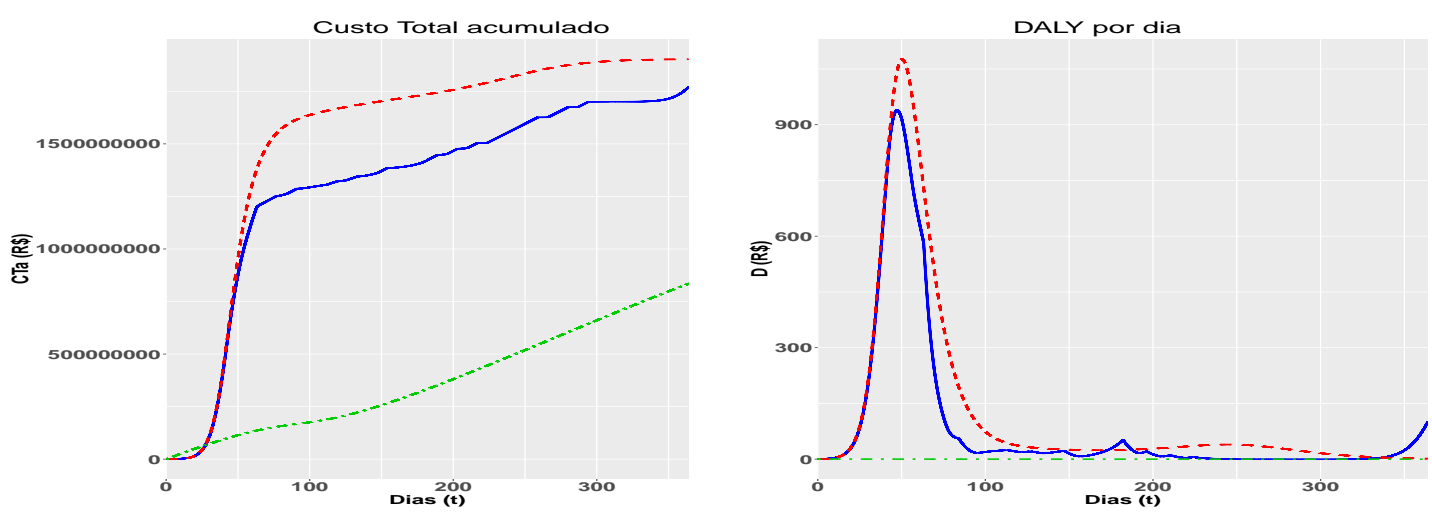

Figura A.12: Custos e DALY - CI 3

\section{Análise dos custos}

\begin{tabular}{lrrrr}
\hline & DALY Acumulado & Controles & Hospitais e Clínicas & Gasto Total \\
\hline Sem Controle & $44.862,43$ & 0 & $1.902 .672 .768,60$ & $1902.672 .768,60$ \\
Restrição do $R_{0}$ & 16,54 & $834.506 .206,12$ & $702.099,72$ & $835.208 .305,84$ \\
Restrição de Custo & $31.622,95$ & $400.000 .106,70$ & $1370.571 .382,76$ & $1.770 .571 .489,46$ \\
\hline
\end{tabular}

Tabela A.4: Comparativo com valores de DALY, Gasto Total, Gasto com Controles e Gasto com Hospitais e Clinicas - CI 3 . 


\section{A.5 Resultados numéricos do cenário 4}

Os resultados dessa simulação são consequência da quarta condição inicial referente ao cenário 4 de Endemia.

\begin{tabular}{c|r|r|r|r|r|r|r}
\hline Condição Inicial & $S_{H}$ & $I_{H}$ & $R_{H}$ & $S_{M}$ & $I_{M}$ & $S_{L}$ & $I_{L}$ \\
\hline \hline 4 & 1.203 .581 & 2.668 & 10.900 .671 & 11.046 .763 & 7.997 & 35.880 .869 & 12.983
\end{tabular}

Tabela A.5: Condição inicial do Cenário 4 de Endemia, com controle distribuído a partir do início do outono

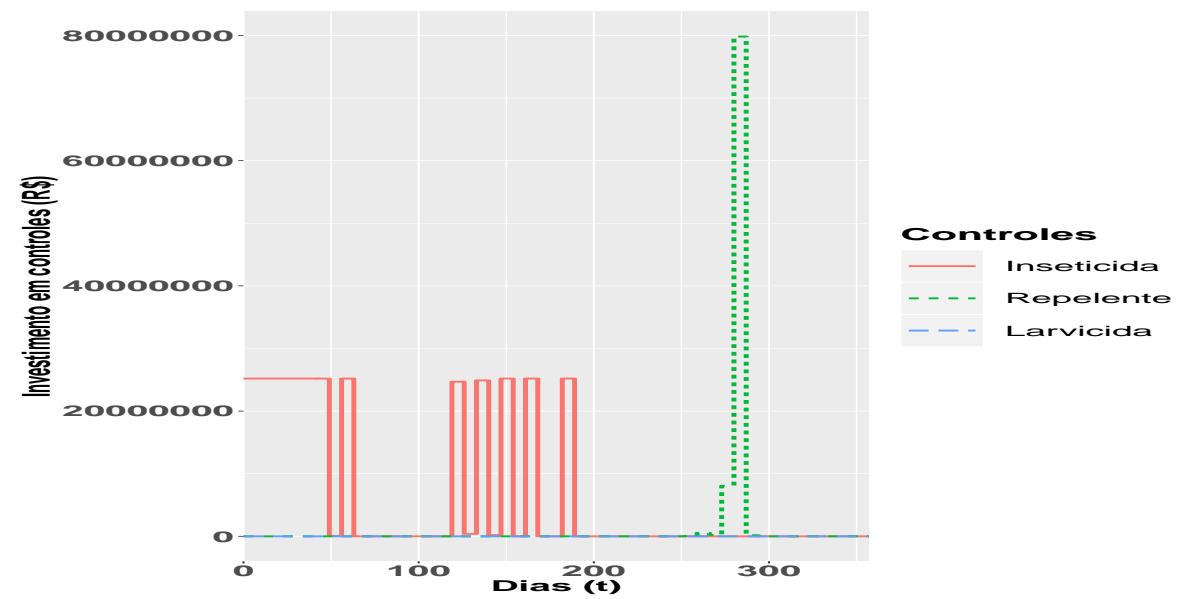

Figura A.13: Melhor combinação - CI 3
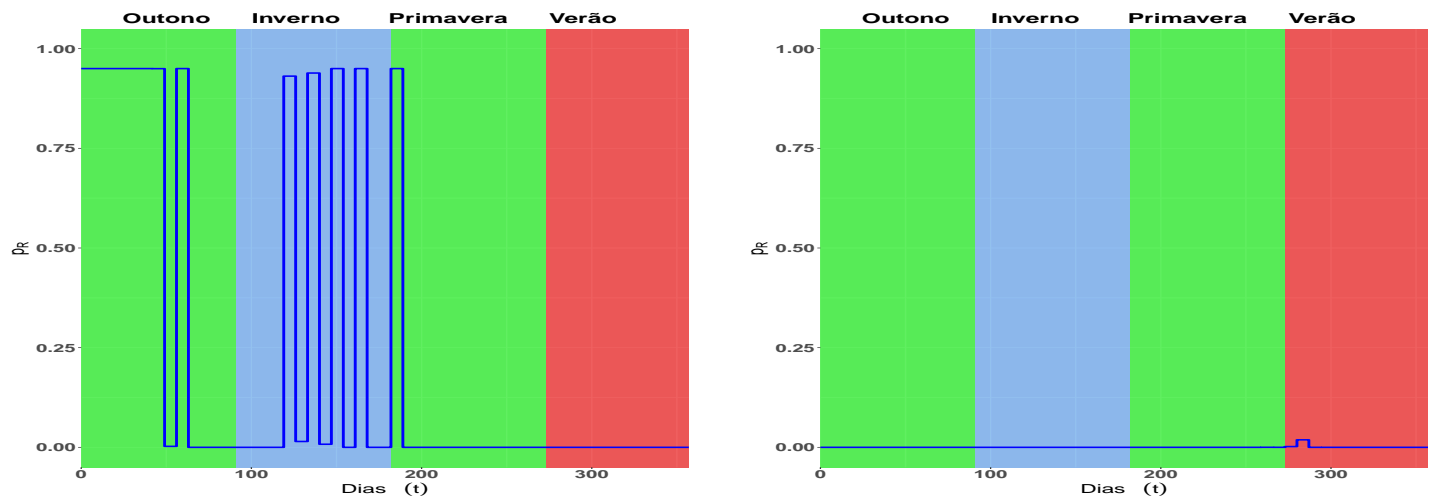

Figura A.14: Uso Inseticida e Repelente - CI 4

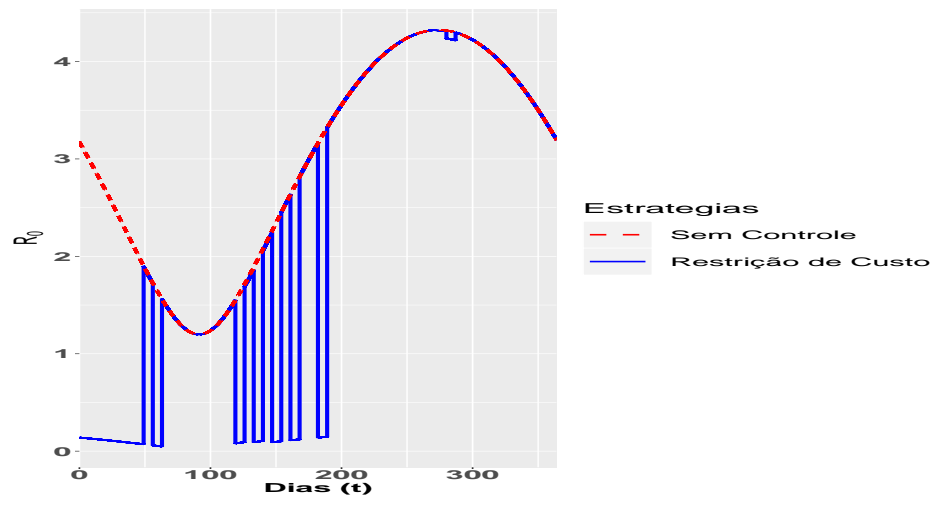

Figura A.15: $R_{0}-C I 4$ 


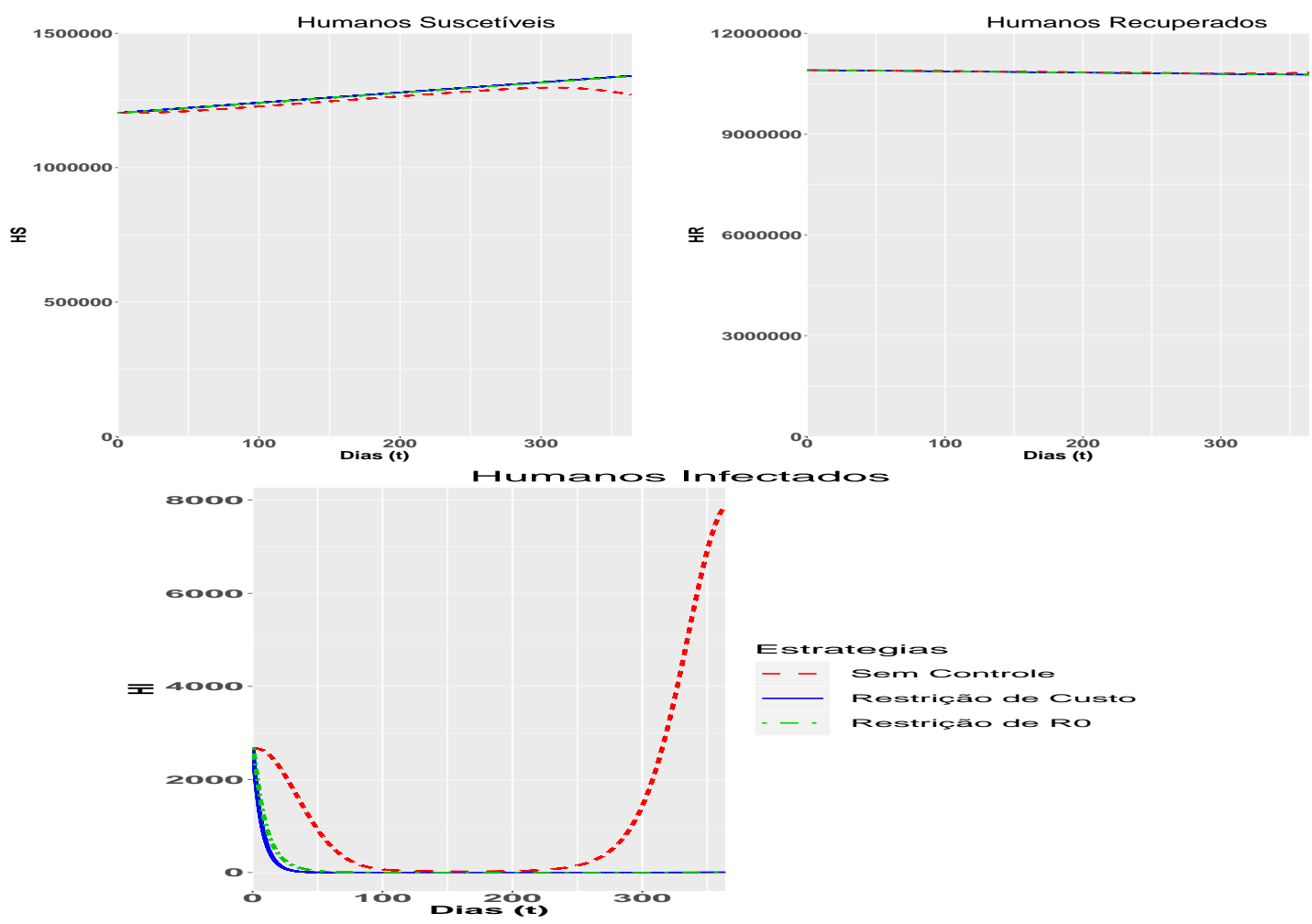

Figura A.16: Humanos suscetiveis, infectados e recuperados - CI 4
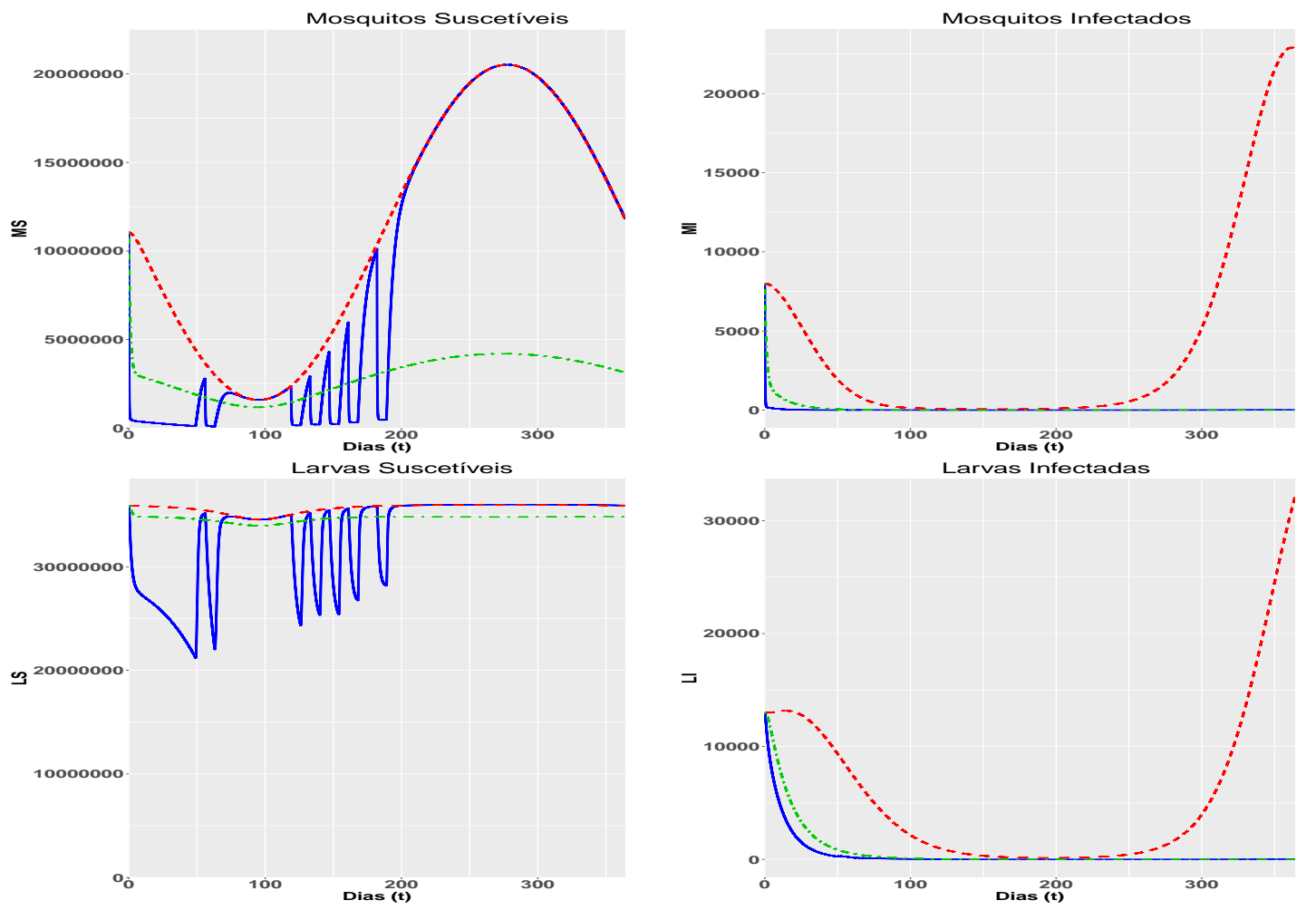

Figura A.17: Mosquitos e larvas suscetiveis e infectados 

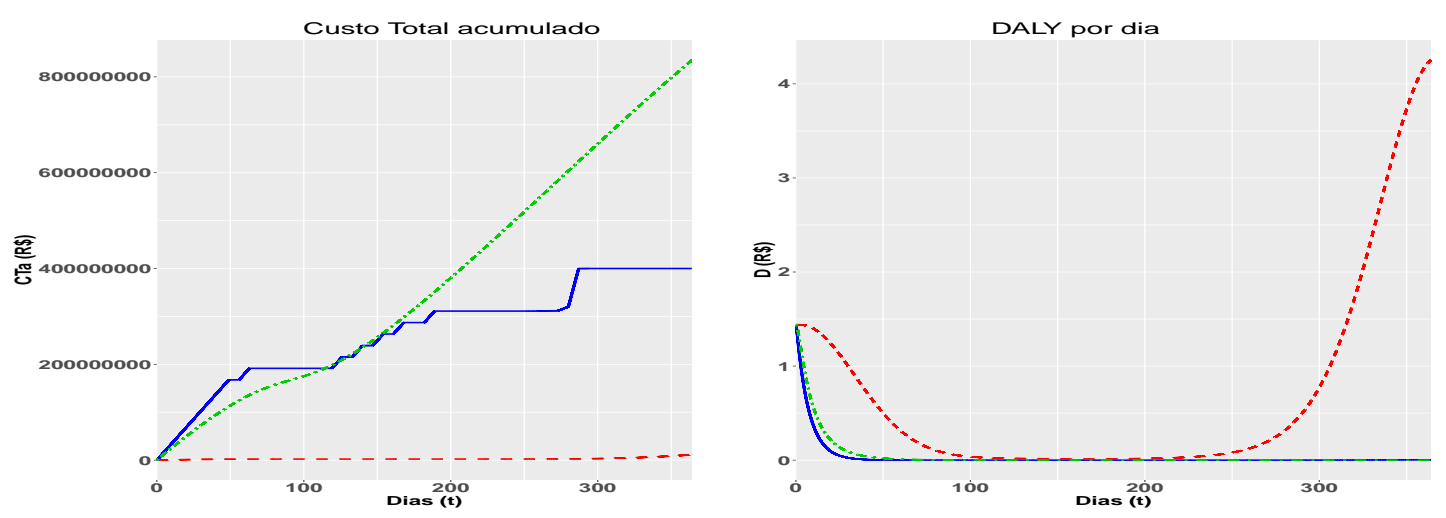

Figura A.18: Custos e DALY - CI 4

\section{Análise dos custos}

\begin{tabular}{lrrrr}
\hline & DALY Acumulado & Controles & Hospitais e Clínicas & Gasto Total \\
\hline Sem Controle & 243,96 & 0 & $11.178 .014,60$ & $11.178 .014,60$ \\
Restrição do $R_{0}$ & 16,00 & $834.506 .206,11$ & $251.808,63$ & $834.758 .014,74$ \\
Restrição de Custo & 10,90 & $400.005 .699,99$ & $36.548,45$ & $400.042 .248,45$ \\
\hline
\end{tabular}

Tabela A.6: Comparativo com valores de DALY, Gasto Total, Gasto com Controles e Gasto com Hospitais e Clinicas - CI 4 . 


\section{A.6 Resultados numéricos do cenário 5}

Os resultados dessa simulação são consequência da quinta condição inicial referente ao cenário 5 de Epidemia.

\begin{tabular}{c|r|r|r|r|r|r|r}
\hline Condição Inicial & $S_{H}$ & $I_{H}$ & $R_{H}$ & $S_{M}$ & $I_{M}$ & $S_{L}$ & $I_{L}$ \\
\hline \hline 5 & 12.106 .920 & 0 & 0 & 1.575 .863 & 1.000 & 34.537 .653 & 0
\end{tabular}

Tabela A.7: Condição inicial do Cenário 5 de Epidemia, com controle distribuído a partir do início do inverno

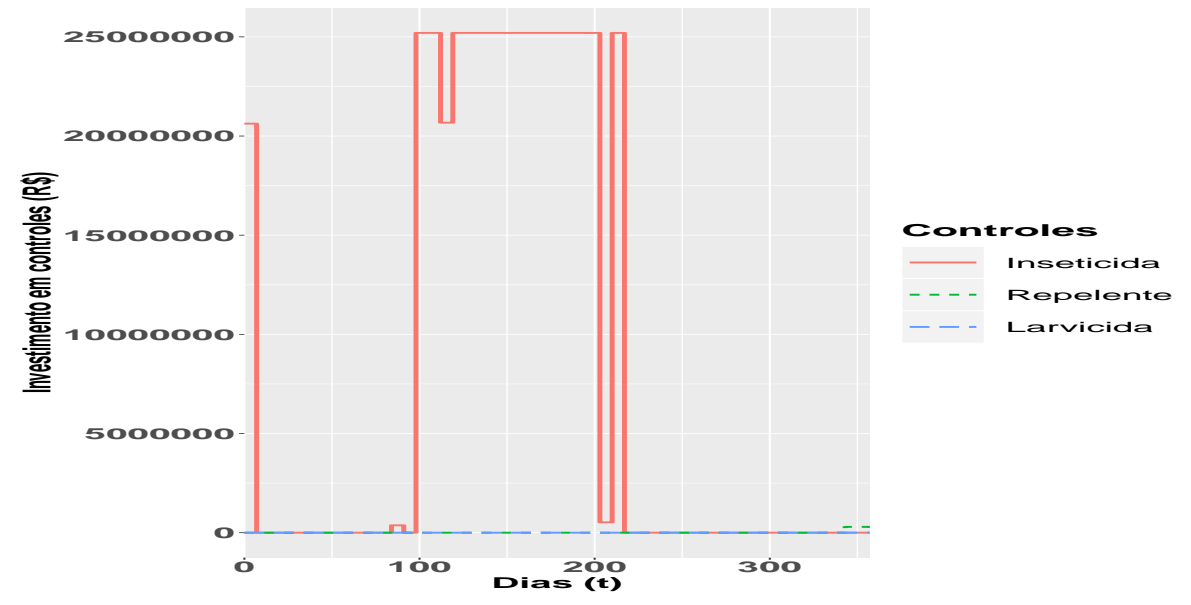

Figura A.19: Melhor combinação - CI 5

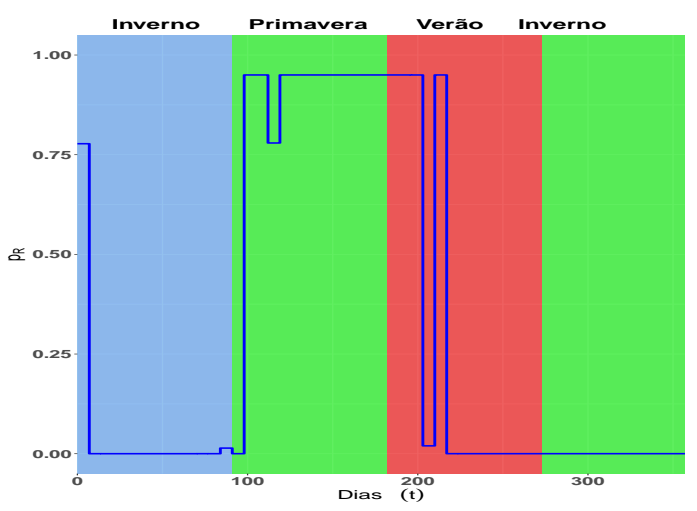

Figura A.20: Uso do Inseticida - CI 5

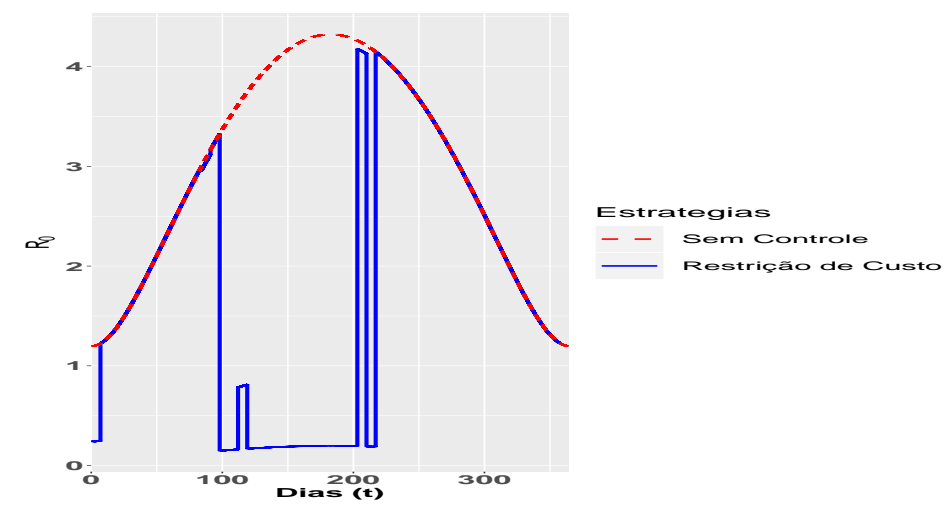

Figura A.21: $R_{0}-C I 5$ 

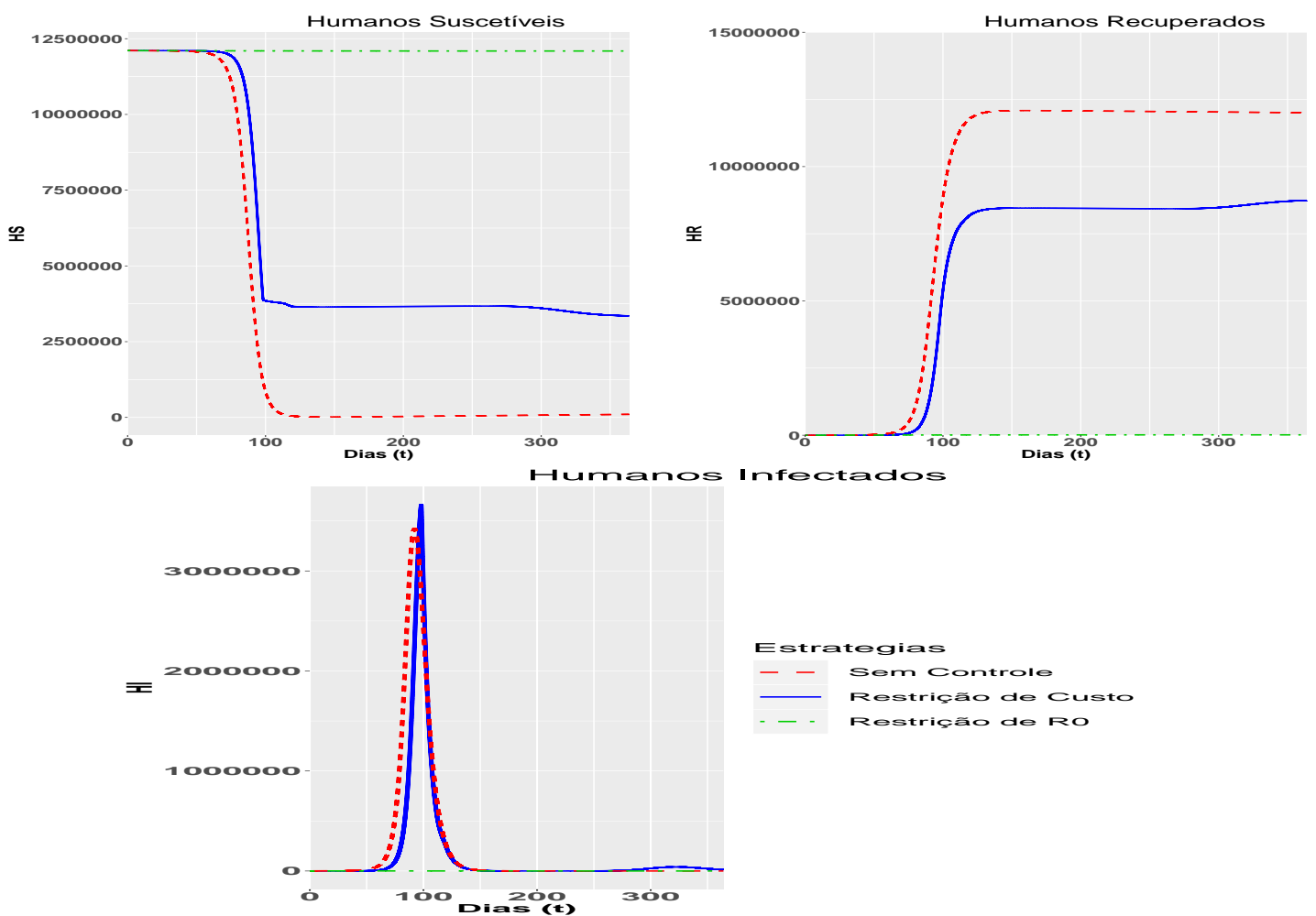

Figura A.22: Humanos suscetiveis, infectados e recuperados - CI 5
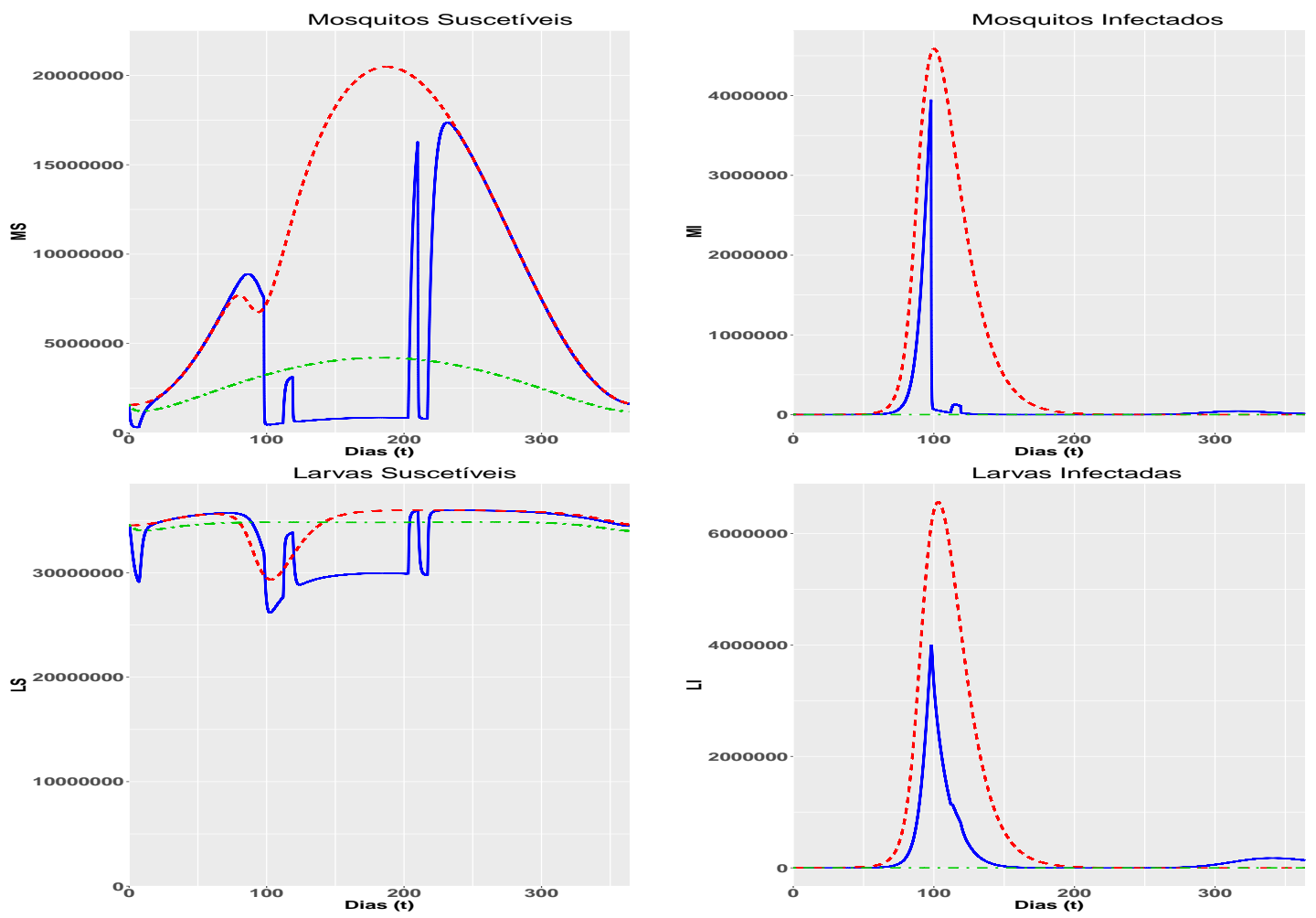

Figura A.23: Mosquitos e larvas suscetiveis e infectados - CI 5 

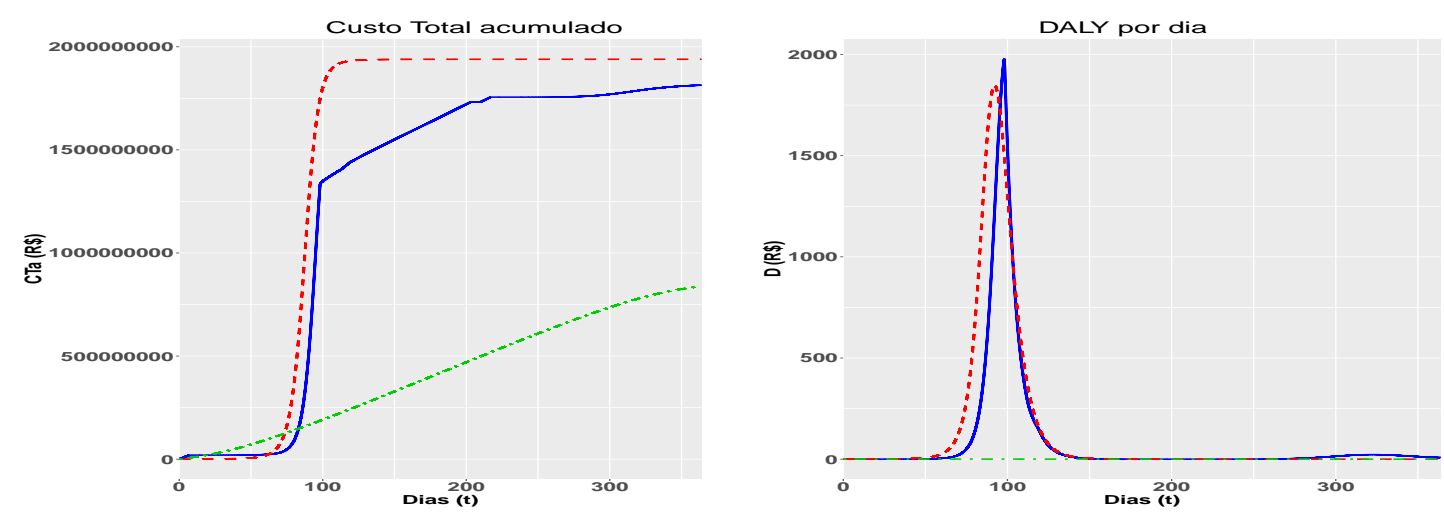

Figura A.24: Custos e DALY - CI 5

\section{Análise dos custos}

\begin{tabular}{lrrrr}
\hline & DALY Acumulado & Controles & Hospitais e Clínicas & Gasto Total \\
\hline Sem Controle & $45.743,25$ & 0 & $1.939 .616 .790,73$ & $1.939 .616 .790,73$ \\
Restrição do $R_{0}$ & 51,94 & $836.200 .006,26$ & $2.203 .945,10$ & $838.403 .951,36$ \\
Restrição de Custo & $33.294,71$ & $400.004 .619,11$ & $1.413 .950 .554,16$ & $1.813 .955 .173,27$ \\
\hline
\end{tabular}

Tabela A.8: Comparativo com valores de DALY, Gasto Total, Gasto com Controles e Gasto com Hospitais e Clinicas - CI 5 . 


\section{A.7 Resultados numéricos do cenário 7}

Os resultados dessa simulação são consequência da sétima condição inicial referente ao cenário 7 de Epidemia.

\begin{tabular}{c|r|r|r|r|r|r|r}
\hline Condição Inicial & $S_{H}$ & $I_{H}$ & $R_{H}$ & $S_{M}$ & $I_{M}$ & $S_{L}$ & $I_{L}$ \\
\hline \hline 7 & 12.106 .920 & 0 & 0 & 11.054 .760 & 1.000 & 35.893 .852 & 0
\end{tabular}

Tabela A.9: Condição inicial do Cenário 7 de Epidemia, com controle distribuído a partir do início do primavera

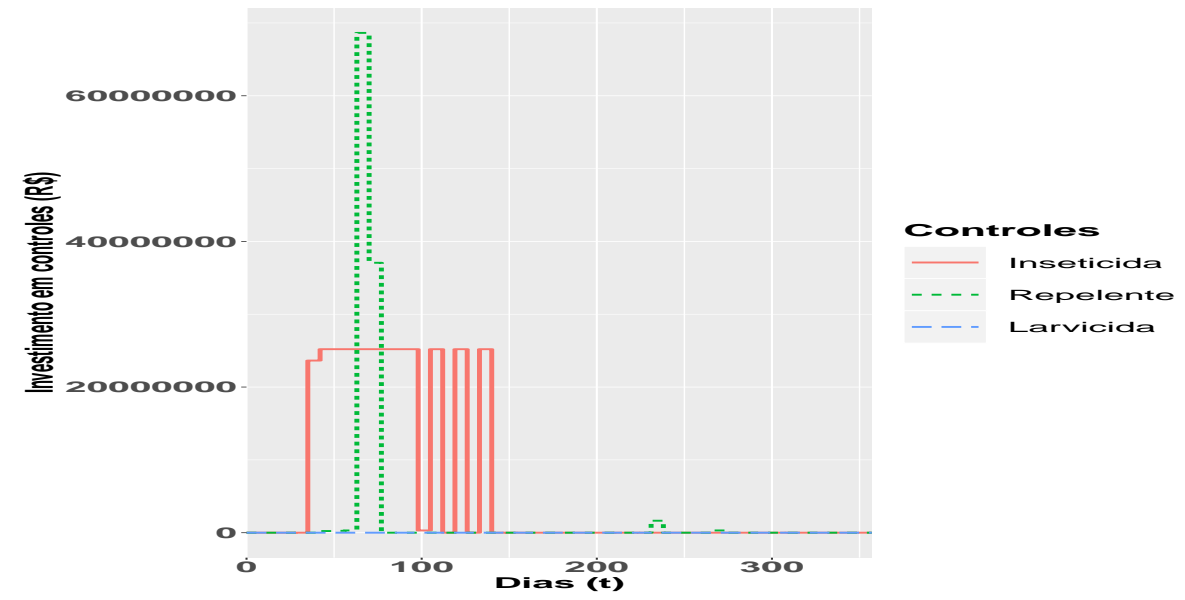

Figura A.25: Melhor combinação - CI 7
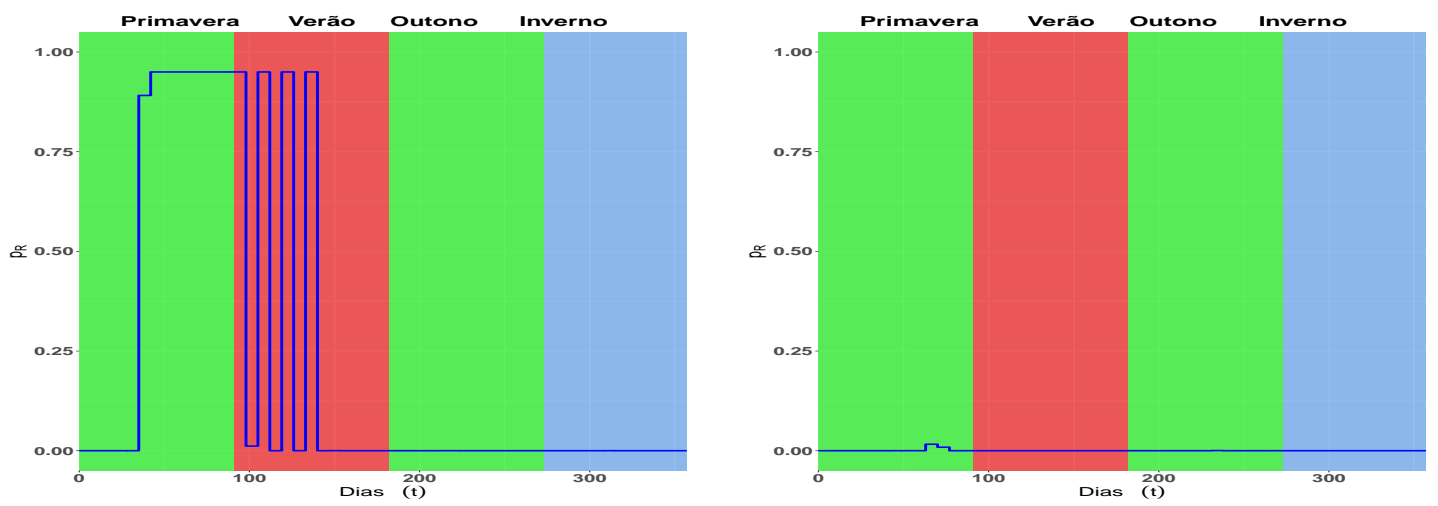

Figura A.26: Uso do Inseticida e Repelente - CI 7

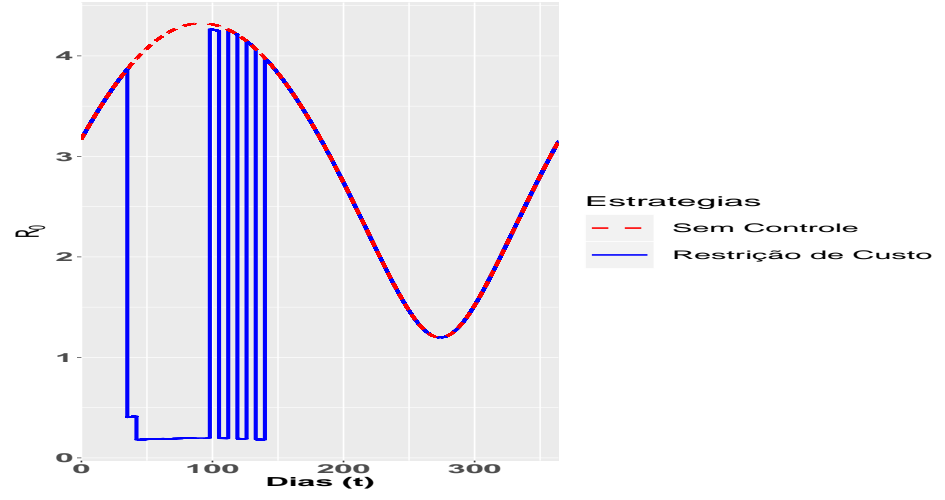

Figura A.27: $R_{0}-C I 7$ 


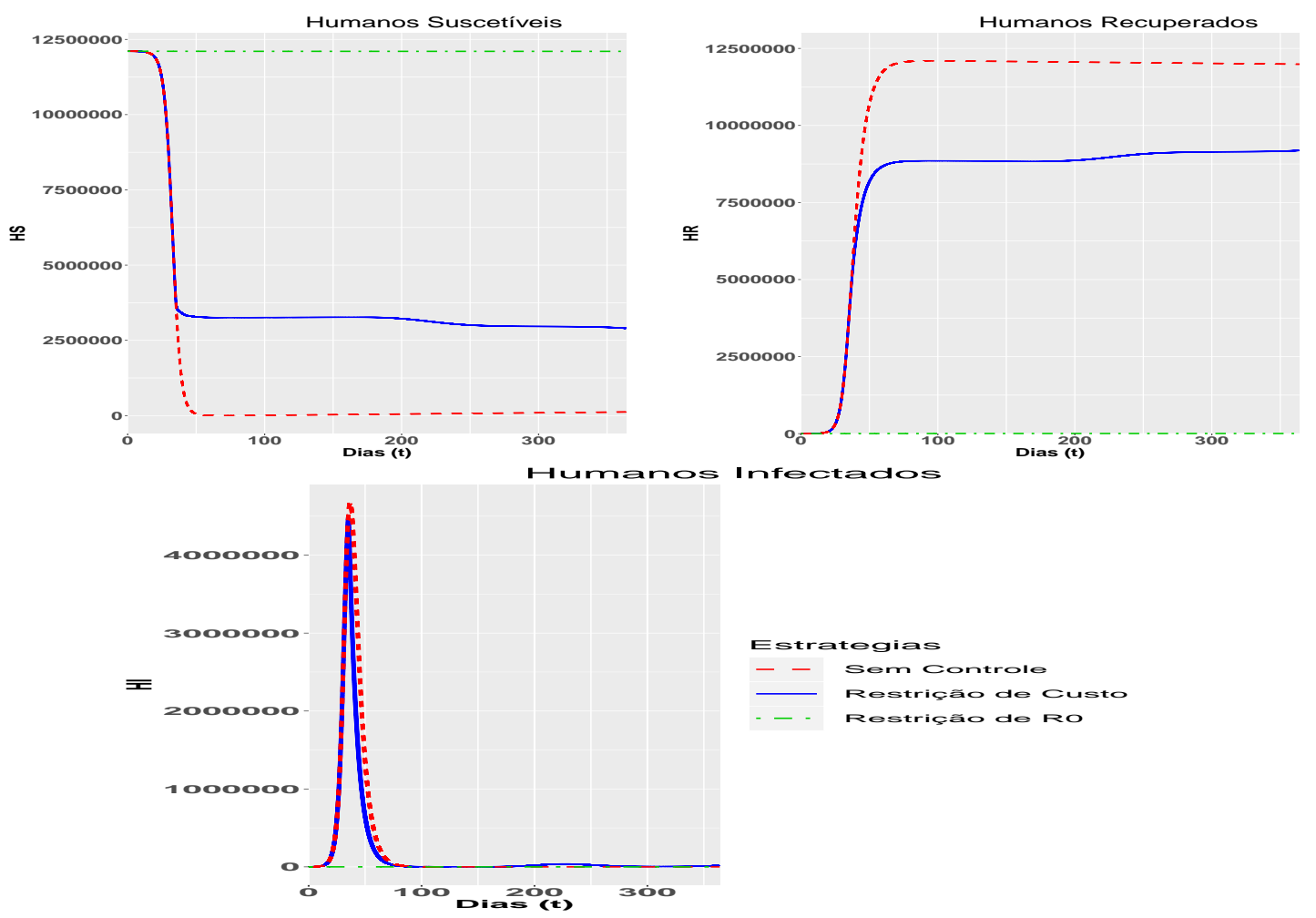

Figura A.28: Humanos suscetiveis, infectados e recuperados - CI 7
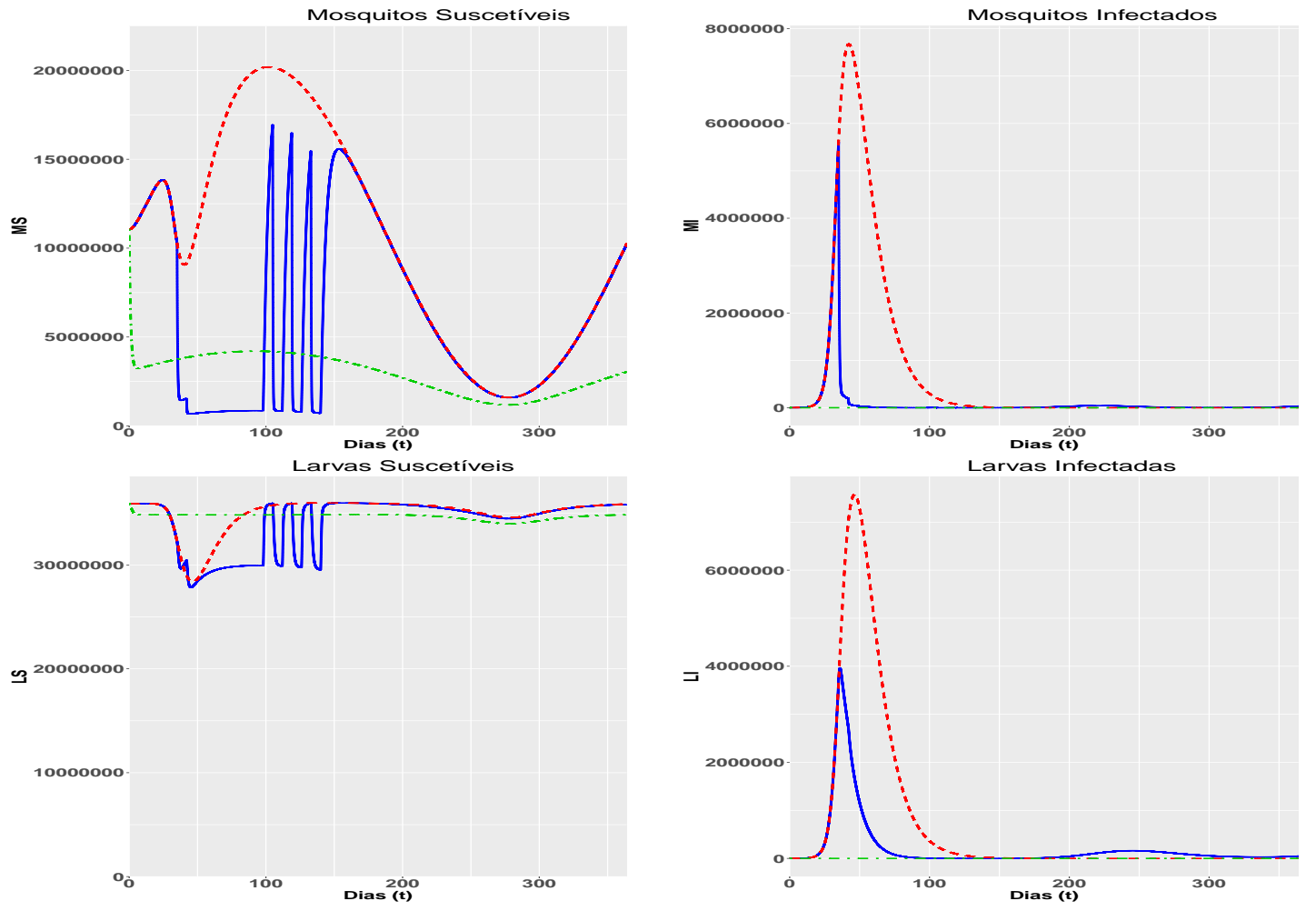

Figura A.29: Mosquitos e larvas suscetiveis e infectados - CI 7 

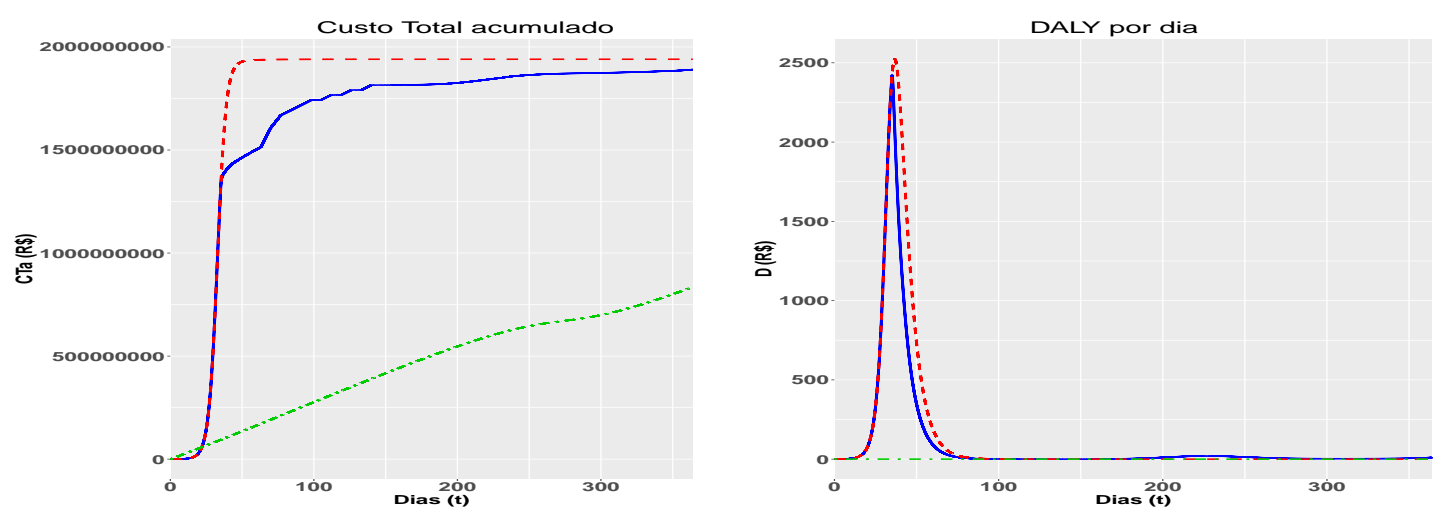

Figura A.30: Custos e DALY - CI 7

Análise dos custos

\begin{tabular}{lrrrr}
\hline & DALY Acumulado & Controles & Hospitais e Clínicas & Gasto Total \\
\hline Sem Controle & $45.761,74$ & 0 & $1.940 .400 .864,64$ & $1.940 .400 .864,64$ \\
Restrição do $R_{0}$ & 15,71 & $834.513 .611,08$ & $666.717,25$ & $835.180 .328,33$ \\
Restrição de Custo & $35.068,29$ & $399.999 .999,99$ & $1.490 .085 .508,56$ & $1.890 .085 .508,56$ \\
\hline
\end{tabular}

Tabela A.10: Comparativo com valores de DALY, Gasto Total, Gasto com Controles e Gasto com Hospitais e Clinicas - CI 7. 


\section{A.8 Resultados numéricos do cenário 8}

Os resultados dessa simulação são consequência da oitava condição inicial referente ao cenário 8 de Endemia.

\begin{tabular}{c|r|r|r|r|r|r|r}
\hline Condição Inicial & $S_{H}$ & $I_{H}$ & $R_{H}$ & $S_{M}$ & $I_{M}$ & $S_{L}$ & $I_{L}$ \\
\hline \hline 8 & 1.203 .581 & 2.668 & 10.900 .671 & 11.046 .763 & 7.997 & 35.880 .869 & 12.983
\end{tabular}

Tabela A.11: Condição inicial do Cenário 8 de Endemia, com controle distribuído a partir do início do primavera

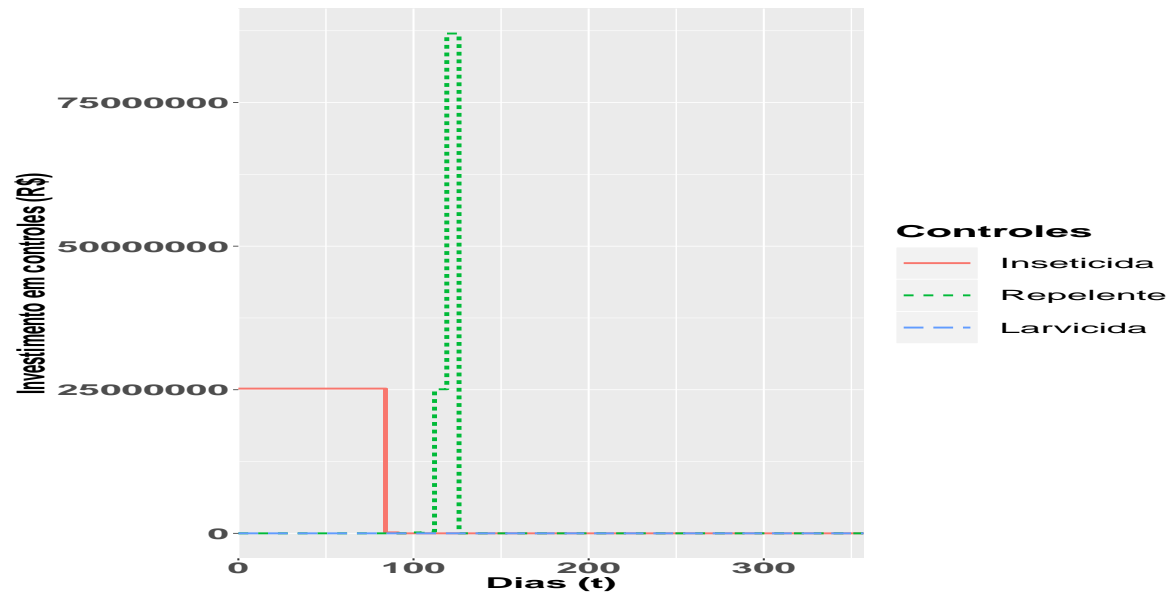

Figura A.31: Melhor combinação - CI 8
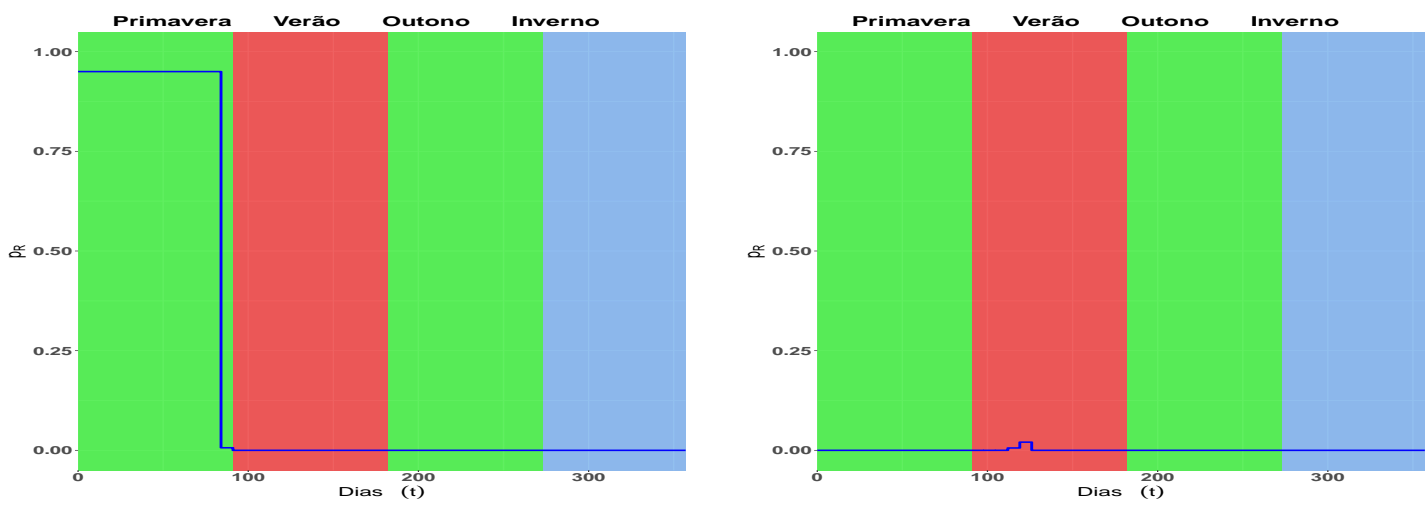

Figura A.32: Uso do Inseticida e Repelente - CI 8

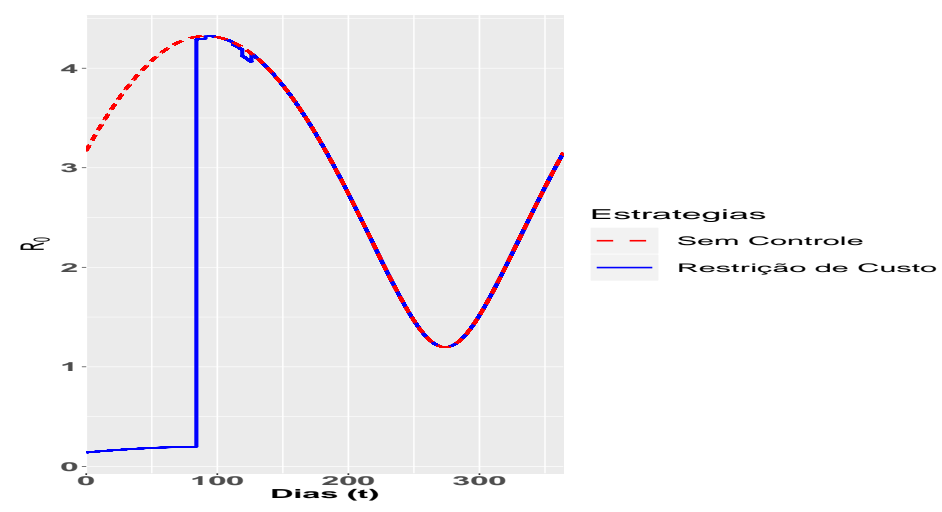

Figura A.33: $R_{0}-C I 8$ 


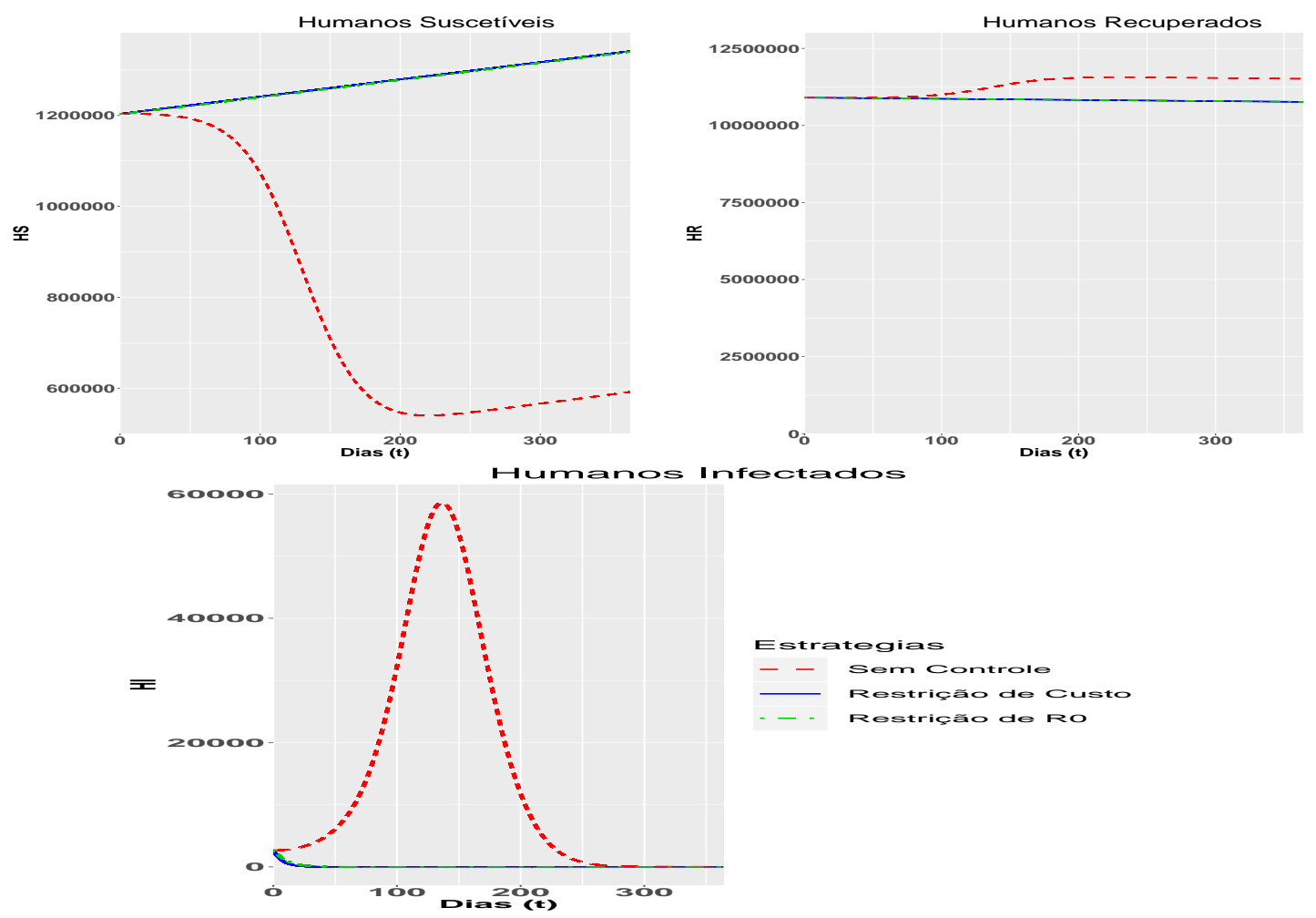

Figura A.34: Humanos suscetiveis, infectados e recuperados - CI 8
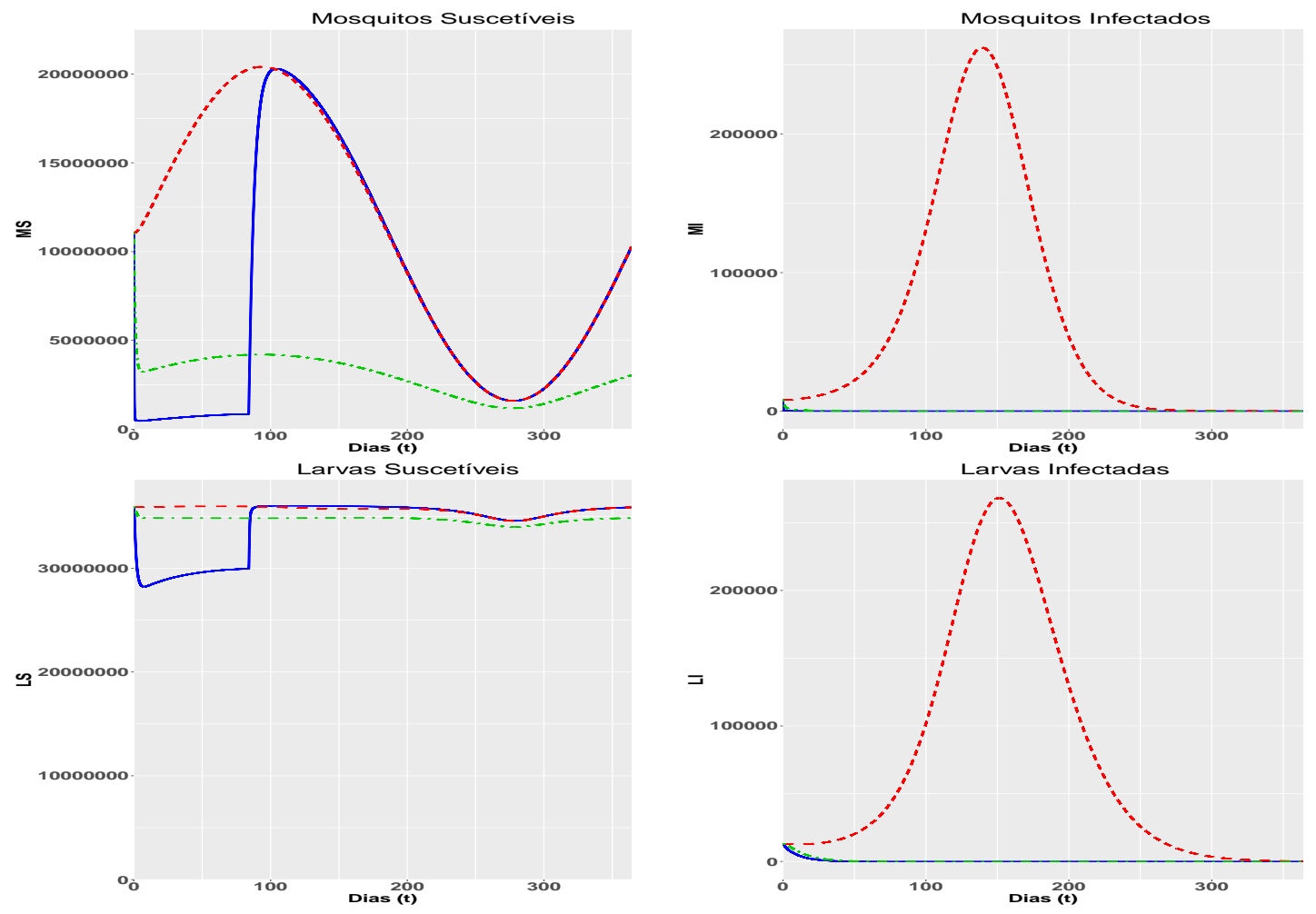

Figura A.35: Mosquitos e larvas suscetiveis e infectados - CI 8 

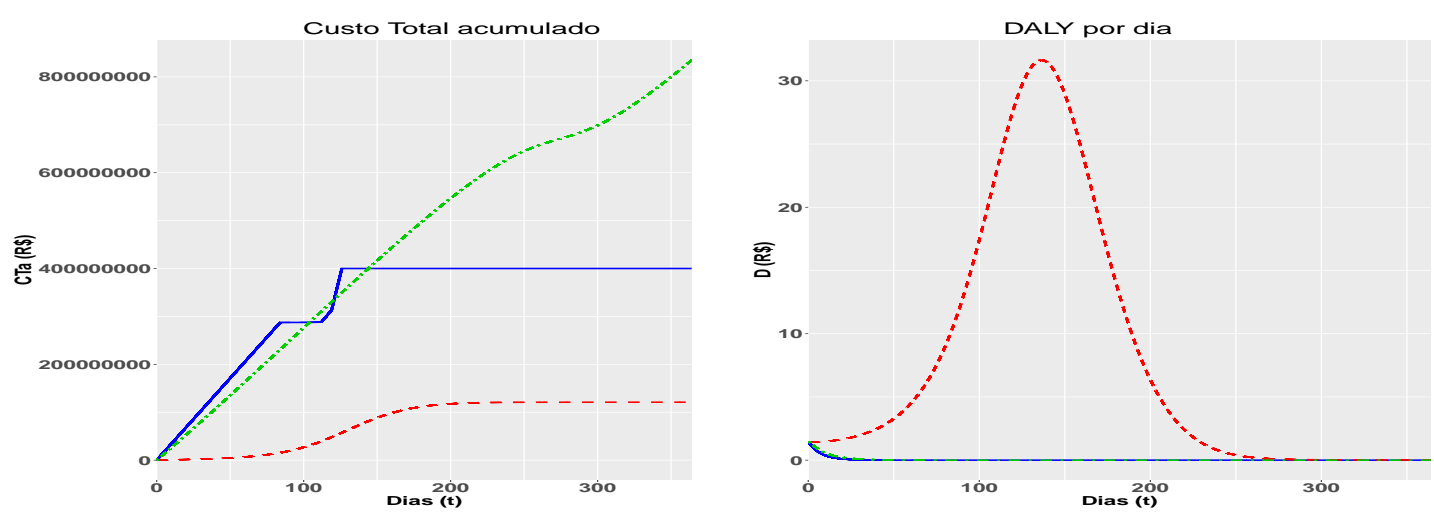

Figura A.36: Custos e DALY - CI 8

\section{Análise dos custos}

\begin{tabular}{lrrrr}
\hline & DALY Acumulado & Controles & Hospitais e Clínicas & Gasto Total \\
\hline Sem Controle & $2.863,40$ & 0 & $120.990 .593,37$ & $120.990 .593,37$ \\
Restrição do $R_{0}$ & 15,97 & $834.513 .611,08$ & $250.268,90$ & $834.763 .879,98$ \\
Restrição de Custo & 10,91 & $400.005 .218,97$ & $35.870,55$ & $400.041 .089,52$ \\
\hline
\end{tabular}

Tabela A.12: Comparativo com valores de DALY, Gasto Total, Gasto com Controles e Gasto com Hospitais e Clinicas - CI 8 . 
APÊNDICE A 


\section{Referências Bibliográficas}

Aldila et al.(2013) Dipo Aldila, Thomas Götz e Edy Soewono. An optimal control problem arising from a dengue disease transmission model. Mathematical biosciences, 242(1):9-16. Citado na pág. 9

Andrighetti et al.(2013) Maria TM Andrighetti, Maria LG Macoris, Luiz Takaku, Karen C Galvani, Rubens P Cardoso, Sirle S Scandar, Carmen M Glasser, Dalva MV Wanderley e Hyun M Yang. Avaliação do efeito do inseticida malathion aplicado sob a forma de ultra baixo volume com equipamentos portátil e pesado sobre aedes aegypti (diptera: Culicidae). Revista de Patologia Tropical, 42(1). Citado na pág. 4

Araújo et al.(2015) Helena Araújo, Danilo Carvalho, Rafaella Ioshino, André Costa-da Silva e Margareth Capurro. Aedes aegypti control strategies in brazil: incorporation of new technologies to overcome the persistence of dengue epidemics. Insects, 6(2):576-594. Citado na pág. 3

Braga e Valle(2007) Ima Aparecida Braga e Denise Valle. Aedes aegypti: histórico do controle no brasil. Epidemiologia e serviços de saúde, 16(2):113-118. Citado na pág. xiv

Bueno et al.(2017) CC Bueno, PR Almeida, AP Castro, A Retamero e LG Clark. Aedes aegypt: Economic impact of prevention versus palliation of diseases caused by the mosquito. Em Value in Health, volume 20, páginas A929-A929. ELSEVIER SCIENCE INC 360 PARK AVE SOUTH, NEW YORK, NY 10010-1710 USA. Citado na pág. xv

Burattini et al.(2008) Marcelo Nascimento Burattini, M Chen, A Chow, FAB Coutinho, KT Goh, LF Lopez, S Ma e E Massad. Modelling the control strategies against dengue in singapore. Epidemiology $\mathscr{G}$ Infection, 136(3):309-319. Citado na pág. 9, 11, 13, 28, 43

Capasso e Serio(1978) Vincenzo Capasso e Gabriella Serio. A generalization of the kermackmckendrick deterministic epidemic model. Mathematical Biosciences, 42(1-2):43-61. Citado na pág. 7

Dayan et al.(2014) Gustavo H Dayan, Juan-Francisco Galán-Herrera, Remi Forrat, Betzana Zambrano, Alain Bouckenooghe, Anke Harenberg, Bruno Guy e Jean Lang. Assessment of bivalent and tetravalent dengue vaccine formulations in flavivirus-naive adults in mexico. Human vaccines $\mathscr{G}$ immunotherapeutics, 10(10):2853-2863. Citado na pág. 4

de Oliveira e Moreira(2012) Caroline Dantas de Oliveira e Luciano Andrade Moreira. Uso de wolbachia no controle biológico. Citado na pág. 3

Devleesschauwer et al.(2014) Brecht Devleesschauwer, Arie H Havelaar, Charline Maertens De Noordhout, Juanita A Haagsma, Nicolas Praet, Pierre Dorny, Luc Duchateau, Paul R Torgerson, Herman Van Oyen e Niko Speybroeck. Calculating disability-adjusted life years to quantify burden of disease. International journal of public health, 59(3):565-569. Citado na pág. 16

Diario da Republica Eletronico(2019) DRE Diario da Republica Eletronico. Tabela nacional de incapacidades por acidentes de trabalho e doencas. http://www.inr.pt/bibliopac/diplomas/ dl_341_93.htm, 2019. Ultimo acesso em 05/04/2019. Citado na pág. 16 
Diekmann et al.(1990) Odo Diekmann, Johan Andre Peter Heesterbeek e Johan AJ Metz. On the definition and the computation of the basic reproduction ratio $\mathrm{r} 0$ in models for infectious diseases in heterogeneous populations. Journal of mathematical biology, 28(4):365-382. Citado na pág. 21

Diekmann et al.(1995) Odo Diekmann, Johan Andre Peter Heesterbeek e Johan AJ Metz. The legacy of kermack and mckendrick. Publications of the Newton Institute, 5:95-115. Citado na pág. 18,19

Dietz e Heesterbeek(2002) Klaus Dietz e JAP Heesterbeek. Daniel bernoullis epidemiological model revisited. Mathematical biosciences, 180(1-2):1-21. Citado na pág. 4

Dorsett et al.(2016) Chasity Dorsett, Hyunju Oh, Marie Laura Paulemond e Jan Rychtář. Optimal repellent usage to combat dengue fever. Bulletin of mathematical biology, 78(5):916-922. Citado na pág. 9

Embrapa(2010) Empresa Brasileira de Pesquisa Agropecuaria Embrapa. Bt horus sc inseticida biologico. https://www.embrapa.br/busca-de-solucoes-tecnologicas/-/produto-servico/ 2478/bt-horus-sc--inseticida-biologico, 2010. Ultimo acesso em 02/04/2019. Citado na pág. 4, 29

Erlanger et al.(2008) TE Erlanger, J Keiser e J Utzinger. Effect of dengue vector control interventions on entomological parameters in developing countries: a systematic review and meta-analysis. Medical and veterinary entomology, 22(3):203-221. Citado na pág. 9

Esteva e Vargas(1998) Lourdes Esteva e Cristobal Vargas. Analysis of a dengue disease transmission model. Mathematical biosciences, 150(2):131-151. Citado na pág. 9

Ferreira e Yang(2003) CP Ferreira e HM Yang. Estudo da transmissão da dengue entre os indivíduos em interação com a população de mosquitos aedes aegypti. Trends in Applied and Computational Mathematics, 4(3):323-332. Citado na pág. 9

Figueiredo et al.(2004) Regina Maria Pinto de Figueiredo, Bedsy Dutary Thatcher, Mário Lira de Lima, Tânia Carvalho Almeida, Wilson Duarte Alecrim e Marcus Vinitius de Farias Guerra. Doenças exantemáticas e primeira epidemia de dengue ocorrida em manaus, amazonas, no período de 1998-1999. Rev Soc Bras Med Trop, 37(6):476-479. Citado na pág. xiii

Fiocruz(2017) Fundacao Oswaldo Cruz Fiocruz. Fiocruz libera aedes com wolbachia no rio de janeiro. https://portal.fiocruz.br/noticia/fiocruz-libera-aedes-com-wolbachia-no-rio-de-janeiro, 2017. Ultimo acesso em $02 / 04 / 2019$. Citado na pág. 3

Flores e ONeill(2018) Heather A Flores e Scott L ONeill. Controlling vector-borne diseases by releasing modified mosquitoes. Nature Reviews Microbiology, página 1. Citado na pág. 3

Fradin e Day(2002) Mark S Fradin e John F Day. Comparative efficacy of insect repellents against mosquito bites. New England Journal of Medicine, 347(1):13-18. Citado na pág. 29

Guia de Compras.org(2019) GC Guia de Compras.org. Qual e o melhor repelente de insetos de 2019. https://guiadecompra.org/melhor-repelente-de-inseto/, 2019. Ultimo acesso em 16/05/2019. Citado na pág. 29

Halstead(1992) Scott B Halstead. The xxth century dengue pandemic: need for surveillance and research. Citado na pág. xiii

Herrera-Basto et al.(1992) Emilio Herrera-Basto, D Rebecca Prevots, Ma Luisa Zarate, J Luis Silva e Jaime Sepulveda-Amor. First reported outbreak of classical dengue fever at 1,700 meters above sea level in guerrero state, mexico, june 1988. The American journal of tropical medicine and hygiene, 46(6):649-653. Citado na pág. xiii 
IESS(2018) Instituto da Saude Complementar IESS. Analise dos custos de internações hospitalares. https://iess.org.br/?p=blog\&id $=690 . h t m l, 2018$. Ultimo acesso em 11/03/2019. Citado na pág. $3,15,29$

Kalyanasundaram e Das(1985) M Kalyanasundaram e PK Das. Larvicidal and synergistic activity of plant extracts for mosquito control. Indian J Med Res, 82(1):19-23. Citado na pág. 4

Keeling e Rohani(2011) Matt J Keeling e Pejman Rohani. Modeling infectious diseases in humans and animals. Princeton University Press. Citado na pág. 4, 7

Kittayapong et al.(2008) Pattamaporn Kittayapong, Sutee Yoksan, Uruyakorn Chansang, Chitti Chansang e Amaret Bhumiratana. Suppression of dengue transmission by application of integrated vector control strategies at sero-positive gis-based foci. The American journal of tropical medicine and hygiene, 78(1):70-76. Citado na pág. 3

Krishnamoorthy et al.(2009) K Krishnamoorthy, KT Harichandrakumar, A Krishna Kumari e LK Das. Burden of chikungunya in india: estimates of disability adjusted life years (daly) lost in 2006 epidemic. Journal of vector borne diseases, 46(1):26. Citado na pág. 16

Kumar et al.(2011) Sarita Kumar, Naim Wahab e Radhika Warikoo. Bioefficacy of mentha piperita essential oil against dengue fever mosquito aedes aegypti 1. Asian Pacific journal of tropical biomedicine, 1(2):85-88. Citado na pág. 29

Lau et al.(2015) Koon Weng Lau, Chee Dhang Chen, Han Lim Lee, Yusoff Norma-Rashid e Mohd Sofian-Azirun. Evaluation of insect growth regulators against field-collected aedes aegypti and aedes albopictus (diptera: Culicidae) from malaysia. Journal of medical entomology, 52(2):199206. Citado na pág. 3

Lee et al.(2011) Bruce Y Lee, Diana L Connor, Sarah B Kitchen, Kristina M Bacon, Mirat Shah, Shawn T Brown, Rachel R Bailey, Yongjua Laosiritaworn, Donald S Burke e Derek AT Cummings. Economic value of dengue vaccine in thailand. The American journal of tropical medicine and hygiene, 84(5):764-772. Citado na pág. 16, 29

Li e Muldowney(1995) Michael Y Li e James S Muldowney. Global stability for the seir model in epidemiology. Mathematical biosciences, 125(2):155-164. Citado na pág. 21

Loja Agropecuaria(2019) LA Loja Agropecuaria. Inseticida malathion. https:// www.lojaagropecuaria.com.br/Malathion-500-Ce-Nitrosin-1-litro/p, 2019. Ultimo acesso em 16/05/2019. Citado na pág. 29

Lupi et al.(2007) Omar Lupi, Carlos Gustavo Carneiro e Ivo Castelo Branco Coelho. Manifestações mucocutâneas da dengue mucocutaneous manifestations of dengue. An Bras Dermatol, 82(4): 291-305. Citado na pág. xiii

Marini et al.(2019) Giovanni Marini, Giorgio Guzzetta, Cecilia A Marques Toledo, Mauro Teixeira, Roberto Rosà e Stefano Merler. Effectiveness of ultra-low volume insecticide spraying to prevent dengue in a non-endemic metropolitan area of brazil. PLoS computational biology, 15(3):e1006831. Citado na pág. 29

Massad et al.(2011) Eduardo Massad, Francisco Antonio Bezerra Coutinho, Luis Fernandez Lopez e Daniel Rodrigues Da Silva. Modeling the impact of global warming on vector-borne infections. Physics of Life Reviews, 8(2):169-199. Citado na pág. xiv

Matias(2014) Ricardo Soares Matias. Como agem os inseticidas nos insetos. http: //matiassinantropicos.blogspot.com/2014/11/como-agem-os-inseticidas-nos-insetos.html, 2014. Ultimo acesso em 11/03/2019. Citado na pág. 3 
Meira(1916) R Meira. Urucubaca gripe ou dengue? dengue. Gráfica O Estado de S. Paulo, páginas 273-85. Citado na pág. xiii . Clínica médica. são Paulo:

Mercado Livre(2019) ML Mercado Livre. Bt horus sc inseticida preco. https://produto. mercadolivre.com.br/MLB-821178541-larvicida-bt-horus-sc-10-litros-_JM, 2019. Ultimo acesso em $16 / 5 / 019$. Citado na pág. 29

Ministerio da Saude(2019a) MS Ministerio da Saude. Ministerio da saude alerta para aumento de $149 \%$ dos casos de dengue no pais. http://www.saude.gov.br/noticias/agencia-saude/ 45257-ministerio-da-saude-alerta-para-aumento-de-149-dos-casos-de-dengue-no-pais, 2019a. U1timo acesso em 10/06/2019. Citado na pág. 1

Ministerio da Saude(2019b) MS Ministerio da Saude. Boletins epidemiologicos. http:// portalms.saude.gov.br/boletim-epidemiologico, 2019b. Último acesso em 15/5/2019. Citado na pág. xiv

Ministerio da Saude(2014a) MS Ministerio da Saude. Larvicidas. http://portalms.saude.gov. $\mathrm{br}$ /saude-de-a-z/controle-de-vetores-inseticidas-e-larvicidas/larvicidas, 2014a. Ultimo acesso em 02/04/2019. Citado na pág. 4, 29

Ministerio da Saude(2017) MS Ministerio da Saude. Sao paulo registra 65 municipios em situação de alerta para dengue, zika e chikungunya. http://portalms.saude.gov.br/noticias/agencia-saude/ 42082-sao-paulo-registra-65-municipios-em-situacao-de-alerta-para-dengue-zika-e-chikungunya, 2017. Ultimo acesso em $02 / 04 / 2019$. Citado na pág. 2

Ministerio da Saude(2014b) MS Ministerio da Saude. Recomendacoes sobre o uso de malathion emulsao aquosa - ea $44 \%$ para o controle de aedes aegypti em aplicacoes espaciais a ultra baixo volume (ubv). http://portalarquivos2.saude.gov.br/images/pdf/2014/setembro/02/ Recomenda----es-para-o-uso-de-malathion-EW.pdf, 2014b. Ultimo acesso em 11/03/2019. Citado na pág. $3,4,29$

Ministerio da Saude(2019c) MS Ministerio da Saude. Inseticida malathion. http://portalarquivos2.saude.gov.br/images/pdf/2014/setembro/02/ Recomenda----es-para-o-uso-de-malathion-EW.pdf, 2019c. Ultimo acesso em 16/05/2019. Citado na pág. 15

Nagpal et al.(2015) BN Nagpal, SK Ghosh, Alex Eapen, Aruna Srivastava, MC Sharma, VP Singh, BD Parashar, Shri Prakash, MJ Mendki, SN Tikar et al. Control of aedes aegypti and ae. albopictus, the vectors of dengue and chikungunya, by using pheromone c21 with an insect growth regulator: results of multicentric trials from 2007-12 in india. J Vector Borne Dis, 52(3):224-31. Citado na pág. 3

Naowarat et al.(2012) Surapol Naowarat, Prasit Thongjaem e I Ming Tang. Effect of mosquito repellent on the transmission model of chikungunya fever. Citado na pág. 9

Nogueira et al.(2005) Rita Maria Ribeiro Nogueira, Hermann Gonçalves Schatzmayr, Ana Maria Bispo De Filippis, Flávia Barreto Dos Santos, Rivaldo Venâncio Da Cunha, Janice Oliveira Coelho, Luiz José De Souza, Flávia Ramos Guimarães, Eliane Saraiva Machado De Araújo, Thatiane Santos De Simone et al. Dengue virus type 3, brazil, 2002. Emerging infectious diseases, 11(9):1376. Citado na pág. xiv

Ogaugwu e Durvasula(2017) Christian E Ogaugwu e Ravi V Durvasula. Developing the arsenal against pest and vector dipterans: inputs of transgenic and paratransgenic biotechnologies. Em Biological Control of Pest and Vector Insects. IntechOpen. Citado na pág. 3 
Ong e Jaal(2015) Song-Quan Ong e Zairi Jaal. Investigation of mosquito oviposition pheromone as lethal lure for the control of aedes aegypti (1.)(diptera: Culicidae). Parasites 63 vectors, 8(1): 28. Citado na pág. 3

Phaijoo e Gurung(2017) GR Phaijoo e DB Gurung. Mathematical model of dengue disease transmission dynamics with control measures. Journal of Advances in Mathematics and Computer Science, 23(3):1-12. Citado na pág. 9

Ponlawat et al.(2005) Alongkot Ponlawat, Jeffrey G Scott e Laura C Harrington. Insecticide susceptibility of aedes aegypti and aedes albopictus across thailand. Journal of Medical Entomology, 42(5):821-825. Citado na pág. 4, 9

Portal transparencia SP(2019) PTSP Portal transparencia SP. Lei de orcamento anual loa. http://transparencia.prefeitura.sp.gov.br/contas/Paginas/LeiOrcamentoAnual.aspx, 2019. Ultimo acesso em 04/04/2019. Citado na pág. 2

Prefeitura de Sao Paulo(2016a) Prefeitura Prefeitura de Sao Paulo. Mapa da prefeitura de sp aponta areas com mais risco de epidemia de dengue. https://www1.folha.uol.com.br/cotidiano/2016/01/ 1729771-mapa-da-prefeitura-de-sp-aponta-areas-com-mais-risco-de-epidemia-de-dengue.shtml, 2016a. Ultimo acesso em 03/04/2019. Citado na pág. 2

Prefeitura de Sao Paulo(2016b) Prefeitura Prefeitura de Sao Paulo. Força tarefa trabalha para eliminar focos de pernilongos na area do rio pinheiros. https://www.prefeitura.sp.gov.br/cidade/ secretarias/saude/noticias/? $p=228382,2016 b$. Ultimo acesso em $04 / 04 / 2019$. Citado na pág. xiv

Prefeitura de Sao Paulo(2016c) Prefeitura Prefeitura de Sao Paulo. Casos confirmados de dengue caem $47 \%$ nos dois primeiros meses de 2016. https://www.prefeitura.sp.gov.br/cidade/ secretarias/saude/noticias/?p=214465, 2016c. Ultimo acesso em 04/04/2019. Citado na pág. xiv

Prefeitura de Sao Paulo(2019) PSP Prefeitura de Sao Paulo. Historico dengue cidade sao paulo. https://www.prefeitura.sp.gov.br/cidade/secretarias/saude/vigilancia_em_saude/index. $\mathrm{php} ? \mathrm{p}=245603,2019$. Último acesso em 15/5/2019. Citado na pág. 1

Qiao et al.(2011) Ming Qiao, David Shaw, Remi Forrat, Anh Wartel-Tram e Jean Lang. Priming effect of dengue and yellow fever vaccination on the immunogenicity, infectivity, and safety of a tetravalent dengue vaccine in humans. The American journal of tropical medicine and hygiene, 85(4):724-731. Citado na pág. 4

Reiter e Colon(1991) Paul Reiter e MAAAN Colon. Enhancement of the cdc ovitrap with hay infusions for daily monitoring of aedes aegyp?/populations. Citado na pág. xiv

Rigau-Pérez et al.(1998) José G Rigau-Pérez, Gary G Clark, Duane J Gubler, Paul Reiter, Eduard J Sanders e A Vance Vorndam. Dengue and dengue haemorrhagic fever. The Lancet, 352 (9132):971-977. Citado na pág. 9

Rodrigues et al.(2010) Helena Sofia Rodrigues, M Teresa T Monteiro e Delfim FM Torres. Insecticide control in a dengue epidemics model. Em AIP Conference Proceedings, volume 1281, páginas 979-982. AIP. Citado na pág. 9

Rodrigues et al.(2014) Helena Sofia Rodrigues, M Teresa T Monteiro e Delfim FM Torres. Vaccination models and optimal control strategies to dengue. Mathematical biosciences, 247:1-12. Citado na pág. 28

Santos et al.(2008) Maria Alice Varjal de Melo Santos et al. Aedes aegypti (diptera: culicidae): estudos populacionais e estratégias integradas para controle vetorial em municípios da região metropolitana do Recife, no período de 2001 a 200\%. Tese de Doutorado. Citado na pág. 29 
Scott et al.(1993) Thomas W Scott, Gary G Clark, Leslie H Lorenz, Priyanie H Amerasinghe, Paul Reiter e John D Edman. Detection of multiple blood feeding in aedes aegypti (diptera: Culicidae) during a single gonotrophic cycle using a histologic technique. Journal of Medical Entomology, 30(1):94-99. Citado na pág. xiv

Seng et al.(2008) Chang Moh Seng, To Setha, Joshua Nealon, Doung Socheat, Ngan Chantha e Michael B Nathan. Community-based use of the larvivorous fish poecilia reticulata to control the dengue vector aedes aegypti in domestic water storage containers in rural cambodia. Journal of Vector Ecology, 33(1):139-145. Citado na pág. 3

Smith et al.(2012) David L Smith, Katherine E Battle, Simon I Hay, Christopher M Barker, Thomas W Scott e F Ellis McKenzie. Ross, macdonald, and a theory for the dynamics and control of mosquito-transmitted pathogens. PLoS pathogens, 8(4):e1002588. Citado na pág. 4, 6, 7

Soares(1928) P Soares. Etiologia symptomatologia e prophylaxia da dengue- a epidemia do aviso francês antarès no porto da bahia. Arquivo do Hospital de Isolamento em MontSerrat. SalvadorBahia. Citado na pág. xiii

Stefani et al.(2009) Germana Pimentel Stefani, Antonio Carlos Pastorino, Ana Paula BM Castro, Angela Bueno F Fomin e Cristina Miuki A Jacob. Repelentes de insetos: recomendações para uso em crianças. Revista Paulista de Pediatria, 27(1):81-89. Citado na pág. 4, 29

Strogatz(2018) Steven H Strogatz. Nonlinear Dynamics and Chaos with Student Solutions Manual: With Applications to Physics, Biology, Chemistry, and Engineering. CRC Press. Citado na pág. 16

Tang(1994) Z Bo Tang. Adaptive partitioned random search to global optimization. IEEE Transactions on Automatic Control, 39(11):2235-2244. Citado na pág. 25

Teich et al.(2017) Vanessa Teich, Roberta Arinelli e Lucas Fahham. Aedes aegypti e sociedade: o impacto econômico das arboviroses no brasil. JBES: Brazilian Journal of Health Economics/Jornal Brasileiro de Economia da Saúde, 9(3). Citado na pág. xv

Teixeira et al.(1999) Maria da Glória Teixeira, Maurício Lima Barreto e Zouraide Guerra. Epidemiologia e medidas de prevenção do dengue. Informe epidemiológico do SUS, 8(4):5-33. Citado na pág. xiii

Törn e Žilinskas(1989) Aimo Törn e Antanas Žilinskas. Global optimization, volume 350. Springer. Citado na pág. 25

Van den Driessche e Watmough(2002) Pauline Van den Driessche e James Watmough. Reproduction numbers and sub-threshold endemic equilibria for compartmental models of disease transmission. Mathematical biosciences, 180(1-2):29-48. Citado na pág. 18, 19, 21

Werren et al.(2008) John H Werren, Laura Baldo e Michael E Clark. Wolbachia: master manipulators of invertebrate biology. Nature Reviews Microbiology, 6(10):741. Citado na pág. 3

Wilder-Smith e Schwartz(2005) Annelies Wilder-Smith e Eli Schwartz. Dengue in travelers. New England journal of medicine, 353(9):924-932. Citado na pág. xiv

Wilder-Smith et al.(2012) Annelies Wilder-Smith, Karl-Erik Renhorn, Hasitha Tissera, Sazaly Abu Bakar, Luke Alphey, Pattamaporn Kittayapong, Steve Lindsay, James Logan, Christoph Hatz, Paul Reiter et al. Denguetools: innovative tools and strategies for the surveillance and control of dengue. Global health action, 5(1):17273. Citado na pág. 3

Wong et al.(2011) Jacklyn Wong, Steven T Stoddard, Helvio Astete, Amy C Morrison e Thomas W Scott. Oviposition site selection by the dengue vector aedes aegypti and its implications for dengue control. PLoS neglected tropical diseases, 5(4):e1015. Citado na pág. 3 
Yang e Ferreira(2008) Hyun Mo Yang e Cláudia Pio Ferreira. Assessing the effects of vector control on dengue transmission. Applied Mathematics and Computation, 198(1):401-413. Citado na pág. 9 